\title{
Experimentally-Induced Savoring and its Impact on Positive Emotions, Cognitions, and Behaviors: Investigating Individual Differences in Effectiveness
}

\author{
Cara A. Palmer \\ West Virginia University
}

Follow this and additional works at: https://researchrepository.wvu.edu/etd

\section{Recommended Citation \\ Palmer, Cara A., "Experimentally-Induced Savoring and its Impact on Positive Emotions, Cognitions, and Behaviors: Investigating Individual Differences in Effectiveness" (2014). Graduate Theses, Dissertations, and Problem Reports. 102.}

https://researchrepository.wvu.edu/etd/102

This Dissertation is protected by copyright and/or related rights. It has been brought to you by the The Research Repository @ WVU with permission from the rights-holder(s). You are free to use this Dissertation in any way that is permitted by the copyright and related rights legislation that applies to your use. For other uses you must obtain permission from the rights-holder(s) directly, unless additional rights are indicated by a Creative Commons license in the record and/ or on the work itself. This Dissertation has been accepted for inclusion in WVU Graduate Theses, Dissertations, and Problem Reports collection by an authorized administrator of The Research Repository @ WVU.

For more information, please contact researchrepository@mail.wvu.edu. 
Experimentally-Induced Savoring and its Impact on Positive Emotions, Cognitions, and Behaviors: Investigating Individual Differences in Effectiveness

Cara A. Palmer, M.S.

Dissertation submitted to the Eberly College of Arts and Sciences

at West Virginia University

in partial fulfillment of the requirements for the degree of

Doctor of Philosophy in

Life-Span Developmental Psychology

Amy L. Gentzler, Ph.D., Chair

Julie H. Patrick, Ph.D.

Aaron Metzger, Ph.D.

Natalie J. Shook, Ph.D.

Patricia A. Haught, Ed.D.

Department of Psychology

Morgantown, West Virginia

2014

Keywords: savoring, emotion, positive affect, emotion regulation, attachment, self-esteem, age, future-time perspective, free time, global-local processing, broaden and build theory 


\begin{abstract}
Experimentally-Induced Savoring and its Impact on Positive Emotions, Cognitions, and Behaviors: Investigating Individual Differences in Effectiveness
\end{abstract}

Cara A. Palmer

By broadening cognitions and actions, positive affect increases our ability to engage in novel behaviors and build resources, which can lead to better social relationships, better health, more success, and increased resilience (Fredrickson, 2001). Thus, finding ways to increase and maintain positive affect and its broadening effects is essential. One way to up-regulate positive affect is by savoring, or actively trying to prolong or intensify a positive feeling. Although savoring is associated with a number of positive outcomes, the nature of the relationship between savoring, positive affect, and the resulting cognitive effects is not well explored. Furthermore, while some preliminary work has highlighted individual differences in the ability to savor, immediate changes in affect are typically not assessed, and savoring ability is often measured through self-report. The current study randomly assigned participants to savor by cognitively reminiscing on a previously experienced positive event in order to investigate how savoring may promote positive affect, broadened cognitions, and the willingness to engage in a variety of behaviors. Furthermore, based on theory and previous empirical work, individual differences in savoring ability were examined, including self-esteem, anxious attachment, age, perceptions of free time, and future time perspective. Additional analyses examined self-reported trait savoring and trait mindfulness, along with distraction, effort, and impatience during the task as factors that may predict increased savoring effectiveness. Results suggest that after recalling a positive event, savoring was linked to the maintenance of both general and high-arousal positive affect, increases in low-arousal positive affect, and the maintenance of low levels of negative affect and poignancy. Contrary to hypotheses, results suggest that greater increases in positive affect after 
savoring was linked to less broadened cognitions. Similar to previous research, increased positive affect was linked to a willingness to engage in a greater number of behaviors. However, this did not differ between the savoring group or the control group, indicating that savoring does not promote a greater willingness to engage in more behaviors beyond the typical effects of positive affect. Controlling for baseline affect, some individual differences emerged in savoring ability. Specifically, those with higher self-esteem had a greater self-reported capacity to savor. However, self-esteem was linked to increases in positive affect after the task for the control group only. Those who reported higher levels of anxious attachment had lower levels of selfreported savoring ability, but attachment was not a significant predictor of affect after the savoring task. Age was unrelated to both self-reported savoring and affect after the savoring task. Free time was unrelated to self-reported savoring or affect after the savoring task, but was it related to less post-task negative affect for the control group. Overall future time perspective and a focus on opportunities were unrelated to both self-reported and task savoring, and a focus on limitations was related to less negative affect after the task for both groups, but was unrelated to self-reported savoring. Furthermore, a focus on limitations was also related to more effort and also more distraction during the savoring task. This study provides new, unique information on who can savor and how this savoring ability impacts positive emotions and their related benefits. 


\section{ACKNOWLEDGEMENTS}

I am greatly indebted to all who helped make this project a possibility. I would like to thank the Eberly College of Arts and Sciences and the Department of Psychology for their financial contribution and support for this project, along with the Blaney Fellowship for financial support during the planning and proposal stages of project development. I would especially like to thank Dr. Amy Gentzler for being my biggest advocate and an extraordinary mentor throughout my graduate school tenure. I am grateful to have had a working relationship that fostered creativity, engagement, and enthusiasm for both developmental and affective science. Her years of unwavering support, guidance, and expertise are truly immeasurable. In addition, I would like to thank my fellow lab members Jennifer Morey, Chit Yuen Yi, Meagan Ramsey, and Katelyn Black for their continued support, and for the years of countless “positive events.” I am also appreciative of the comments, feedback, and time invested by my committee members Drs. Aaron Metzger, Julie Hicks Patrick, Natalie Shook, and Patricia Haught. Finally, I would not be where I am today if it was not for the unconditional love and support of my wonderful family, husband, and friends. Without their encouragement and understanding this would have not been possible. Thank you for always being in my corner! 


\section{TABLE OF CONTENTS}

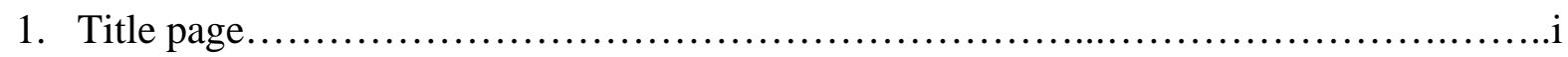

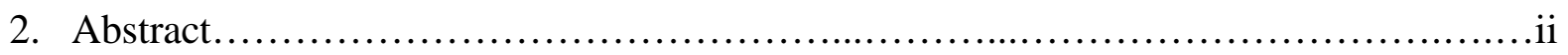

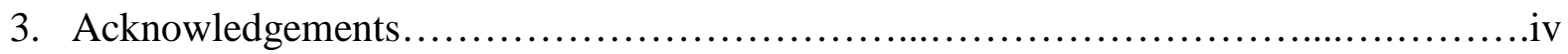

4. List of tables..................................................................

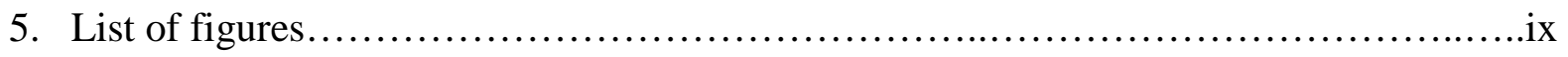

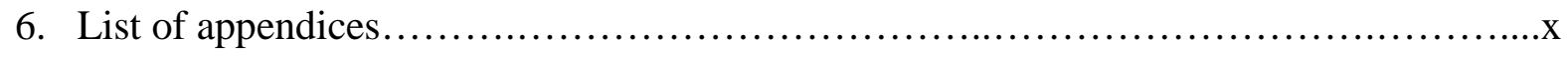

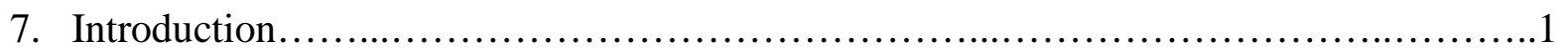

7.1 Positive Emotions.................................................................

7.2 The Broadening Effect of Positive Emotion ........................................2

7.3 Savoring and Positive Emotion ................................................ 4

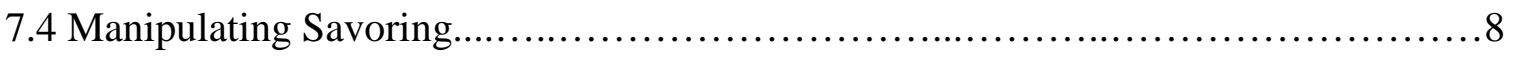

7.5 Savoring and the Broaden and Build Theory .......................................10

7.6 Individual Differences in Savoring...............................................11

7.6.1 Self-Esteem.......................................................13

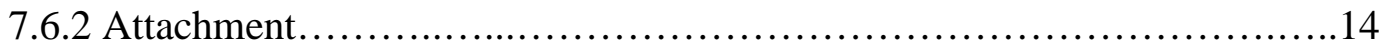

7.6 .3 Age.................................................................

7.6.3.1 Age and Future Time Perspective...............................18

7.6.3.2 Age and Perceptions of Free Time................................19

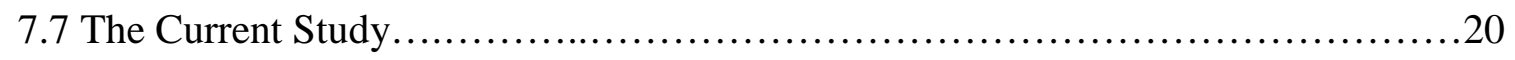

7.7.1 Research Questions and Hypotheses..................................21

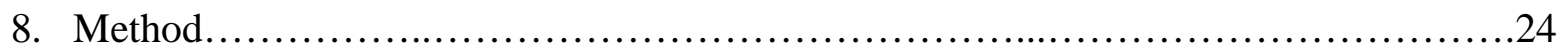

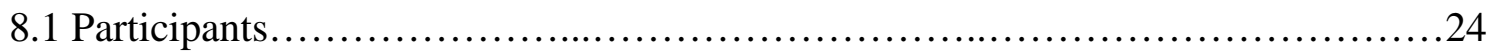




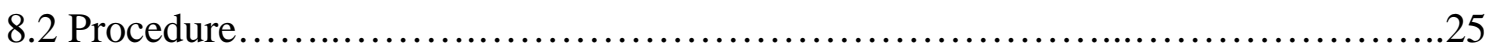

8.2.1 Experimental Manipulations..........................................27

8.2.1.1 Positive Event Recall.........................................27

8.2.1.2 Savoring and Control Induction............................27

8.3 Measures................................................................28

8.3.1 Affect............................................................28

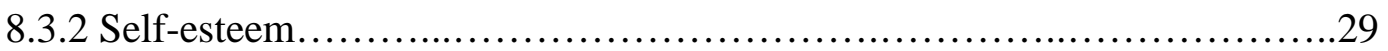

8.3.3 Attachment........................................................ 30

8.3.4 Future time perspective...........................................30

8.3.5 Perceptions of free time......................................... 31

8.3.6 Global-local processing...........................................31

8.3.7 Thought-action repertoires.......................................32

8.3.8 Thinking task variables.........................................33

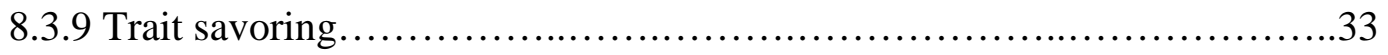

8.3.10 Mindfulness...................................................34

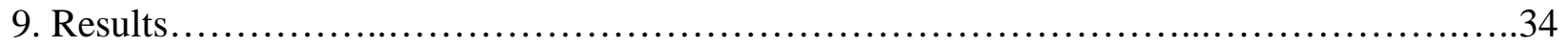

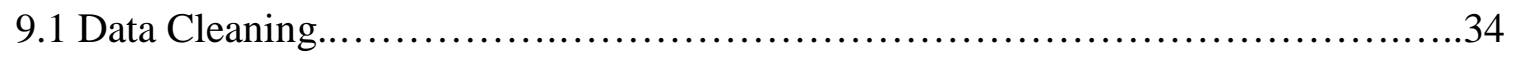

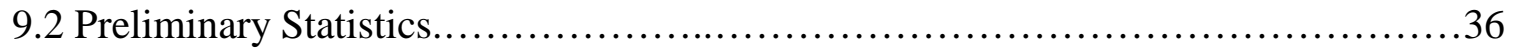

9.3 Research Question 1: Momentary Affect Benefits of Savoring................................40

9.4 Research Question 2: Broadening Cognitive and Behavioral Effects of Savoring....43

9.5 Research Question 3: Individual Differences in Savoring........................45

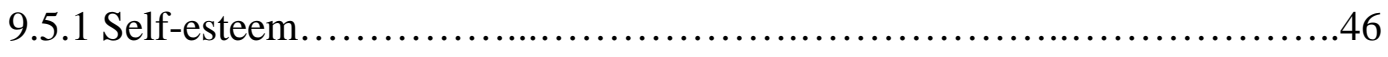

9.5 .2 Attachment........................................................46 


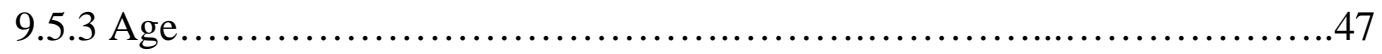

9.6 Research Question 4: Age-Related Mediators....................................47

9.7 Additional Analyses...........................................................50

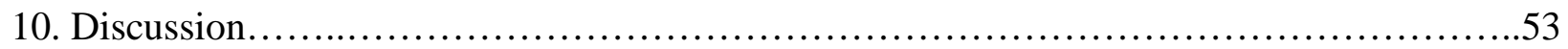

10. 1 Momentary Benefits of Savoring.........................................54

10.2 Savoring and the Broaden and Build Theory ....................................57

10.3 Individual Differences in Affect and Savoring.................................61

10.3.1 Self-esteem......................................................61

10.3.2 Anxious attachment.............................................62

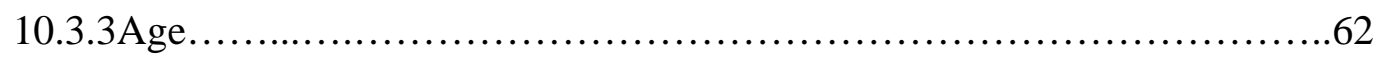

10.3.4 Future time perspective..........................................64

10.3.5 Perceptions of free time...........................................65

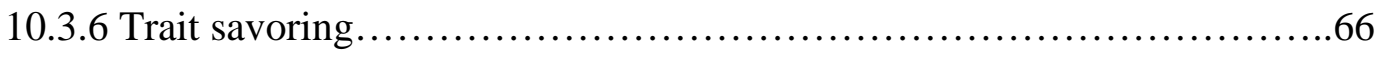

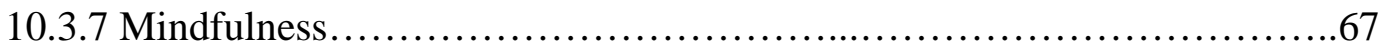

10.4 Limitations and Future Directions...........................................67

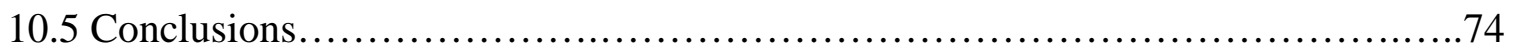

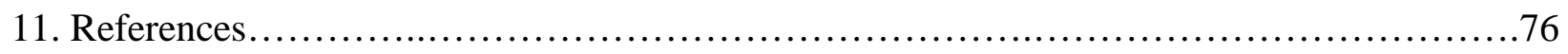

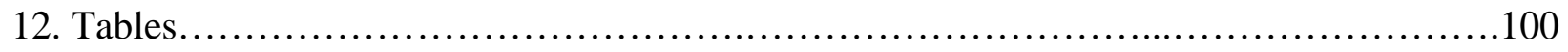

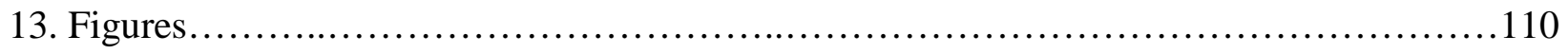

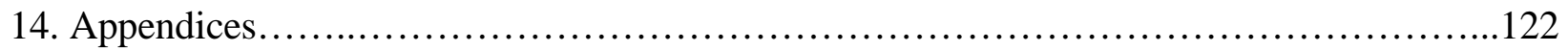




\section{LIST OF TABLES}

1. Table 1: Demographics by Age............................................. 100

2. Table 2: Preliminary Correlations, Means, and Standard Deviations for all Demographic and Individual Difference Variables and Baseline Emotions.........................101

3. Table 3: Preliminary Bivariate and Partial Correlations, Means, and Standard Deviations for all Post-Task Variables and Demographics for the Savoring Group................102

4. Table 4: Preliminary Bivariate and Partial Correlations, Means, and Standard Deviations for all Post-Task Variables and Demographics for the Control Group....................103

5. Table 5: Preliminary Correlations between all Individual Difference Variables and Baseline Emotions .104

6. Table 6: Preliminary Correlations between Individual Difference Variables, Emotion Difference Scores, and Post-Task Variables for the Savoring Group....................105

7. Table 7: Preliminary Correlations between Individual Difference Variables, Emotion Difference Scores, and Post-Task Variables for the Control Group....................106

8. Table 8: Self-Esteem Predicting Post-Task Affect...............................107

9. Table 9: Anxious Attachment Predicting Post-Task Affect...........................108

10. Table 10: Age Predicting Post-Task Affect.......................................109 


\section{LIST OF FIGURES}

1. Figure 1: Upward Spirals of Positive Emotion ......................................110

2. Figure 2: Full Conceptual Model..............................................111

3. Figure 3: Study Timeline ........................................................ 112

4. Figure 4: General PA Subscale Means for the Control and Savoring Group across all 3 Emotion Assessments ........................................................113

5. Figure 5: High-Arousal PA Means for the Control and Savoring Group across all 3 Emotion Assessments......................................................................... 114

6. Figure 6: Low-Arousal PA Means for the Control and Savoring Group across all 3 Emotion

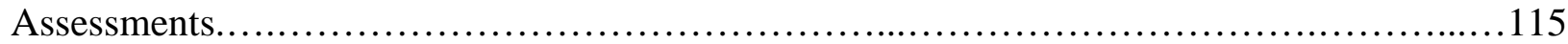

7. Figure 7: NA Subscale Means for the Control and Savoring Group across all 3 Emotion

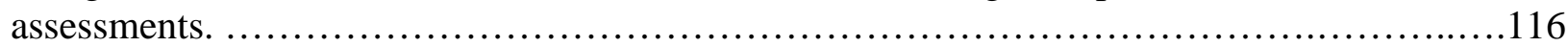

8. Figure 8: Poignancy means for the control and savoring group across all 3 Emotion Assessments.

9. Figure 9: PA difference score and global-local processing by group.....................118

10. Figure 10: Self-esteem and post-task positive affect by group.........................119

11. Figure 11: Self-esteem and post-task high-arousal PA by group. ......................120

12. Figure 12: Conceptual and Statistical Model for Research Question 4..................121 


\section{LIST OF APPENDICES}

1. Appendix A: Demographic Questionnaire.............................................. 122

2. Appendix B: Positive Event Recall.................................................... 124

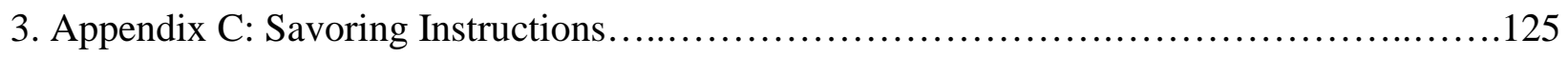

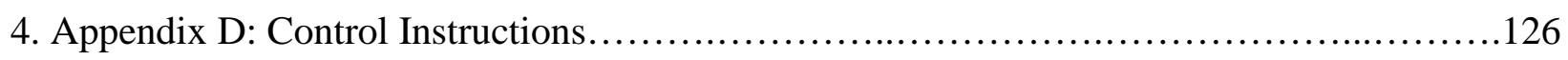

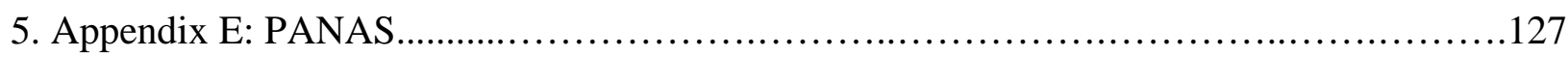

6. Appendix F: Experiences in Close Relationships Scale ....................................128

7. Appendix G: Rosenberg Self-Esteem Scale ..........................................131

8. Appendix H: Future Time Perspective...................................................132

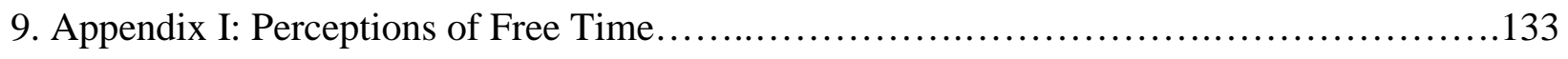

10. Appendix J: Global-Local Processing Task...............................................134

11. Appendix K: Thought-Action Repertoires................................................135

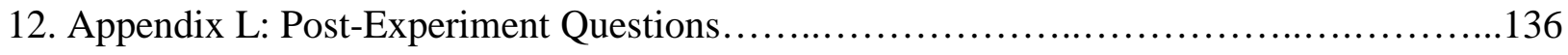

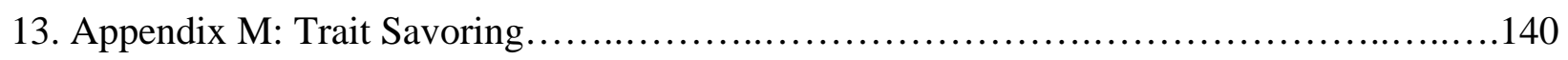

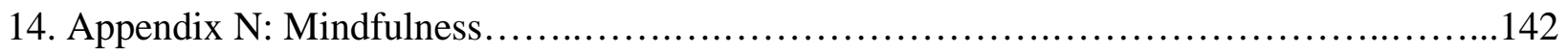


Experimentally-Induced Savoring and its Impact on Positive Emotions, Cognitions, and Behaviors: Investigating Individual Differences in Effectiveness

\section{Positive Emotions}

Emotion research has generally focused on negative emotions and how to alleviate them. However, positive affect (PA) is a large component of happiness and well-being. Recently, the United Nations recognized the importance of happiness as an essential piece of national development, even beyond economic growth (Helliwell, Layard, \& Sachs, 2012). Furthermore, people report that happiness is a central goal that they pursue (Diener, 2000) and that it makes life worth living (King \& Napa, 1998). However, despite the acknowledged importance of happiness, PA has received much less scholarly attention when compared to negative affect (NA). Yet, an increased focus on happiness and PA is an important step for the field of psychology and for emotion research.

There are a myriad of benefits that have been linked with experiencing PA, even beyond their initial, immediate good feelings. In a review of 225 cross-sectional, longitudinal, and experimental studies, Lyubomirksy, King, and Diener (2005) provide evidence that PA is not only associated with positive outcomes, but precedes, and in some cases might actually cause these outcomes. For example, PA promotes positive social relationships (Diener \& Seligman, 2002), more success in the workplace (Boehm \& Lyubomirsky, 2008), better physical health (Fredrickson, Cohn, Coffey, Pek, \& Finkel, 2008; Pettit, Kline, Gencoz, Gencoz, \& Joiner, 2001; Veenhoven, 2008) and better mental health (Folkman \& Moskowitz, 2000; Lyubomirsky, King, et al., 2005). PA might also “undo” the adverse physiological effects (Fredrickson, Mancuso, Branigan, \& Tugade, 2000) and cognitive effects of negative emotions (Falkenstern, Schiffrin, Nelson, Ford, \& Keyser, 2009). Furthermore, in addition to general health benefits, PA may 
protect adults from decline associated with old age (Ostir, Markides, Black, \& Goodwin, 2000), and has been associated with living a longer life (Carstensen et al., 2011; Danner, Snowdon, \& Friesen, 2001; Maruta, Colligan, Malinchoc, \& Offord, 2000)

\section{The Broadening Effect of Positive Emotion}

One reason that has been posited for how PA causes such beneficial outcomes is the broadening effect that PA has on our cognitions and the actions that we are readily able to engage in at a given moment in time (Fredrickson, 2001). Emotions have evolved over time because they produce specific action tendencies toward certain thoughts, actions, and physiological responses that are adaptive for our survival (Tooby \& Cosmides, 2008). Generally, within the realm of negative emotions, these action and thought tendencies are narrowed, allowing the individual's cognitive resources to focus on the stimulus eliciting the negative emotional response (e.g., a snake) and the body to actively deal with that stimulus (e.g., get away from danger, Derryberry \& Tucker, 1994). Initial work on PA links positive emotional states to some specific action tendencies as well, however it has been noted that these action tendencies have been vague (Fredrickson, 1998), and that PA is typically not associated with physiological responses that evoke particular action (Levenson, Ekman, \& Friesen, 1990).

According to the broaden and build theory (Fredrickson, 2001), PA tends to occur in situations that are perceived as safe. Therefore, instead of narrowing an individual's focus on a particular stimulus, PA broadens our cognitions and our momentary thought-action repertoires, which allow us to take in more information and engage in a wider variety of behaviors. These tendencies are adaptive because these novel behaviors and thoughts help the individual build personal resources that they can use at a later time. For example, the experience of joy is linked to an increased tendency to play and push the limits, which can help build physical resources, 
and assist cognitive and social-affective skill acquisition through rough-and-tumble, object, and social play (Fredrickson, 1998). Another example is interest, which is associated with increased tendencies to explore (Izard, 1977) and can help build a larger knowledge base (Fredrickson, 1998). These increased resources not only help us in times of danger, but also provide us with increased opportunities to experience more PA, a process that has been called upward spirals of positive emotion (see Figure 1, Fredrickson \& Joiner, 2002).

There is a growing body of empirical evidence that supports Fredrickson's hypothesis that PA broadens our thoughts and actions (Gasper \& Clore, 2002; Schmitz, De Rosa, \& Anderson, 2009). For example, past research shows that when induced to feel elated, adults have more interest in a wider variety of activities (Cunningham, 1988). Furthermore, college students experimentally manipulated to feel contentment and amusement use more global processing and are willing to engage in more behaviors (Fredrickson \& Branigan, 2005). PA is also linked to the flexibility of attention in undergraduates and adults (Compton, Wirtz, Pajoumand, Claus, \& Heller, 2004; Dreisbach \& Goschke, 2004; Phillips, Bull, Adams, \& Fraser, 2002). This attentional style allows for more details when recalling autobiographical memories (Talarico, Berntsen, \& Rubin, 2009), less assumptions of out-group homogeneity (Fredrickson, 2001; Johnson \& Fredrickson, 2005), more attention to novel stimuli (Carver, 2003), openness to information (Estrada, Isen, \& Young, 1997), creativity (Isen, Johnson, Mertz, \& Robinson, 1985; Isen, Rosenzweig, \& Young, 1991), and a preference for variety in behavior (Kahn \& Isen, 1993). Furthermore, these links have been found for a multitude of tasks and contexts, including real-life scenarios. For example, physicians induced to experience PA have more flexibility in solving clinical problems (Estrada et al., 1997; Isen et al., 1991). 
It is through these broadened cognitive states and increased thought-action repertoires that individuals are able to reap the benefits of PA and build durable resources, such as better relationships, better health, and more intellectual capabilities. Therefore, finding ways to increase and maintain PA, which generally only lasts anywhere from a few seconds to a few hours (Verduyn, Delvaux, Van Coillie, Teurlinckx, \& Van Mechelen, 2009), might increase opportunities for broadening effects and increase engagement in adaptive, building behaviors.

\section{Savoring and Positive Emotion}

Much of our overall happiness is influenced by factors largely out of our control, such as genes or current circumstances (e.g., marital status, income). However, about $40 \%$ of our happiness is determined by controllable, day to day activities (Lyubomirsky, Sheldon, \& Schkade, 2005), which leaves extensive variation that individuals can seek to maximize. Nevertheless, experiencing positive daily activities does not necessarily guarantee the experience of positive moods. This may be because individuals generally do not passively experience emotional states and events, but are active agents that influence the duration and intensity of their emotions (e.g., John \& Gross, 2007). When people focus their attention on and appreciate a positive experience, they are engaging in what Bryant and Veroff (2007) broadly refer to as savoring (although previous research has used various terminologies; see maximizing, Gentzler, Morey, Palmer, \& Yi, 2013 and capitalizing, Langston, 1994). Savoring involves responses to a positive event that can amplify or maintain PA. There are a plethora of these activities that may up-regulate PA (Livingstone \& Srivastava, 2012). However, some commonly researched savoring strategies include, but are not limited to, actively enjoying the event by focusing on the positive feelings associated with the experience, or focusing on good qualities of the self that led to the occurrence of that event (Feldman, Joormann, \& Johnson, 2008; Gentzler, Kerns, \& 
Keener, 2010), expressing thankfulness (Bryant \& Veroff, 2007), outwardly expressing PA (Bryant \& Veroff, 2007; Gentzler et al., 2010; Langston, 1994) and sharing (or thinking about sharing) the positive event with another person (Bryant \& Veroff, 2007; Gentzler et al., 2010; Langston, 1994).

Bryant and Veroff (2007) differentiate various savoring strategies using several dimensions. The first dimension is time orientation, which is savoring that focuses on something in the present, or something that is not part of the current temporal experience (such as reflecting on a past event or anticipating a future one). The focus of savoring can be on the self or focused on other people (e.g., thinking about how great you are for getting a promotion at work versus thinking about how thankful you are for your supportive coworkers). Savoring can also be behavioral (e.g., sharing with others, going out to celebrate) or cognitive (e.g., reflecting on good feelings). While there are countless strategies that people may use to intentionally up-regulate their PA (Bryant \& Veroff, 2007; Livingstone \& Srivastava, 2012), the current study examined savoring that involves cognitive reflection on a past event.

Empirical work suggests that savoring is generally associated with increases in PA and positive outcomes. For example, mental reappearances of a positive stimulus or event may lead to a longer duration of joy in undergraduates (Verduyn et al., 2009; Verduyn, Van Mechelen, \& Tuerlinckx, 2011) and increases in PA for dysphoric women (McMakin, Siegle, \& Shirk, 2011). Savoring is also associated with boosts in happiness and lowered depressive symptoms (e.g., Fava, Rafanelli, Cazzaro, Conti, \& Grandi, 1998; Hurley \& Kwon, 2012; Quoidbach, Berry, Hansenne, \& Mikolajczak, 2010; Werner-Seidler, Banks, Dunn, \& Moulds, 2013). Research examining an assortment of behaviors empirically linked to happiness has found that savoring has the strongest relationship to happiness when compared to other activities (Warner \& 
Vroman, 2011). Savoring is also linked to more PA even when savoring specific events. Focusing on the positive during daily walks is related to more happiness (Bryant \& Veroff, 2007), and savoring is linked to increased happiness and well-being both during and after a vacation (de Bloom, Geurts, \& Kompier, 2013). Furthermore, people might need at least some degree of savoring to experience any PA at all after a positive event (Jose, Lim, \& Bryant, 2012).

A related concept to savoring is gratitude. Gratitude involves the cognitive appraisal of an event, experience, or aspect of life as something that is appreciated and has been caused by an external source (Weiner, 1985). Bryant and Veroff (2007) note that feeling grateful and appreciative can be a specific strategy to up-regulate PA. However, savoring may also involve the passive reflection and cognitive replaying of an event, and does not necessitate any active interpretation or judgment, and may be self-focused in nature (Bryant \& Veroff, 2007). Nonetheless, while gratitude is not a necessary part of savoring, savoring can often include this appreciative appraisal. There is substantial evidence from the gratitude literature that suggests that this appreciative stance may lead to increases in PA. Generally, gratitude interventions demonstrate large effects on well-being and PA across adolescence and adulthood (Emmons \& McCullough, 2003; Froh, Emmons, Card, Bono, \& Wilson, 2011; Froh, Sefick, \& Emmons, 2008; Froh, Yurkewicz, \& Kashdan, 2009; Kashdan, Uswatte, \& Julian, 2006; Lyubomirsky, Dickerhoof, Boehm, \& Sheldon, 2011; Seligman, Steen, Park, \& Peterson, 2005). Additionally, a recent meta-analysis on positive psychology interventions, which often incorporate elements of savoring and gratitude, reported that they lead to increases in happiness (Sin \& Lyubomirsky, 2009). Moreover, research on trait gratitude, although limited in its correlational nature, highlights associations between grateful dispositions and experiencing more PA, as well as less 
NA (e.g., Emmons \& McCullough, 2003; Seligman et al., 2005; Watkins, Woodward, Stone, \& Kolts, 2003).

Another concept that is related to savoring is mindfulness. Mindfulness is an open, receptive awareness and attention to one’s current experience (Brown \& Ryan, 2003). According to Bryant and Veroff (2007), savoring involves a meta-awareness of current PA, a skill that necessitates proficiency in mindfulness. However, mindfulness entails an awareness and objective acceptance of internal states without any interpretation or judgment about current thoughts and feelings (Baer, Smith, Hopkins, Krietemeyer, \& Toney, 2006; Bishop et al., 2004; Brown \& Ryan, 2003; Cardaciotto, Herbert, Forman, Moitra, \& Farrow, 2008). Conversely, savoring might entail cognitive interpretations of the event or explicit intentions to change current affective states (Bryant \& Veroff, 2007). Mindfulness is also defined as being oriented to the present (Brown \& Ryan, 2003), whereas savoring can happen in the moment, or through what researchers have termed “mental time travel” by thinking about past or future events (Quoidbach, Berry, et al., 2010). Nonetheless, mindfulness may have important implications for the ability to savor effectively. Mindfulness involves the ability to sustain attention and remain relatively free from distractions (Mrazek, Smallwood, \& Schooler, 2012). Negative, intrusive thoughts may occur when savoring and dampen feelings of PA (e.g., "I only got the promotion because no one else wanted the extra workload," or “My coworkers are supportive because they think I am struggling.”). Individuals high on mindfulness may be more likely to notice when these intrusive feelings may begin to permeate their thoughts, and therefore can better direct their attention to more positive aspects of the situation if desired (Teper, Segal, \& Inzlicht, 2013). Thus, although mindfulness and savoring are distinct processes, mindfulness may promote savoring proficiency. 


\section{Manipulating Savoring}

Despite the success of savoring-related interventions and associations between natural savoring tendencies and positive emotional benefits, the relationship between momentary savoring processes and increases in immediate PA, and PA's related benefits, is less clear-cut. Therefore, experimentally manipulating savoring in the moment, as opposed to in a long-term intervention, might be crucial to understand its immediate, momentary benefits.

Although small in number, previous research that has asked participants to savor a positive stimulus in the moment has been limited in its success to produce increased PA, and two studies even lead to decreases in PA. Adults asked to continually monitor their enjoyment or to make themselves happy when listening to hedonically ambiguous music (Schooler, Ariely, \& Loewenstein, 2003) or to attend to their responses to humorous cartoons (Cupchik \& Leventhal, 1974), showed reduced enjoyment. Giuliani, McRae, and Gross (2008) found that telling undergraduates to increase their amusement did lead to increases in PA, but this was only in comparison to participants who were told to decrease their amusement or who were given no instruction at all. However, in another study, undergraduates asked to consciously try to improve their mood when listening to positively valenced (vs. not trying or listening to neutral music) experienced increases happiness (Ferguson \& Sheldon, 2013).

A review of empirical work and these mixed findings suggests that it is not necessarily savoring that is problematic, but the type of savoring that studies have induced or savoring within particular contexts. It has been suggested that too much focus on PA can dampen one’s feelings and disrupt one’s affective experience (Bryant \& Veroff, 2007). For example, in the study by Schooler and colleagues (2003), giving participants the goal of making themselves happy or to continually evaluate their enjoyment might undermine their ability to just enjoy the moment. It has also been suggested that analyzing a positive event might lead the individual to 
question the event or think about downsides. Making sense of our positive events reduces the pleasure that we derive from them and make them seem, ordinary, mundane, and common place. This is something that Wilson, Centerbar, Kermer, and Gilbert (2005) refer to as the "pleasure paradox.” This is supported by research that suggests that people who are happy tend to be less introspective about why they behave and feel happy (Lyubomirsky \& Lepper, 1999; Veenhoven, 1988). Furthermore, asking people to make themselves happy might produce an expectation that they should be happy, which may create worry and preoccupation with this end-goal (Bryant \& Veroff, 2007), and excessively valuing happiness might lead to disappointment if people feel that they are not meeting that goal (e.g., Mauss, Tamir, Anderson, \& Savino, 2011).

Another alternative to analyzing PA and positive events is to simply think repetitively and passively about the positive event and its related feelings. This type of reflection is related to increased or maintained PA (Feldman et al., 2008). Studies that have asked undergraduates to reexperience positive events or envision future positive events without asking them to analyze it have been effective in producing positive results (Burton \& King, 2004; King, 2001; Lyubomirsky, Sousa, \& Dickerhoof, 2006).

Due to the mixed success of studies that have attempted to increase momentary PA through cognitive means, the savoring manipulation in the current study was developed using suggestions based on theory and previous research. Instead of systematically analyzing a positive experience and the precursors to that event, or explicitly asking participants to increase positive mood, savoring in the current study involved simply recalling a positive event and passively reflecting on that experience.

\section{Savoring and the Broaden and Build Theory}


An examination of the current research suggests that if PA leads to broadened cognitions and behavior, and savoring leads to increases in PA, then savoring will lead to an increased broadened effect. An alternative hypothesis might be that focusing one's attention on a positive stimulus, a crucial component of savoring, might actually narrow one's attention to that stimulus. Despite this alternative possibility, there is some evidence that suggests that savoring a positive event might indeed broaden, and not narrow, cognition. For example, high levels of genuine facially expressed PA may be associated with broader attention and flexibility in undergraduates (Johnson, Waugh, \& Fredrickson, 2010), a savoring strategy that is related to more intense PA (Bryant \& Veroff, 2007; Langston, 1994). Research on mindfulness suggests that the components of mindfulness that are most indicative of a broadened mindset are related to more positive reactivity to everyday positive events in a community sample of adults (Catalino \& Fredrickson, 2011). The authors of this study hypothesized that the greater reactivity might be due to better savoring of positive events, although savoring in this study was not directly assessed.

In addition, some of the positive outcomes that are associated with savoring may be due to the resource-building processes outlined in the broaden and build theory. For example, savoring processes are associated with more self-worth, optimism, and greater life satisfaction (Bryant, 2003; Feldman et al., 2008; Quoidbach, Berry et al., 2010). Other research on sharing positive events, a specific type of savoring, is associated with better relationship well-being (Gable, Reis, Impett, \& Asher, 2004) and might actually cause the individual to have a more prosocial orientation towards the person with whom the individual shared the event with (Reis et al., 2010), at least when people respond to the sharing attempt in a positive, active way. Additionally, experimentally manipulated gratitude is associated with more prosocial behavior 
towards a benefactor (Tsang, 2006). However, these studies have only investigated specific components of savoring positive events and their association with building behaviors or positive outcomes, without measuring the relationship between savoring and broadening effects directly. Therefore, the current study examined if participants randomly assigned to savor experienced more broadened cognitions and actions, and if this effect was due to savoring-related increases in PA.

\section{Individual Differences in Savoring}

Similar to the individual differences found in the types of regulatory strategies people employ for their NA (e.g., John \& Gross, 2007), research has found individual differences when assessing self-reported savoring of PA (e.g., Bryant \& Veroff, 2007; Feldman et al., 2008; Wood, Heimpel, \& Michela, 2003). Generally, people differ in the type and amount of emotion they want to feel, and it has been argued that the general notion that everyone wants to feel good may not be clear cut (Tamir, 2009). In other words, there are individual differences in the motivations people have to experience positive feelings (Wood et al., 2003) and some people are more likely to engage in thoughts that actually dampen PA (Feldman et al., 2008).

However, most of the research on individual differences in savoring thus far have been done using self-reported surveys, which ask participants what they have done to respond to a positive event that they experienced (e.g., Gentzler et al., 2010; Gentzler et al., 2013), what they would do in response to hypothetical events (Gentzler, Palmer, \& Ramsey, 2014; Palmer, Ramsey, Morey, \& Gentzler, 2014; Nélis, Quoidbach, Hansenne, \& Mikolajczak, 2011), or their perceived ability to savor (Bryant, 2003). These self-report measures allow for assessment of cognitive strategies that cannot be readily observed, but they may be confounded with reporting biases or inaccurate self-perceptions. However, there have been a few studies that have assessed savoring behaviorally. Quoidbach, Dunn, Petrides, and Mikolajczak (2010) used a real-time 
behavioral measure of savoring by examining how much and how long college students enjoyed a piece of chocolate after being exposed to either money or a neutral prime. Another study manipulated adults' attitudes about the equivalence of time and money, and assessed savoring by the ability to derive pleasure from leisure time on the internet or from listening to a pleasant song (DeVoe \& House, 2012). Gentzler and colleagues (2010) gave colleges students positive feedback about themselves after meeting a new person, and measured the extent to which people had positive reflections on their feedback, themselves, or the interaction as an index of savoring. These real-time tasks minimize the impact that self-report biases may have on the assessment of savoring. However, these studies only examined differences across experimental groups or individual differences in the amount of savoring, and did not report individual variation in how effective people are at savoring to increase their PA.

Given the current research, little is known about what individual difference variables are associated with the ability to savor positive experiences effectively. Although there is individual variation in self-reported savoring ability (Bryant, 2003), individual differences in the real-time, momentary affective benefits of savoring are largely unknown. Additionally, reports of savoring strategy frequency (Gentzler et al., 2010; Gentzler et al., 2013) do not report the affective benefits of these strategies and may be confounded with individual differences in the initial motivation to savor, situational constraints that may prevent the ability to savor effectively, or the quality and quantity of positive events that one experiences (Bryant \& Veroff, 2007). The current study examined savoring ability by providing participants with the same encouragement to savor to more accurately assess individual variation in ability.

Bryant, Chadwick, and Kluwe (2011) suggest that future research should strive to examine savoring in real-time, much like Quoidbach, Dunn and colleagues (2010), DeVoe and 
House (2012), and Gentzler and colleagues (2010). However, capturing this process as it naturally occurs is not an easy task to accurately observe due to the cognitive nature of some savoring strategies. Therefore, examining differences in affective outcomes after being encouraged to savor might more precisely get at the ability to savor in individuals, similar to the method used in DeVoe and House (2012). However, instead of comparing between-group differences of a manipulated variable, the current study examined naturally occurring individual differences in the quality of the savoring process.

Self-esteem. One individual difference that might contribute to savoring ability is selfesteem. Some research suggests that people are more likely to accept a mood if they view it as typical of themselves (Mayer \& Stevens, 1994; Parrot, 1993) and people actively seek out information that is consistent with their current self-perceptions (Swann, 2011). According to the self-verification theory, people are motivated to accept feelings consistent with their self-views in order to maintain predictability and stability (Swann \& Schroeder, 1995). Those with lower self-esteem are more likely to have a negative self-perception (Baumeister, Tice, \& Hutton, 1989), and therefore may be more likely to accept and seek feelings that correspond with these negative self-views.

This is evidenced by studies that have found that having more positive beliefs about the self is related to increased experiences of PA (Alessandri, Zuffiano, Fabes, Vecchione, \& Martin, 2014). These observed differences in PA may be due to interpretative processes regarding positive events, such as savoring or dampening thoughts. Correlational studies have investigated the link between self-esteem and savoring in college students, and they have found that selfesteem is positively associated with self-perceived savoring ability (Bryant, 2003), and that those with lower self-esteem are more likely to engage in dampening of PA (Wood et al., 2003; Wood, 
Heimpel, Newby-Clark, \& Ross, 2005). According to Bryant and Veroff (2007), low self-esteem may inhibit savoring that involves cognitive reflection through self-praise or self-admiration (Bryant \& Veroff, 2007; Feldman et al., 2008). Therefore, it was expected that in the current study, those with lower self-esteem would experience less PA after the savoring induction than those with higher self-esteem.

Attachment. Another individual difference variable that might impact the ability to savor is attachment. Attachment is related to emotional experience through internal working models of the self and other people, which contribute to individuals' interpretations of emotional events (Fraley \& Shaver, 2000; Griffin \& Bartholomew, 1994; Hazan \& Shaver, 1987). Whereas most research on attachment and affect has focused on how this may relate to the coping of negative feelings and distress, there is evidence that attachment may impact responses to positive events as well (Mikulincer \& Shaver, 2008). Positive experiences typically occur in relatively benign settings where an individual should be able to relax and experience positive feelings, but the ability to do so may depend on attachment (Mikulincer \& Shaver, 2008).

Some research suggests that having a more secure attachment is associated with more frequent and intense positive moods in college students and children (Kerns, Abraham, Schlegelmilch, \& Morgan, 2007; Shiota, Keltner, \& John, 2006; Tidwell, Reis, \& Shaver, 1996) and a greater capability to reap benefits from PA (Diamond \& Aspinwall, 2003; Mikulincer \& Sheffi, 2000). The direct relationship between attachment style and savoring is not wellexplored, but there is evidence that undergraduates who are less anxiously attached may be more likely to reflect on an experimentally manipulated positive event (Gentzler et al., 2010), and research with young adolescents suggests that attachment with fathers may be related to more savoring of an event (Gentzler, Ramsey, Yi, Palmer, \& Morey, in press). 
This research is in line with evidence that suggests that attachment style might moderate the relationship between PA and broadened cognitions. Mikulincer and Sheffi (2000) found that usual patterns of PA on broader categorization and more creativity was apparent in securely attached undergraduates, but PA had no effect for those who were avoidantly attached, and those with anxious attachment styles showed a narrower categorization and less creativity. It has been suggested that it may not just be affective valence that causes changes in broadened cognitions, but the perception of situations as being benign or threatening (Friedman \& Förster, 2010). Anxious individuals might interpret PA as a cue for danger if they believe that there is a threat for negative outcomes (Shaver \& Hazan, 1993). This heightened focus on threat might detract from their ability to fully savor and enjoy their positive feelings. Therefore, the current study investigated how anxious attachment impacts the effectiveness of savoring by examining affective outcomes after savoring a positive event, and it was hypothesized that participants reporting higher levels of anxious attachment would be less able to savor.

Age. Age differences in emotional experience suggest that adults generally experience more low-arousal PA with age (Isaacowitz \& Blanchard-Fields, 2012; Mroczek \& Kolarz, 1998; Pinquart, 2001; Stanley \& Isaacowitz, 2011). When investigating curvilinear effects in the age differences in PA, Grühn, Kotter-Grühn, and Röcke (2010) found a U-shaped pattern, with middle-aged adults reporting the lowest PA scores compared to younger and older adults, while older adults reported the highest. Urry and Gross (2010) discuss how these age-related differences in emotional experience might be due to emotion regulation strategies. Older adults tend to be better at the regulation of negative emotions (Blanchard-Fields, 2007; Charles \& Carstensen, 2007; Phillips, Henry, Hosie, \& Milne, 2008). Although less is known about age differences in the regulation of PA, some research suggests that older adults may be better at 
meeting their PA goals (Scheibe, English, Tsai, \& Carstensen, 2012). Potentially, savoring might play a role in the relationship between PA and age.

There is some evidence that older adults may take more from their positive events. They attend more to positive stimuli (Isaacowitz, Wadlinger, Goren, \& Wilson, 2006a, 2006b; Mather \& Carstensen, 2003), recognize and remember positive images more than negative ones when compared to young adults (Carstensen \& Mikels, 2005; Charles, Mather \& Carstensen, 2003; Mikels, Larkin, Reuter-Lorenz, \& Carstensen, 2005) and use more cognitive resources to direct attention in ways that promote their happiness and well-being (Kryla-Lighthall \& Mather, 2009). This age-related positive bias has been referred to as the "positivity effect" and has been found reliably across contexts and laboratories (Scheibe \& Carstensen, 2010). Positive emotional experiences tend to be more long lasting in older adults (Carstensen, Pasupathi, Mayr, \& Nesselroade, 2000). Older adults also report more motivation to feel PA (Riediger, Schmiedek, Wagner, \& Lindenberger, 2010), especially low-arousal PA (Schiebe et al., 2012). However, while many researchers theorize a link between this tendency to engage in positive cognitive processes and increased PA in older adulthood (Isaacowitz \& Blanchard-Fields, 2012), very little research has tested this direct link and it is not clear if these cognitive changes are associated with more PA.

Very few studies have directly measured savoring to investigate age differences in PA in adulthood. One study that examined cross-sectional age differences in savoring found that older adults reported a greater ability to savor when compared to college students (Bryant \& Veroff, 2007). In contrast, other cross-sectional work found no direct effect of age in self-reported savoring ability across adulthood, but an indirect effect of age through perceptions of time left in life to live (Ramsey \& Gentzler, 2014). Due to the scarcity of research on age and savoring in 
adulthood, it has been noted that more research is needed on how savoring differs across the lifespan (Bryant et al., 2011). Furthermore, research has yet to investigate adult age differences in savoring using a behavioral task. In addition, any age-related savoring differences may vary based on the type of affect being up-regulated. Older adults may be better able to savor lowarousal PA as opposed to high-arousal PA for several reasons. First, the age increases in PA across adulthood seem to be limited to low-arousal PA (Pinquart, 2001). Second, older adults value low-arousal positive mood states more than high-arousal states (Schiebe et al., 2012). Third, older adults are at a disadvantage for experiencing high-arousal mood states due to decreased physiological flexibility (Charles, 2010).

Although previous researchers have suggested that older adults may derive more PA from their savoring experiences, it is possible that they may also experience more poignancy (experiencing PA and NA simultaneously). Written descriptions of emotions demonstrate more of this affective complexity among older adults (Labouvie-Vief, DeVoe, \& Bulka, 1989), and both cross-sectional and longitudinal research suggests that the experiences of mixed emotions, or emotional complexity, increase with age (Carstensen et al., 2000; Carstensen et al., 2011; Ong \& Bergeman, 2004). Poignancy may result when a good event is occurring for the last time (Ersner-Hershfield, Mikels, Sullivan, \& Carstensen, 2008). For older adults, some positive events might trigger some negative feelings if the event also represents an ending. For example, having a child get married is typically a joyous occasion. However, if this is the last child in the family to get married, it may be accompanied by bittersweet feelings of loss. Within old age in particular, the experience of "last times" may be more frequent, and therefore may produce more feelings of poignancy. 
In the current study, the relationship between savoring and age was examined by using a behavioral task to investigate savoring-related increases in general PA, high-arousal PA, lowarousal PA, along with NA and poignancy. However, it is well-established that age is not an explanatory variable, but a proxy for other causes (Wohlwill, 1970). While it is likely that the increase in emotion regulation with age is partially due to increased experience (BlanchardFields, 2007; Gross et al., 1997), other age-related changes that may mediate age effects were explored in this study.

Age and future time perspective. One potential explanation for age-related differences in savoring ability is future time perspective. According to Carstensen’s socioemotional selectivity theory, older adults have a limited future time perspective and are more likely to view their time left in life as limited, which is typically associated with pursuing more emotionally salient goals in order to maximize PA and experiences (e.g., Carstensen, Fung, \& Charles, 2003; Carstensen, Isaacowitz, \& Charles, 1999). Overall, older adults tend to show the most limited future time perspective when compared to other age groups (Charles \& Carstensen, 2010). This might cause older adults to actively pursue positive "here and now” moments as opposed to more futureoriented goals such as gaining new information or knowledge (Fung \& Carstensen, 2006). To date, one study has investigated the link between age, future time perspective, and savoring, and found indirect effects of age on savoring, through future time perspective (Ramsey \& Gentzler, 2014). However, contrary to expectations and research that suggests that a more limited time perspective might increase PA experiences, a more expansive future time perspective (or feeling like there is more time left in life) was related to more perceived savoring ability. Potentially, feeling like there is less time left in life may prompt older adults to feel like there is not enough time to enjoy all that life has to offer, and hence resulted in less perceived ability to savor. An 
additional, alternative explanation for this finding might be that while older adults may try to maximize positive feelings, feeling that the end of life is drawing near might prompt increased feelings of NA or poignancy, resulting in less perceived savoring ability. For example, thinking about being somewhere for the last time or thinking about endings seems to result in greater mixed emotion, even during positive events (Ersner-Hershfield et al., 2008). In the current study, the relationship between future time perspective and savoring's emotional outcomes were examined to determine if any age differences in savoring are partially mediated by feeling like there is less time left in life.

Age and perceptions of free time. Savoring involves lingering on a positive feeling, moment, or event, and calls for increased attentional resources (Bryant \& Veroff, 2007; Frijda \& Sundararajan, 2007). Multitasking or thinking about other things takes away from the ability to savor (Friedman \& Ulmer, 1985; Zimbardo \& Boyd, 1999), and when people are in a rush they may enjoy an event more briefly (Bryant \& Veroff, 2007). Potentially, the amount of free time that a person perceives having might impact their ability to focus on the here and now if they are focused on tasks that must be completed in the near future. Distractions in the form of thoughts unrelated to the positive event may decrease the intensity or shorten the duration of the emotional episode by ending the positive feelings (Bryant \& Veroff, 2007; Verduyn et al., 2011). This is supported by research that suggests that always feeling rushed is associated with lower life satisfaction (Robinson \& Godbey, 1997) and time pressure from work is associated with an inability to cognitively detach from work (Sonnentag, 2012). Furthermore, lack of time is a common reason for not taking the time to experience leisure (Mannell \& Zuzanek, 1991).

Although the relationship between the amount of free-time that one perceives and savoring has not been directly examined, Bryant and Veroff (2007) hypothesize that this may be 
a major reason for older adults' higher perceived savoring ability, because retirement might bring more inclination and time to savor without work-related needs. On the other hand, middle adulthood is likely associated with high levels of work and family demands (Mroczek \& Almeida, 2004). In a recent Gallup poll, 55-58\% middle-aged and younger adults (18-54) indicated that they did not have enough time to do what they want to do, as opposed to only $28 \%$ of older adults (Carroll, 2008). Since savoring involves stretching out a positive moment to "linger" in the positive feeling, it becomes minimized when people are bombarded by other demands. This age-related pattern of free time emulates patterns found for PA, with low-arousal PA and free time both increasing with age after middle adulthood (e.g., Bryant \& Veroff, 2007; Grühn et al., 2010). Therefore, in the current study, it was hypothesized that the amount of free time perceived would be positively associated with age. It was also hypothesized that this agerelated difference would partially mediate the relationship between age and savoring ability.

\section{The Current Study}

The current study assessed immediate emotional benefits after randomly assigning participants to savor. Using random assignment minimized confounding factors that may be associated with natural savoring tendencies to more accurately assess savoring ability and its cognitive effects. Additionally, both the control group and the savoring group recalled a past positive event before the task, to ensure that any savoring-related benefits were due to the actual savoring process, and not simply thinking about a positive event.

This study contributes to research on savoring and positive emotion in several, distinct ways. First, by investigating the momentary, emotional benefits of savoring a positive event, this study builds on past research that has investigated affect-related benefits of savoring in longitudinal interventions or through self-reported savoring. Second, by investigating savoring in 
the moment, this study examined the impact that savoring has on broadened cognitions and thought-action repertoires typical of PA experiences. While we know that PA is beneficial for overall success and well-being (Lyubomirsky, King, et al., 2005), and that savoring may increase PA (e.g., de Bloom et al., 2013; Gentzler et al., 2013; Jose et al., 2012; McMakin et al., 2011), not much is known about how specific savoring strategies may impact PA's typical benefits. Third, this study expanded on previous research on individual differences in savoring, which has primarily relied on self-reported savoring ability. This study fills a critical need for savoring research by investigating the momentary benefits of savoring and further exploring who can savor and why. The proposed study had four main research questions (for the full conceptual model depicting all research questions, please see Figure 2).

\section{Research Question 1: Momentary Affect Benefits of Savoring}

Does providing participants instructions to savor lead to increases in PA when compared to a control group asked to think about a more neutral topic? Specifically, participants were asked to savor a past, positive event. This savoring task was based on literature that suggests that thinking repetitively and passively about a positive feeling leads to increases in PA (Burton \& King, 2004; King, 2001; Lyubomirsky et al., 2006; Wilson et al., 2000), and on instructions used in efficacious savoring interventions (Bryant \& Veroff, 2007; McMakin et al., 2011).

Furthermore, although only some participants were asked to savor, all participants were asked to recall and describe a positive event to the experimenter to ensure that any increases in PA were not simply due to the memory of the positive event itself, but to the actual savoring of the event.

Hypothesis 1. It was expected that participants randomly assigned to the savoring group would experience greater increases in PA and decreases in NA when compared to a control group (after controlling for affect after the event recall). 


\section{Research Question 2: Broadening Cognitive and Behavioral Effects of Savoring}

Does savoring cause more broadened cognitions and actions than what would typically be experienced by increased PA, and are these increases mediated by increased levels of PA after savoring? This question was based on prior work that suggests that PA is associated with broadened cognitions and a willingness to engage in a wider variety of behaviors (Fredrickson, 2001; Fredrickson \& Branigan, 2005).

Hypothesis 2a. It was expected that participants in the savoring group would report more broadened cognitions than the control group.

Hypothesis 2b. It was expected that participants in the savoring group would report more broadened thought-action repertoires than the control group.

Hypothesis 2c. I was expected that the effects in hypotheses $2 \mathrm{a}$ and $2 \mathrm{~b}$ would be mediated by the savoring condition's increased PA.

\section{Research Question 3: Individual Differences in Savoring}

Are there individual differences in savoring ability? By providing participants with savoring instructions, this study may limit confounding factors that relate to individual differences in savoring ability typically found in the literature. Furthermore, this study used affect changes after savoring as an indicator of savoring effectiveness, which limits potential biases associated with self-reported savoring ability. The individual differences in effectiveness that were examined in the current study are based on theory and prior research on PA and savoring, including attachment, self-esteem, and age. Specifically, these individual difference variables were examined as predictors of PA increases after the savoring task. Group assignment was included as a moderator to assess if individual differences in PA are due to savoring, as opposed to general positivity or simply recalling a past, positive event. 
Hypothesis 3a. Participants with lower self-esteem were expected to have less postsavoring PA and greater NA, even when controlling for affect before the task.

Hypothesis 3b. Participants with higher anxious attachment were expected to have lower post-savoring PA and greater NA, even when controlling for affect before the task.

Hypothesis 3c. Older participants were expected to have more post-savoring PA, even when controlling for PA before the task.

\section{Research Question 4: Age-Related Mediators}

Are there mediating factors associated with any age differences in savoring effectiveness? Specifically, the indirect effects of future time perspective and perceptions of free time were investigated to examine if these variables contribute a significant amount of variance to the relationship between age and savoring.

Hypothesis 4a. It was expected that the relationship between age and savoring would be partially mediated by future time perspective. Specifically, it was expected that older adults would have a more limited future time perspective, which would partially mediate the age effect on savoring.

Hypothesis 4b. It was expected that the relationship between age and savoring would be partially mediated by perceptions of free time. Specifically, it was expected that older adults would have more free time, and this would partially mediate the age effect on savoring.

\section{Additional Analyses}

This study also examined how much participants actually savored during the savoring task, and the implications this may have for savoring effectiveness. Analyses were conducted to determine how much effort participants put into the task, and how distracted and impatient they felt. These variables were tested as moderators of the relationship between experimental group 
and post-task PA. Additionally, a measure of trait savoring behavior was included to assess if participants typically savored using the cognitive strategies encouraged in the savoring instructions, and this was also tested as a moderator of savoring effectiveness. Finally, following literature that suggests that maintaining a mindful state might be critical to savoring effectively (Bryant \& Veroff, 2007), trait mindfulness was assessed and examined in relation to savoring to determine if those who are more mindful may also be better equipped to savor in the current behavioral task.

\section{Method}

\section{Participants}

Participants were 120 adults recruited through West Virginia University, participants from past studies in the West Virginia University Psychology Department, the local Morgantown community, and the Baltimore area. The study was advertised as a study on emotions and memory. The number of participants needed was estimated using G*Power (Faul, Erdfelder, Buchner, \& Lang, 2009; Faul, Erdfelder, Lang, \& Buchner, 2007) in order to detect a medium effect $\left(f^{2}=.15\right)$ with $80 \%$ power and 5\% error probability. Participants were selectively recruited to obtain an adequate age distribution, such that a roughly equal number of participants fell between the age groups of 18-29, 30-59, or 60 and older. The average age of participants was $44.61(S D=20.69$, range $=18-94)$, and they were roughly half female $(62.5 \%)$, and primarily White/Caucasian (87.5\%, 6.7\% Black or African American, 4.2\% Asian or Pacific Islander, and 1.7\% other; an additional $2.5 \%$ of participants indicated that they were Hispanic American/Latino). Participants had all completed high school and were generally well-educated (5\% completed high school, $32.5 \%$ some college, $23.3 \%$ graduated college, $7.5 \%$ some graduate school, and 28.3\% completed graduate school), and on average they indicated that they did not 
have a difficult time paying their monthly bills, rated on a 7-point scale from 1 (not at all) to 7 ( $a$ great deal), $M=2.97, S D=1.89$. Most participants were single (36.7\%) or married (40\%), and not retired (80.8\%). For more information about these demographics, and reports of demographics by age, please see Table 1.

\section{Procedure}

The first portion of the study involved a preliminary survey assessing demographics (see Appendix A), attachment, self-esteem, future time perspective, free time, trait savoring, and trait mindfulness. Most participants completed the survey online before the study $(n=110)$, while some participants $(n=10)$ opted to complete the survey on paper. The second portion of the study involved an in-person session, and all in-person sessions were conducted by the same female researcher. The majority of participants completed this in-person session in the lab, whereas others completed this in-person session either in their home $(n=15)$ or at another quiet, public location (e.g., library; $n=22$ ). Some participants completed all or part of the survey online $(n=6)$ but declined to complete the in-person session $(n=1)$ or did not show up for their scheduled appointment and were not able to be rescheduled $(n=5)$. These participants are not included in the final sample size of 120 .

During the in-person session, participants consented to the study and were offered water and a snack, then completed a baseline emotion assessment. All participants then completed a positive event recall which involved describing a positive event in detail to the researcher. This positive event recall was audio recorded. All participants received the same prompt, and based on the amount of detail provided by the participant, several possible probes were given by the researcher. The script for the positive event recall can be found in Appendix B. After the positive event recall participants completed another emotion assessment in order to control for initial reactivity to the event recall. 
Participants were then randomly assigned to either a savoring group or a control group. Random assignment was ensured by putting together an equal number of experimental and control group tasks in sealed, opaque, indiscriminate envelopes labeled “Thinking Task” prior to the start of data collection. An equal number of control and savoring task envelopes were set aside for each age group (18-29, 30-59, and 60 or older) to ensure an adequate age distribution across experimental groups. An envelope was then randomly selected during the participant's inperson session. In order to prevent experimenter biases, the experimenter was blind to participant condition, and the experimenter left the room during the task so that the instructions were read by the participant in private. Participants were instructed to return the instructions to the envelope before the experimenter returned. After the completion of the experimental manipulation, participants completed another emotion assessment, and then they completed tasks that assessed broadened cognitions and broadened momentary thought-action repertoires.

Finally, participants completed a post-experiment questionnaire about the positive event recall and about the task to obtain more information about the positive event they chose and their effort, distraction, and impatience during the savoring induction (or control task). After completion of the survey, participants were asked to state what they believed the study hypotheses were in order to investigate if they were aware of the hypotheses or suspected at any point during the study that the researcher was trying to influence their mood. Participants were then debriefed by explaining the full purpose of the study and the procedure. For the full protocol and timeline for the in-person session, see Figure 3. Participants were paid \$15 for their time and were entered into lottery style drawing to win $\$ 100$.

\section{Experimental Manipulations}

Positive event recall. To ensure that any effects of savoring are not simply due to recall of a positive event, all participants were asked to remember a positive event that still makes them 
happy when they think about it and to describe it to the researcher. Specifically, participants were verbally given the following instructions:

“Now, I'm going to ask you to think of a very positive experience that you would be willing to describe to me. So, take some time to think of a personal experience that has happened to you that made you very happy, and that still makes you feel really good when you think about it. It can be something that happened very recently, or it can be something that happened in the past, as long as it's something that still makes you happy when you think about it. Once you think of something that you'd be willing to describe to me, let me know."

Once participants indicated that they had thought of an event, they were asked, "Would you please describe your experience in detail? For example, you can describe what happened, the people involved, and how it made you feel.” Based on the event description and the amount of detail provided by the participant, several possible probes were given by the researcher. The script for the positive event recall along with possible probes can be found in Appendix B. This positive event recall was audio recorded (although one participant opted not to be recorded).

Savoring and control tasks. Participants were given an envelope titled “Thinking Task.” The experimenter told participants that she would leave the room, and asked that once she left the room that they open the envelope and follow the instructions provided. Participants were given two minutes to complete the task. This time was measured using a stopwatch by the experimenter. The savoring instructions were adapted from two long-term savoring interventions that ask participants to focus on and relive the details of the experience. These interventions have produced increases in PA in past studies (see the daily vacation exercise in Bryant \& Veroff, 2007, p. 211; and the Positive Affect Stimulation and Sustainment Module, which is described in McMakin et al., 2011). The instructions encourage participants to think about the positive event they described for the positive event recall, and to re-experience and reflect on this event. See Appendix C for the full savoring instructions. For participants who received the control task, 
they were asked to think about their daily morning routine (e.g., Thoman, 2011). The instructions encourage participants to think about their daily morning by re-experiencing and reflecting on this routine. These instructions use language consistent with the savoring task. See Appendix D for the full control task instructions. Pilot testing of these tasks using a small, undergraduate sample $(N=20)$ indicated that participants randomly assigned to the savoring condition reported significantly higher PA when compared to the control group $(t(18)=-3.33, p=.004,95 \%$ CI [$15.18,-3.42])$.

\section{Measures}

Affect. Affect was assessed using a series of subscales from the Positive and Negative Affect Schedule (PANAS-X, Watson \& Clark, 1994). The PANAS is a well-validated measure, with good internal consistency, test-retest reliability, and validity (Watson, Clark, \& Tellegen, 1988). The general PA scale contains a variety of positive emotion words (active, alert, attentive, determined, enthusiastic, excited, inspired, interested, proud, strong). High and low-arousal PA were assessed using the joviality and the serenity subscales of the PANAS-X (Watson \& Clark, 1994). The joviality subscale contains 8 different words that describe high-arousal positive emotional states (happy, joyful, delighted, cheerful, excited, enthusiastic, lively, energetic), and the serenity subscale contains 3 words designed to assess low-arousal positive emotional states (calm, relaxed, and at ease). NA was also assessed using items from the PANAS-X (Watson \& Clark, 1994). The NA items (afraid, angry, guilty, sad, and worried) were chosen to assess a range of negative emotions.

Participants were asked to indicate the extent that they feel that way right now by writing a number next to each emotion word, from 1 (very slightly or not at all) to 9 (extremely). The total for each subscale was calculated by taking the mean for each set of items. These subscales were administered 3 times throughout the course of the study: once before the positive event 
recall, once after the positive event recall, and once after the savoring or control task. Cronbach's alphas for the scales at each time point ranged from .77-.93 for general PA, .93-.95 for higharousal PA, from .94-.97 for low-arousal PA, and .78-.87 for NA. See Appendix E for these items.

To calculate poignancy, or the amount of negative and positive feelings experienced simultaneously, both the NA and the general PA scale from the PANAS-X (Watson \& Clark, 1994) were used. In accordance with previous research calculating momentary mixed emotions or feelings (Ersner-Hershfield et al., 2008; Larson, McGraw, Mellers, \& Cacioppo, 2004), poignancy was calculated using the following formula:

$$
\text { Poignancy }=\operatorname{MIN}(P A, N A)
$$

Self-esteem. Self-esteem was assessed using the Rosenberg Self-Esteem Scale (Rosenberg, 1965). This scale is widely used across adulthood (Orth, Robins, \& Widaman, 2012), has been well-validated across cultures (Schmitt \& Allik, 2005), and in a recent metaanalytic review assessing its factor structure (Huang \& Dong, 2012). This scale includes 10 items that utilizes a 4-point scale from 0 (strongly agree) to 3 (strongly disagree) and asks questions such as, "I feel that I have a number of good qualities,” and, “At times I think I am no good at all (reverse scored)." Scores were calculated by averaging the items, then reflecting the scale so that higher scores indicated more self-esteem. Reliability for this scale in the current study was .85. See Appendix F for a list of items.

Anxious attachment. Attachment was assessed with the Experiences in Close Relationships Scale (Brennan, Clark, \& Shaver, 1998). The ECR is a 36-item measure that assesses avoidant and anxious attachment in close relationships using a continuous scale. This scale is well-validated (Brennan et al. 1998; Mikulincer \& Shaver, 2007), and has been used with 
older adult samples (Segel-Karpas, Bamberger, \& Bacharach, 2013). Participants were instructed to respond to questions about how they generally feel in emotionally intimate relationships. Items were assessed on a 7-point scale from 1 (strongly disagree) to 7 (strongly agree). Anxious attachment was assessed using the 18-item subscale in this measure, and example items for this anxiety scale included, “I'm afraid I will lose my partner’s love,” and, “I find that my partner(s) don’t get as close as I would like.” Items were averaged, and higher scores indicated higher rates of anxious attachment. The Cronbach’s alpha for anxious attachment was .93. These questions can be found in Appendix G.

Future time perspective. Future time perspective was assessed with the Future Time Perspective Scale (Lang \& Carstensen, 2002). This measure has 10 items that assess the individual's perspective of the time that they have left in life. Items are assessed on a 7-point scale ranging from 1 (very untrue) to 7 (very true) and includes questions such as, "I have the sense that time is running out," (reverse-scored) and, "Many opportunities await me in the future.” The mean of the items was calculated, with higher scores indicating a more expansive future time perspective (a perspective that there is more time left in life to live), and lower scores indicating a more limited time perspective. See Appendix H for these items. Cronbach’s alpha for this scale was .87 .

Additionally, several studies have separated future time perspective into two domains that focus on different aspects of time: a focus on limitations and a focus on opportunities (e.g., Cate \& John, 2007). Therefore, this scale was also separated into two subscales assessing these constructs. The reliability for these subscales was .90 for a focus on limitations and .79 for a focus on opportunities. These additional items can also be found in Appendix H. 
Perceptions of free time. Perceptions of free time were assessed by a measure containing 5 questions about how busy the participant generally perceives themselves as being, and how much leisure time they think they have. The items are a combination of questions used in previous studies (Carroll, 2008; Rudd, Vohs, \& Aaker, 2013) and questions created by the researcher. Examples of questions included, "I have enough time to do what it is I want to do these days,” and, “I am pressed for time” (reversed scored). Participants were asked to respond to questions using a 7-point scale from 1 (very untrue) to 7 (true), and the items were averaged, with higher scores indicating perceptions of more free time. See Appendix I for a full list of items.

An exploratory factor analysis using Varimax rotation indicated that all items loaded onto one component factor, and all items had Eigenvalues of at least .71. Cronbach's alpha for these items was .88. To further validate this questionnaire, participants also reported on their actual free time by reporting the number of hours they have for leisure on the average weekday and on the average weekend day. Both reports of leisure time on the weekday and on the weekend were positively correlated with their scores on this scale $(r(117)=.43, p<.001$, and $r(119)=.28, p=$ .002 , respectively).

Global-local processing. Breadth of attention was measured using an adaptation of a global-local visual processing task (Kimchi \& Palmer, 1982; as used in Fredrickson \& Branigan, 2005; Gable \& Harmon-Jones, 2008; Gasper \& Clore, 2002; Rowe, Hirsch, \& Anderson, 2007). The task included 16 items, and participants were asked to compare two stimuli to a standard figure and decide which of the stimuli most represented the standard figure. Participants were instructed to go with their first, immediate impression. Participants were told that this was a “Similarity Judgment Task,” and it was stressed that there were no right or wrong answers. 
Judgments can be made that reflect either global aspects or local aspects of the figure. These items were chosen because past studies have suggested that this measure produced the most variance in global-local processing when conducting emotion-related research (Kimchi, 1992; Fredrickson \& Branigan, 2005). Responses indicating that the global figure was most like the standard figure were coded as 1 , whereas responses that indicated that the local figure was most like the standard figure were coded as 0 . Proportion scores were computed by calculating the proportion of responses that reflected global processing, with higher scores indicating more global processing, or a more broadened scope of attention (Derryberry \& Tucker, 1994). See Appendix J for examples.

Thought-action repertoires. Breadth of momentary thought-action repertoires were assessed by using the Twenty Statements Test (Fredrickson \& Branigan, 2005). Participants were told that this was an "Imagery Task" and were asked to list all the things they would like to do right now. These instructions were then followed by 20 numbered, blank lines. Participants were told that they had up to 5 minutes to complete this task, but they did not have to use the entire time allotted or use all of the spaces. The number of statements that the participant completed was tallied from 0-20, with higher scores indicating a higher momentary thought-action repertoire. Participant’s responses ranged from interpersonal (e.g., “chat with friends”), mundane (e.g., "brush hair”), leisure (e.g., “visit beach”) and fantasy (e.g., “sing with Axl Rose”). This task can be found in Appendix K.

Thinking task variables. During the post-experiment questionnaire participants were asked to answer several questions about the positive event they chose to think about, along with questions about the savoring or control induction. Participants reported on their level of effort during the savoring or control task by responding to the question, "How hard did you try during 
the thinking exercise?” from 0-100\%. Participants were also asked to report how distracted they felt during the thinking exercise by responding to the question, "How distracted did you feel during the thinking exercise?” from 0-100\%. Participants also reported on their impatience during the induction by responding to an 8-item questionnaire. These questions similar to items used in previous research (DeVoe \& House, 2012) and were adapted to fit the current study. For each item, participants were asked to indicate on a 7-point scale how much they agreed or disagreed with each statement from 1 (strongly disagree) to 7 (strongly agree). Examples of these items include, "I thought the task was a waste of my time," and, ”I was impatient for the task to end so I could finish the study.” Responses were averaged, with higher scores indicating more impatience during the task. Reliability for these items was .73. If participants reported that they felt distracted or impatient, they were asked to report what they were distracted about or what made them impatient. Common distractions and reasons for being impatient included thinking about things that needed to be done or worries (e.g., "I was thinking about the exam I need to pass”), things the participant would rather be doing (e.g., "I want to be outside”), or environmental distractions or physiological needs (e.g., noises, hunger). These questions, along with other items assessed on the post-experiment questionnaire can be found in Appendix L.

Trait savoring. Trait savoring was assessed using the Savoring Beliefs Inventory (Bryant, 2003). This measure is a 24-item scale that assesses perceived savoring ability. Participants were asked to rate how much each item describes them on a 7-point scale from 1 (strongly disagree) to 7 (strongly agree). The scale consists of 3 lower-order factors assessing Reminiscing on Past Events, Savoring the Moment, and Anticipating Future Events. The current study used the 8 items included in the Reminiscing subscale because these items best emulate the savoring task designed for the current study. Examples of items include, "It's easy for me to 
rekindle the joy from pleasant memories," and, “For me, once a fun time is over and gone, it’s best not to think about it” (reverse scored). Items were averaged, with higher scores indicated greater savoring capacity. Reliability for this subscale was .84. Please see Appendix M for this scale.

Mindfulness. Trait mindfulness was assessed using the Mindful Attention Awareness Scale (MAAS, Brown \& Ryan, 2003). The MAAS is a 15-item self-report scale that assesses the dispositional awareness and attention to the present moment, and has been validated in both college student and adult populations (Brown \& Ryan, 2003). Questions were assessed on a 6point scale from 1 (almost always) to 6 (almost never). Scores for all items were averaged and reflected, so that higher scores indicated more mindfulness. Examples of items included, "I find myself doing things without paying attention,” and, "I rush through activities without being really attentive to them.” Cronbach’s alpha for this scale was .89. Please see Appendix N for this scale.

\section{Results}

\section{Data Cleaning}

A series of five validation questions were included throughout the pre-study survey (e.g., “Please choose 2 for this question”) to assess comprehension and attention. Most participants correctly answered all of the validity questions correctly (89.2\%) and all but one participant answered at least $80 \%$ of the validation questions correctly. One participant was incorrect for all validation questions, and their pre-study survey responses were excluded for future analyses. Additionally, during debriefing and manipulation checks, one participant was familiar with psychological research and the use and purpose of the global-local task, so these responses were removed for analyses. 
The majority of participants completed the pre-study survey online. However, some participants $(n=10)$ completed the survey on paper, and a series of independent $t$-tests indicated that form of survey assessment was not associated with any of the variables of interest, with the exception of age. Participants who chose to complete the survey on paper were older on average $(M=71$ years, $S D=14.49)$ than those who completed the survey online $(M=42.22$ years, $S D=$ 19.04). Additionally, a series of $t$-tests examined whether or not participants who completed the study in the lab or at another location differed on any variables of interest. Results indicated that participants who completed the study at another location were significantly older, were more likely to be retired, had less difficulty paying their bills, were less anxiously attached, had a more limited future time perspective, reported less NA at baseline and after the positive event recall, and had less global processing. After controlling for age, location of assessment only significantly predicted global-local processing $\left(F(1,116)=4.63, p=.03\right.$, partial $\left.\eta^{2}=.04\right)$, with those in the lab reporting more global processing $(M=.77, S D=.29)$ than those completing the study in other locations $(M=.64, S D=.29)$.

Examination of missing data indicated that very little data were missing $(<1 \%)$. Some participants indicated that they would prefer not to answer some of the items. However, the rates of these responses were still low $(<1 \%)$, with the exception of the Experiences in Close Relationships Scale (6\% of responses were marked as prefer not to answer). For this scale, 3 people that opted out of this survey entirely, and 9 opted out of at least 1 item. For further analyses, all "Prefer not to answer" options were set to missing. Due to the need for complete data in some of the analyses, mean imputation was used for cases that responded to at least 2 items for the corresponding scale for all variables of interest. 
Descriptive statistics were examined for all variables to assess assumptions of normality. Several variables were significantly skewed. Specifically, NA at baseline, NA after the event recall, poignancy at baseline, and poignancy after the positive event recall were all positively skewed. Additionally, for the control group, NA and poignancy after the control task and distraction during the task were positively skewed, whereas global-local processing and effort were negatively skewed. For the savoring group, NA and poignancy after the task were positively skewed, and global-local processing was negatively skewed. All aforementioned variables were log transformed, and for the ones that were negatively skewed, they were reflected. As a check, all analyses including these variables were run with and without the log transformation. None of the results went from significant to nonsignificant, or vice versa, and therefore all results reported represent analyses with the nontransformed values.

\section{Preliminary Statistics}

A series of independent samples $t$-tests were conducted in order to ensure that participants in the savoring condition did not differ from the control participants in any way. Participants in each condition did not significantly differ on any demographic variables, any of the individual difference variables of interest, any of the baseline emotion subscales, or the emotion subscales after the positive event recall. A $\chi^{2}$ was also conducted with participant condition and gender, and there were no significant gender differences across experimental groups.

Preliminary correlations, means, and standard deviations for all demographic and individual difference variables and baseline emotions are reported in Table 2. Results indicated that older age was associated with less NA at baseline, less poignancy at baseline, lower reports of anxious attachment, less expansive future time perspective, higher focus on limitations, lower 
focus on opportunities, perceptions of more free time, and increased mindfulness. Males reported more baseline general PA and low-arousal PA after the event recall. Difficulty paying bills was associated with higher baseline NA, higher baseline poignancy, higher reports of anxious attachment, and lower reports of self-esteem. Higher education was associated with more selfesteem, but a less expansive future time perspective and less of a focus on opportunities. Those who were retired reported lower baseline NA, more self-esteem and trait mindfulness, but a less expansive future time perspective, more focus on limitations, and less focus on opportunities.

Preliminary correlations, means, and standard deviations for all post-task variables and demographics are reported in Table 3 (for the savoring group) and Table 4 (for the control group). Partial correlations between post-task affect and demographic variables, while controlling for the corresponding emotion subscale after the positive event recall are also reported in these tables. Results indicated that for the savoring group, males reported more global processing and more effort during the savoring task. Males also reported more low-arousal PA after the savoring task when controlling for low-arousal PA after the positive event recall. For the control group, those who reported difficulty paying their bills reported less general PA and high-arousal PA after the task, after controlling for the corresponding emotion subscale after the event recall. Those who had difficulty paying their bills also reported more global processing after the control task and less thought action repertoires. For both groups, age, education, and retirement status were unrelated to all of the post-task variables.

Preliminary correlations between all individual difference variables and baseline emotions are reported in Table 5. Results indicated that several of the individual difference variables were related to the affect subscales. Higher reports of anxious attachment were associated with lower high-arousal PA, higher NA, and higher poignancy at baseline and after 
the positive event recall, but only related to lower rates of low-arousal PA at baseline. Reports of anxious attachment were also associated with less general PA, but only after the positive event recall. Self-esteem was related to higher reports of all types of PA and lower reports of NA and poignancy both before and after the positive event recall, with the exception of baseline lowarousal PA. More expansive future time perspective and an increased focus on opportunities were both associated with high-arousal PA after the positive event recall, but were unrelated to all other affect variables at baseline and after the positive event recall. A focus on limitations and perceptions of free time were unrelated to all of the affect variables. Trait savoring was related to increased PA and decreased NA both at baseline and after the positive event recall. Mindfulness was related to higher scores on all PA subscales, less NA, and less poignancy at both time points, with the exception of post-event recall general PA.

Several of the individual difference variables were also correlated with each other. Specifically, trait savoring, more expansive future time perspective, and mindfulness were all associated with higher self-esteem and more secure attachment, and reports of higher self-esteem was related to lower rates of anxious attachment. Mindfulness was also related to more trait savoring and perceptions of more free time. Additionally, some of the affect subscales were related with one another. Baseline general PA was associated with increased baseline low and high-arousal PA, but not baseline NA. All three types of baseline PA were related to increased PA and less NA after the positive event recall (with the exception of the general PA score). Baseline and post-event recall poignancy was related to less of both baseline and post-event recall high-arousal PA, low-arousal PA, and to more NA.

Preliminary correlations between individual difference variables and post-task variables are reported in Table 6 (for the savoring group) and Table 7 (for the control group). To account 
for reactivity after the positive event recall in the post-task emotions, difference scores were created for general PA, high-arousal PA, low-arousal PA, NA, and poignancy by taking the posttask score and subtracting the score from after the positive event recall, so higher scores indicated greater increases in affect.

For the savoring group, increases in general PA were associated with increases in higharousal PA, less global processing, and less effort during the task. Increases in high-arousal PA were associated with declines in NA, less poignancy and less global processing. Increases in low-arousal PA were associated with declines in negative NA, less poignancy, less mindfulness, and more distraction during the task. Perceptions of free time were related to less global processing, and thought-action repertoires were unrelated to all of the variables. No relationships emerged for self-esteem, a focus on opportunities, or anxious attachment. Those with a more expansive future time perspective were less likely to feel distracted during the task, whereas those who were more focused on limitations felt more distracted. Those who focused more on limitations also reported more effort during the task. Trait savoring was only related to distraction, with those reporting higher rates of trait savoring reporting less distraction during the task. Mindfulness was also related to feeling less distracted. Impatience and distraction were positively correlated with one another.

For the control group, perceptions of free time, anxious attachment, future time perspective, and trait savoring were all unrelated to the variables of interest. However, selfesteem was related to greater increases in general PA and high-arousal PA. Greater increases in general PA were related to increases in thought-action repertoires and less impatience. Greater increases in high-arousal PA were also associated with less impatience. Greater increases in poignancy were related to increases in NA. Similar to the savoring group, distraction and 
impatience were positively correlated with one another, and mindfulness was related to less distraction.

\section{Research Question 1: Momentary Affect Benefits of Savoring}

To determine if the savoring task was effective, a series of between-group, repeated measures ANOVAs were analyzed across all three emotion assessments (baseline, post-event recall, post-task) for each emotion subscale. For the general PA scale, results indicated that there was a main effect of assessment $\left(F(2,234)=24.08, p<.001\right.$, partial $\left.\eta^{2}=.17\right)$, and betweensubjects effects indicated that there was no main effect of participant condition across assessments $(F(1,117)=.01, p=.91)$. However, as expected, a significant condition by assessment interaction emerged $\left(F(2,234)=16.02, p<.001\right.$, partial $\left.\eta^{2}=.12\right)$, with significant differences across group for the post-task PA (Beta $=-.67, \mathrm{SE}=.28, p=.02,95 \%$ CI [-1.24, .11 , partial $\eta^{2}=.05$ ), but not at baseline or post-event recall. Follow-up paired samples $t$-tests indicated that for the control group, PA significantly increased from the baseline to the postevent recall $(t(58)=4.28, p<.001,95 \%$ CI $[.37,1.01])$, then decreased from the post-event recall to the post-task assessment $(t(59)=5.08, p<.001,95 \%$ CI $[.49,1.12])$. However, posttask PA was not significantly different from baseline PA for the control group. For the savoring group, PA significantly increased from baseline to post-event recall $(t(59)=5.52, p<.001,95 \%$ CI $[.43, .93])$. Although PA after the savoring induction remained significantly higher than baseline $(t(59)=6.41, p<.001,95 \%$ CI $[.57,1.08])$, it did not significantly increase from postevent recall to post-task. These results are displayed in Figure 4.

For the high-arousal PA subscale, similar results emerged. Results indicated that there was a main effect of assessment $\left(F(2,234)=49.56, p<.001\right.$, partial $\left.\eta^{2}=.30\right)$, and although between-subjects effects indicated that there was no main effect of participant condition across 
all three assessments, $(F(1,117)=2.41, p=.12)$, a significant condition by assessment interaction emerged $\left(F(2,234)=22.85, p<.001\right.$, partial $\left.\eta^{2}=.16\right)$. Parameter estimates indicated that there were significant differences across group for the post-task PA (Beta $=-1.21, \mathrm{SE}=.30$, $p<.001,95 \%$ CI [-1.81, -.61], partial $\eta^{2}=.12$ ), but not at baseline or at the post-event recall. Follow-up $t$-tests indicated that reports of high-arousal PA increased from baseline to post-event recall for the control group $(t(58)=7.74, p<.001,95 \%$ CI $[.80,1.36])$ and the savoring group $(t(59)=6.37, p<.001,95 \%$ CI $[.65,1.24])$. For the control group, post-task high-arousal PA significantly declined from post-event recall $(t(59)=6.46, p<.001,95 \%$ CI [.73, 1.38]), but post-task PA did not differ from baseline. For the savoring group, post-task high-arousal PA was significantly higher than baseline $(t(59)=7.40, p<.001,95 \%$ CI $[.82,1.43)$, but it did not increase from post-event recall. These results are displayed in Figure 5.

Somewhat different findings emerged for a between-within ANOVA for the low-arousal PA scale. Tests of within-subject effects indicated that there was a main effect of assessment $\left(F(2,234)=8.07, p<.001\right.$, partial $\left.\eta^{2}=.07\right)$, but there was no main effect of condition, and there was no interaction between condition and assessment. In contrast to general PA and high-arousal PA, follow-up t-tests indicated that reports of affect slightly decreased from baseline to postpositive event recall for the control group $(t(58)=-2.03, p=.047,95 \%$ CI [-.68, -.004]). Reports of low-arousal PA also slightly decreased from baseline to post-positive event recall for savoring group as well, although this was non-significant $(t(59)=-1.20, p=.27,95 \%$ CI $[-.43,1.10])$. However, reports of low-arousal PA then significantly increased from post-event recall to posttask for the control group $(t(59)=-2.10, p=.037,95 \%$ CI $[-.65,-.02])$, and this did not significantly differ from baseline levels. The savoring group also reported more low-arousal PA post-task than after the event recall $(t(59)=-4.86, p<.001,95 \%$ CI [-.72, -.30]), and this was 
significantly higher than reports of affect at baseline $(t(59)=2.28, p=.026,95 \%$ CI [.04-.66]). These results are displayed in Figure 6.

For the NA scale, a between-within ANOVA was also conducted. Tests of within-subject effects indicated that there was a main effect of assessment $\left(F(2,234)=9.53, p<.001\right.$, partial $\eta^{2}$ $=.08$ ), but there was no main effect of condition, and there was no interaction between condition and assessment. Follow-up $t$-tests indicated that NA decreased from baseline to the post-event recall for both the control group $(t(58)=-2.72, p=.008,95 \%$ CI [-.33, -.05]) and the savoring group $(t(59)=-.287, p=.006,95 \%$ CI [.26, -.05]). Additionally, NA did not significantly differ from post-event recall to post-task for either group. However, the savoring group reported significantly less NA post-task than at baseline $(t(59)=-3.18, p=.002,95 \%$ CI [-.29, - .07]), whereas the control group returned to baseline levels $(t(59)=-2.73, p=.075,95 \%$ CI [-.33, .05]). These results are displayed in Figure 7.

Similar to the other scales, a between-within ANOVA was conducted for poignancy. A significant Mauchly’s test indicated that the assumption of sphericity was violated. The Greenhouse-Geisser estimate was greater than .75, which suggests that the Greenhouse Geisser correction may be too conservative (Girden, 1992; Huynh \& Feldt, 1976). Therefore, the HuynhFeldt correction was used. Tests of within-subject effects indicated that there was a main effect of affect assessment $\left(F(1.89,21.39)=12.83, p<.001\right.$, partial $\left.\eta^{2}=.10\right)$, but there was no main effect of condition, and there was no interaction between condition and assessment. Follow-up paired samples $t$-tests indicated that for the savoring group, poignancy decreased from baseline to post-event recall $(t(59)=2.93, p=.005,95 \%$ CI $[.05, .24])$, but not from post-event recall to post-task $(t(59)=1.05, p=.30,95 \%$ CI $[-.02, .08])$. Post-task poignancy was significantly lower than baseline for the savoring group $(t(59)=3.26, \mathrm{p}=.002,95 \%$ CI $[.07, .27])$. Similar to the 
savoring group, the control group decreased in poignancy from baseline to post-event recall $(t(59)=2.97, p=.004,95 \%$ CI $[.05, .28])$, remained stable from post-event recall to post-task $(t(59)=-.88, p=.38,95 \%$ CI $[-.15, .06])$, and poignancy was significantly lower at post-task than at baseline $(t(59)=3.29, p=.02,95 \%$ CI $[.02, .22])$. These results are displayed in Figure 8 .

\section{Research Question 2: Broadening Cognitive and Behavioral Effects of Savoring}

To investigate group differences in broadened cognitions, a mediation model was tested using the PROCESS macro for SPSS (Hayes, 2013). Using 5,000 bootstrapping samples (as suggested by Hayes, 2009) and 95\% bias-corrected confidence intervals, global-local processing was entered as the dependent variable, with participant condition as the independent variable. Furthermore, mediating effects of post-task affect were examined while including post-event recall affect as a covariate to control for individual differences in reactivity. Results indicated that there were no significant differences in global-local processing for group. Additionally, global-local processing was not associated with reports of general PA, high-arousal PA, lowarousal PA, NA, or poignancy. These findings remained when including gender, location of assessment, and difficulty paying bills as covariates.

However, preliminary analyses indicated that there was a significant negative correlation for the savoring group between the general PA difference score and global-local processing, indicating that those who experienced greater increases in their PA while savoring used more local processing. Therefore, this relationship was further explored. Specifically, a regression was conducted with global-local processing as the dependent variable, the PA difference score as a predictor, and group as a moderator. The overall model was significant $\left(F(3,115)=4.07, R^{2}=\right.$ $.07, p<.009)$. Results indicated that group was not a predictor of global-local processing, but the PA difference score was (Beta $=.19, \mathrm{SE}=.08, p=.02,95 \%$ CI $[.03, .35])$. Furthermore, a 
significant interaction emerged between group and PA (Beta $=-.19, \mathrm{SE}=.07, p=.004,95 \% \mathrm{CI}$ $[-.32,-.06])$. Specifically, for the savoring group (Beta $=-.19, \mathrm{SE}=.06, p=.002,95 \% \mathrm{CI}[-.31$, .07]), greater increases in PA from after the event recall to after the savoring task were associated with less global processing. The relationship between PA and processing was not significant for the control group (Beta $=.00, \mathrm{SE}=.03, p=.99,95 \% \mathrm{CI}[-.05, .05])$. These findings remained significant even when including gender, location, and difficulty paying bills in the model. This interaction is displayed in Figure 9. A similar moderation analyses was examined for higharousal PA, and a similar pattern of results emerged. Results indicated that the interaction between group and the affect difference was significant (Beta $=-.12, \mathrm{SE}=.06, p=.03,95 \% \mathrm{CI}$ $[-.23,-.01])$, although the overall model was only marginally significant $\left(F(3,115)=2.10, R^{2}=\right.$ $.10, p=.06)$. Simple slopes indicated that the relationship between high-arousal PA and global processing was significant for the savoring group (Beta $=-.11$, SE $=.04, p=.01,95 \%$ CI $[-.20$, $.03]$ ), but not the control group (Beta $=.01, \mathrm{SE}=.03, p=.86,95 \% \mathrm{CI}[-.06, .07])$. Similar to general PA, greater increases in high-arousal PA from the event recall to post-task was associated with less global processing. The difference scores for low-arousal PA, NA, and poignancy were not significant predictors of global-local processing.

To investigate group differences in broadened thought-action repertoires, mediation models were tested using the PROCESS macro for SPSS (Hayes, 2013). Using 5,000 bootstrapping samples and 95\% bias-corrected confidence intervals, the total number of actions listed was entered as the dependent variable, with participant condition as the independent variable. Furthermore, mediating effects of post-task affect were examined while including postevent recall affect as a covariate. Results indicated that when including general post-task PA in the model, group was not a significant predictor of thought-action repertoires, but the 
relationship between post-task PA and thought-action repertoires was significant (Beta = 1.02, $\mathrm{SE}=.44, p=.02,95 \% \mathrm{CI}[.15,1.89])$. Furthermore, group predicted post-task PA $($ Beta $=.92$, $\mathrm{SE}=.17, p<.001,95 \% \mathrm{CI}[.57,1.27])$. Examination of indirect effects suggested that although the direct effect of group on thought-action repertoire was not significant $($ Beta $=-1.50, \mathrm{SE}=$ $1.09, p=.17,95 \%$ CI $[-3.66, .66])$, the indirect effect of PA on thought action-repertoires was significant $($ Beta $=.94, \mathrm{SE}=.46, p<.001,95 \% \mathrm{CI}[.11,1.95])$, indicating that any variation in thought-action repertoires that was accounted for by group was partially due to group-related differences in general post-task PA. Similar mediation analyses indicated that there were no significant direct or indirect effects when examining high-arousal PA, low-arousal PA, NA, and poignancy, with the exception of a significant relationship between high-arousal PA and group $($ Beta $=1.22, \mathrm{SE}=.19, p<.001,95 \%$ CI $[.84,1.61])$. These findings remained even after including difficulty paying bills as a covariate, which was related to thought-action repertoires.

Preliminary correlations indicated that the relationship between PA and thought-action repertoires may have been limited to participants in the control group. Therefore, moderation analyses were conducted with thought action repertoires as the outcome, PA difference scores as the predictor, and group as the moderator. However, none of the predictors in the model, or the overall model was significant.

\section{Research Question 3: Individual Differences in Savoring}

To examine individual differences in savoring ability, analyses were conducted using the PROCESS macro for SPSS (Hayes, 2013) using 5,000 bootstrapping samples and 95\% biascorrected confidence intervals. First, post-task affect was entered into the model as the dependent variable, the individual difference variable was entered as a predictor, and group was entered as a 
moderator. Post-event recall affect for the corresponding affect subscale was included as a covariate for all models to account for initial reactivity to the positive event recall.

Self-esteem. Results indicated that when predicting general post-task PA, group, selfesteem, post-event recall PA, and the interaction term were all significant. Simple slopes analyses indicated that self-esteem was a significant predictor of post-task PA for the control group $($ Beta $=.79, \mathrm{SE}=.26, p=.003,95 \% \mathrm{CI}[.27, .13])$, but not for the savoring group $($ Beta $=$ $.15, \mathrm{SE}=.18, p=.29,95 \% \mathrm{CI}[-.42, .13])$. This interaction is displayed in Figure 10. A similar pattern of findings emerged for high-arousal PA. Again, group, self-esteem, post-event recall PA, and the interaction term were all significant predictors of high-arousal PA. Again, simple slopes analyses indicated that self-esteem was a significant predictor of greater post-task PA for the control group (Beta $=.98, \mathrm{SE}=.27, p<.001,95 \% \mathrm{CI}[.44,1.52])$, but not the savoring group $($ Beta $=-.07, \mathrm{SE}=.23, p=.76,95 \% \mathrm{CI}[-.52, .38])$. The findings for each model remained even when controlling for difficulty paying bills, education, and retirement status. This interaction is displayed in Figure 11. Self-esteem or group was not a significant predictor of post-task lowarousal PA, post-task NA, or post-task poignancy. All of these results are presented in Table 8. Attachment. Regression analyses were conducted with anxious attachment predicting post-task affect, group as a moderator, and post-positive event recall as a covariate. Anxious attachment, group, and the interaction between the two were not significant for all affect subscales. However, post-event affect was a significant predictor of post-task affect for all affect subscales, indicating that much of the variance in post-task affect was accounted for by baseline affect after the event recall. These findings remained even when controlling for difficulty paying bills and age. These results are displayed in Table 9. 
Age. Regression analyses using PROCESS (Hayes, 2013) indicated that when including age in the model, post-event recall affect predicted post-task affect for all affect subscales. Group was a significant predictor of general post-task PA and high-arousal post-task PA, but not lowarousal PA, NA, or poignancy. Age and the interaction between age and group were not significant for any of the models. These results are displayed in Table 10. To explore curvilinear effects, curve estimation regression models were conducted with age as a predictor of the difference score between post-event recall affect and post-task affect for each affect subscale. These models were investigated separately for the savoring and control groups. All models indicated that there were no significant linear, quadratic, or cubic effects of age for either group.

\section{Research Question 4: Age-Related Mediators}

First, initial associations between perceptions of free time, future time perspective, and savoring ability were assessed by including each as a predictor of post-task affect, while including the corresponding post-event recall affect subscale as a covariate, and group as a moderator. Results indicated that greater perceptions of free time was a significant predictor of less NA (Beta $=-.20, .20, p=.048,95 \%$ CI [-.39, -.002]), and this was qualified by a marginal interaction with group $($ Beta $=.11, \mathrm{SE}=.06, p=.07,95 \% \mathrm{CI}[-.01, .23])$. Simple slopes indicated that perceptions of free time was marginally associated with NA for the control group $($ Beta $=-.09, \mathrm{SE}=.06, p=.053,95 \% \mathrm{CI}[-.18, .001])$, but not the savoring group (Beta $=.02, \mathrm{SE}$ $=.04, p=.59,95 \%$ CI $[-.06, .10])$. A focus on limitations was marginally associated with greater NA (Beta $=.16, \mathrm{SE}=.09, p=.077,95 \%$ CI [-.02, .34]). However, group and the interaction between focus on limitations and group were not significant.

Although direct effects of age on post-task affect were not significant, it is still possible that variables may account for a significant amount of variance in the relationship between age 
and savoring on PA (Shrout \& Bolger, 2002). Therefore, future time perspective and perceptions of free time were examined as mediators to test if they account for any variance in post-task affect related to age. Both proposed mediators were examined in parallel, which allows both indirect effects of the moderating effect of age and group to be tested simultaneously and offers several strengths. This method allows for detection of an overall, total indirect effect, determination of what extent each mediator produces an indirect effect while accounting for the other, the assessment of the relative magnitude of each mediator, and strengthens the model by reducing parameter bias. A bootstrapping method for 95\% bias corrected confidence intervals was specified with 5,000 bootstrap samples. For each model, post-task affect was entered as the outcome, age as the predictor, the corresponding post-event recall affect as a covariate, futuretime perspective and perceptions of free time as the mediators, and participant group as a moderator of the direct effect of age on affect, and a moderator of the indirect effect of each mediator on affect. See Figure 12 for a conceptual and statistical model. Additionally, a focus on opportunities and a focus on limitations were examined in separate mediation models to assess if they account for any variance in the relationship between age and post-task affect.

For general PA, age $($ Beta $=-.03, \mathrm{SE}=.004, p<.001,95 \%$ CI $[-.04,-.02])$ and post-event recall PA $(\mathrm{Beta}=.16, \mathrm{SE}=.08, p=.047,95 \% \mathrm{CI}[.002, .32])$ were both significantly related to future-time perspective, and age significantly predicted perceptions of free time (Beta $=.02$, SE $=.01, p=.02,95 \%$ CI $[.002, .03])$. These findings suggest that older adults reported a less expansive future time perspective and more free time, and general PA after the event recall was higher for those with a more expansive future time perspective. However, when predicting posttask PA, age, perceptions of free time, future time perspective were nonsignificant. Additionally, the conditional indirect effects and the conditional direct effect were all nonsignificant predictors 
of post-task PA. The only significant predictor of post-task PA was post-event recall PA $($ Beta $=$ $.88, \mathrm{SE}=.06, p<.001,95 \% \mathrm{CI}[.76, .10])$. In separate mediation models, a focus on limitations and a focus on opportunities were not associated with post-task affect.

For high-arousal PA, a similar pattern of results emerged. Age (Beta $=-.03, \mathrm{SE}=.004, p$ $<.001,95 \%$ CI $[-.04,-.02])$ and post-event recall affect (Beta $=.15, \mathrm{SE}=.07, p=.02,95 \% \mathrm{CI}$ $[.02, .28])$ were significant predictors of future time perspective, and age significantly predicted perceptions of free time $($ Beta $=.01, \mathrm{SE}=.01, p=.02,95 \% \mathrm{CI}[.002, .03])$. When predicting post-event PA, age, perceptions of free time, future time perspective, all of the conditional indirect effects, and the conditional direct effect were all nonsignificant. Post-event recall higharousal PA predicted post-task high-arousal PA $($ Beta $=.80, \mathrm{SE}=.07, p<.001,95 \%$ CI [.66, .94]). In separate mediation models, a focus on limitations and a focus on opportunities were not associated with post-task affect.

For low-arousal PA, age was a significant predictor of future time perspective (Beta = $.03, \mathrm{SE}=.004, p<.001,95 \% \mathrm{CI}[-.04,-.02])$ and perceptions of free time (Beta $=.01, \mathrm{SE}=.01$, $p=.03,95 \%$ CI $[.002, .03])$. Post-event recall affect was a significant predictor of post-task affect $($ Beta $=.73, \mathrm{SE}=.08, p<.001,95 \%$ CI $[.58, .89])$. Age, future time perspective, perceptions of free time, and the conditional effects were not significant. In separate mediation models, a focus on limitations and a focus on opportunities were not associated with post-task affect.

For NA, age predicted future time perspective (Beta $=-.03, \mathrm{SE}=.004, p<.001,95 \% \mathrm{CI}$ $[-.04,-.02])$ and perceptions of free time (Beta $=.02, \mathrm{SE}=.01, p=.03,95 \% \mathrm{CI}[.002, .03])$. Post-event recall affect predicted post-task affect (Beta $=1.11$, SE $=.23, p<.001,95 \%$ CI $[.65$, 1.58]), but age, future time perspective, perceptions of free time, and the conditional effects were 
not significant. In a separate mediation model, a focus on limitations was related to more NA $($ Beta $=.22, \mathrm{SE}=.09, p=.02,95 \% \mathrm{CI}[.03, .41])$ along with post-event recall NA (Beta $=1.11$, $\mathrm{SE}=.07, p<.001,85 \% \mathrm{CI}[.97,1.25])$. A significant interaction emerged between a focus on limitations and group (Beta $=-.11, \mathrm{SE}=.06, p=.049,95 \%$ CI [-.23, -.003]). However, neither slope was significant, although the slope was stronger for the control group (Beta $=-.01, \mathrm{SE}=$ $.003, p=.071,95 \% \mathrm{CI}[-.01, .001])$ than the savoring group $($ Beta $=.0003, \mathrm{SE}=.002, p=.90$, 85\% CI [-.01, .01]). A focus on opportunities was not related to post-task affect.

For poignancy, age was related to future time perspective (Beta $=-.03, \mathrm{SE}=.004, p<$ $.001,95 \% \mathrm{CI}[-.04,-.02])$ and to perceptions of free time (Beta $=.02, \mathrm{SE}=.01, p=.02,95 \% \mathrm{CI}$ $[.002, .03])$, but age, future time perspective, perceptions of free time, and the conditional effects were nonsignificant. In separate mediation models, a focus on limitations and a focus on opportunities were not associated with post-task affect.

\section{Additional Analyses}

Additional analyses were conducted to examine how certain aspects of the savoring process, such as the amount of effort put into the task, how distracted participants felt, and how impatient they felt, might impact savoring effectiveness. Additionally, trait savoring and mindfulness were also examined as moderators to determine if affect changes are dependent on savoring experience or trait mindfulness.

Effort was examined as a predictor of post-task affect, while controlling for the corresponding post-event recall affect subscale and including group as a moderator. Effort was not a significant predictor of general PA, high-arousal PA, low-arousal PA, or NA. However, effort was positively related to poignancy (Beta $=.01, \mathrm{SE}=.003, \mathrm{p}=.02,95 \% \mathrm{CI}[.002, .01])$. A significant interaction emerged between effort and condition (Beta $=-.004, \mathrm{SE}=.002, \mathrm{p}=.03$, 
95\% CI [-.01, -.004]). Simple slopes indicated that effort was associated with more poignancy in the control group $($ Beta $=.04, \mathrm{SE}=.002, p=.02,95 \% \mathrm{CI}[.001, .01])$, but not the savoring group $($ Beta $=-.001, \mathrm{SE}=.003, p=.55,95 \%$ CI $[-.003, .002])$.

Distraction during the task was also examined as a predictor of post-task affect, while controlling for post-event affect and including group as a moderator. Distraction was not a significant predictor of general PA, high-arousal PA, low-arousal PA, or NA. Distraction was a significant predictor of poignancy (Beta $=-.01, \mathrm{SE}=.003, p=.049,95 \%$ CI $[.001, .014])$, but the interaction with group was not significant.

Similar models were also examined for impatience, and results indicated that impatience was a significant predictor of general PA $($ Beta $=-1.03, \mathrm{SE}=.26, p<.001,95 \%$ CI [-1.55, -.52]), and a significant interaction emerged between impatience and group (Beta $=.38, \mathrm{SE}=.16, p=$ $.02,95 \%$ CI $[.07, .70])$. Simple slopes indicated that for both groups, more impatience was related to less post-task PA. However, this slope was stronger for those in the control group $($ Beta $=-.65, \mathrm{SE}=.12, p<.001,95 \% \mathrm{CI}[-.90,-.40])$ than in the savoring group (Beta $=-.27, \mathrm{SE}$ $=.12, p=.03,95 \%$ CI [-.50, -.03]). Impatience was also a significant predictor of post-task higharousal PA (Beta $=-1.03, \mathrm{SE}=.36, p<.01,95 \%$ CI [-1.74, -.32]), with more impatience predicting less high-arousal PA. However, no significant interaction by group emerged. Impatience did not significantly predict low-arousal PA, NA, or poignancy.

Trait savoring was examined as a moderator of savoring by including post-task affect as the outcome, trait savoring as the predictor, the corresponding post-event recall affect subscale as a covariate, and group as a moderator. Trait savoring was associated with reports of high-arousal PA $($ Beta $=.85, \mathrm{SE}=.39, p=.03,95 \% \mathrm{CI}[.07,1.63])$, and this was moderated by group $($ Beta $=$ $-.46, \mathrm{SE}=.23, p=.046,95 \%$ CI [-.91, -.01]). Simple slopes analyses indicated that higher 
reports of trait savoring were associated with increased high-arousal PA for the control group $($ Beta $=.39, \mathrm{SE}=.20, p=.049,95 \%$ CI $[.001, .78])$ but not the savoring group $($ Beta $=-.07, \mathrm{SE}=$ $.17, p=.69,95 \%$ CI $[-.40, .26])$. Trait savoring was marginally related to poignancy (Beta $=-.19$, $\mathrm{SE}=.10, p=.059,95 \% \mathrm{CI}[-.38, .01])$, but this did not differ by group. Trait savoring was unrelated to general PA, low-arousal PA, or NA.

Mindfulness was examined as a moderator of savoring by including post-task affect as the outcome, mindfulness as the predictor, the corresponding post-event recall affect subscale as a covariate, and group as a moderator. Results indicated that the model for general PA was significant $\left(F(4,112)=51.97, R^{2}=.65, p<.001\right)$. Specifically, group $($ Beta $=2.61, \mathrm{SE}=.85, p=$ $.003,95 \%$ CI $[.92,4.29])$, mindfulness (Beta $=.72, \mathrm{SE}=.32, p=.03,95 \%$ CI $[.90,1.35])$, postevent recall affect $($ Beta $=.87, \mathrm{SE}=.07, p<.001,95 \% \mathrm{CI}[.74,1.00])$, and the interaction term between group and mindfulness (Beta $=-.42$, SE $=.41, p=.048,95 \%$ CI [-.83, -.005]) were all significant. Simple slopes indicated that mindfulness was associated with more post-task PA for the control group (Beta $=.30, \mathrm{SE}=.14, p=.03,95 \% \mathrm{CI}[.02, .58])$, and not the savoring group $($ Beta $=-.11, \mathrm{SE}=.15, p=.47,95 \%$ CI $[-.42, .19])$. Similar results emerged for high-arousal PA $\left(F(4,112)=52.38, R^{2}=.65, p<.001\right)$, with group $($ Beta $=3.14, \mathrm{SE}=.94, p=.001,95 \% \mathrm{CI}$ $[1.28,4.99])$, mindfulness $($ Beta $=.86, \mathrm{SE}=.35, p=.02,95 \% \mathrm{CI}[.16,1.56])$, post-event recall affect (Beta $=.78, \mathrm{SE}=.06, p<.001,95 \% \mathrm{CI}[.66, .91])$, and the interaction term between group and mindfulness $($ Beta $=-.47, \mathrm{SE}=.23, p=.04,95 \% \mathrm{CI}[-.93,-.02])$ were all significant. Again, simple slopes analyses indicated that mindfulness was positively associated with high-arousal PA for the control group (Beta $=.38, \mathrm{SE}=.96, p=.01,95 \% \mathrm{CI}[.08, .69])$, and not the savoring group $($ Beta $=-.09, \mathrm{SE}=.17, p=.60,95 \% \mathrm{CI}[-.42, .45])$. 
For low-arousal PA $\left(F(4,112)=50.81, R^{2}=.64, p<.001\right)$, the only significant predictor of post-task affect was post-event recall affect (Beta $=.74, \mathrm{SE}=.06, p<.001,95 \% \mathrm{CI}[.63$, $.85])$. Group $($ Beta $=1.67, \mathrm{SE}=.84, p=.051,95 \% \mathrm{CI}=[-.01,3.34])$ and the interaction term $($ Beta $=-.36, \mathrm{SE}=.21, p=.08,95 \% \mathrm{CI}[-.77, .05])$ were both marginally significant. Simple slopes indicated that the line for the savoring group was negative, and marginally significant (Beta $=-.27, \mathrm{SE}=.15, p=.07,95 \%$ CI $[-.57, .03])$, but it was not significant for the control group $($ Beta $=.09, \mathrm{SE}=.14, p=.55,95 \% \mathrm{CI}[-.19, .37])$. Mindfulness was not a significant predictor of post-task NA or post-task poignancy.

\section{Discussion}

PA is linked to innumerable benefits, including more career success, better health, and better social relationships (Lyubomirsky, King et al., 2005). The broaden and build theory suggests that PA may lead to these positive outcomes through the broadening effect positive emotions have on our cognitions and behavior (Fredrickson, 2001). The current study expanded on this literature to investigate how cognitive savoring strategies, over and above the experience of PA, may impact these emotion-related benefits. Furthermore, the current study examined individual differences in the emotional benefits that individuals can derive from savoring a past event. Although past research has investigated individual differences in savoring ability, most studies have relied on self-report (e.g., Gentzler et al., 2014; Ramsey \& Gentzler, 2014; Wood et al., 2005), have not examined how savoring relates to changes in affect (e.g., Gentzler et al., 2010; Quoidbach, Berry et al., 2010), or have only examined experimentally manipulated variables that may impact the savoring process (DeVoe \& House, 2012).

The current study had several strengths. First, savoring was assessed using a real-time task, which allowed for investigation of momentary emotional benefits, as opposed to long-term 
outcomes or correlational links, and helps eliminate potential bias that occurs when assessing self-reported savoring ability. Additionally, the current study randomly assigned participants to savor, which helps minimize confounding factors that may be associated with natural savoring tendencies to more accurately assess savoring ability and its cognitive effects. Moreover, the current study built on previous interventions that have examined positive affect after cognitively reminiscing on a positive event (McMakin et al., 2011) by requiring both the control group and the savoring group to recall a past positive event before the task. This ensures that any savoringrelated benefits were due to the actual savoring process, and not simply due to thinking about a positive event, and strengthens the support that the current study provides for the affect benefits of savoring.

\section{Momentary Benefits of Savoring}

In the current study, savoring a positive event was associated with the maintenance of general PA and high-arousal PA and increases in low-arousal PA after describing the event. Moreover, savoring was linked to the maintenance of lower levels of NA and poignancy. These affective outcomes differed post-task between the savoring and the control group. Furthermore, all affect subscales were significantly different post-task than at baseline for the savoring group, but not for the control group. This suggests that savoring maintained current affect states after recalling a positive event, but it generally did not increase general PA or high-arousal PA or decrease NA. However, because of the positive event recall, many participants were already experiencing relatively high levels of PA and low levels of NA. Thus, by prolonging PA, these findings add to the current literature on savoring that suggest that incorporating savoring into daily life leads to increases in emotional well-being (Bryant, Smart, \& King, 2005; Jose et al., 2012). These findings also contribute unique evidence for the benefits of savoring by 
highlighting affect change and stability as an immediate consequence of savoring, which to date has been relatively unexamined (for an exception, see McMakin et al., 2011).

Although it was not a focus of the current study, an interesting finding that emerged was that participants reported less low-arousal PA after recalling a positive event. Research generally indicates that sharing positive events with others is linked with more PA (Gable et al., 2004). A recent study examining specific types of PA found that sharing positive experiences with others is specifically linked to more vitality and energy (Lambert, Qwinn, Fincham, \& Stillman, 2011). Because the positive event recall, which involved sharing their positive event to the experimenter, also increased high-arousal PA in the current study, it suggests that sharing positive experiences may increase high-arousal affect but at the cost of low-arousal PA.

The current study also assessed how much effort participants put into the task, how distracted they were, and how impatient they felt. Initial correlations indicated that for the savoring group, distraction during the task was related to less low-arousal PA (although this relationship was no longer significant in the overall regression model). However, these initial correlations are consistent with past research that suggests that distraction leads to less positive emotion (Quoidbach, Berry et al., 2010), and that experiencing positive emotion is associated with a better ability to return attention to a task once becoming distracted (Smallwood, Fitzgerald, Miles, \& Phillips, 2009). This finding also supports previous research that suggests that mind wandering (even to neutral topics) is generally associated with lower levels of happiness (Killingsworth \& Gilbert, 2010). However, both affect and distraction were assessed after the completion of the task, so it is difficult to determine which preceded the other (distraction or less low-arousal PA), or if they were mutually antagonistic. Additionally, participants who reported that they felt more distracted during the task also felt more mixed 
emotions, regardless of whether or not they were in the savoring or the control group. Again, it is not possible to determine causality or direction with these findings. Previous research suggests that negative moods increase the frequency of mind wandering (Smallwood et al., 2009), so experiencing negative thoughts about a positive event may have led to increased rates of poignancy. Although the content of these distractions was not explicitly examined, it may be that individuals who have a tendency to experience intrusive, negative thoughts, or ruminate on negative feelings or events may have been more likely to become distracted during this task.

Impatience was related to less post-task general PA and less post-task high-arousal PA, suggesting that feeling impatient did not allow participants to reap the benefits of the savoring task. These findings are in line with recent work suggesting that feeling impatient about a task may lead to less enjoyment of positive experiences (House, DeVoe, \& Zhong, 2013). However, similar to participants' distracting thoughts, the reasons for feeling impatient were not analyzed in the current study. An alternative explanation may be that those who did not enjoy the task as much or who struggled with the task may have felt more impatient. Notably, although this relationship between impatience and affect was significant for all participants, it was stronger for those in the control group. Although impatience was still linked to less PA for the savoring group, the smaller magnitude of this relationship suggests that savoring may have been a protective factor against impatience by minimizing affect-related declines.

Some participants also reported that they put more effort into the task than did others. Initial correlations suggested that the more effort someone put into the savoring task, the less PA they reported after the task. Although this relationship was no longer significant in the more robust, regression models, this lends support to previous work suggesting that people who intentional try to make themselves happier may struggle doing so (Cupchik \& Leventhal, 1974; 
Schooler et al., 2003), and that people who value happiness to a greater extent may feel more disappointed when they do not achieve it (Mauss et al., 2011). However, in the current study we did not assess why participants were trying, so it is unclear if the purpose of their effort was with the intention of increasing PA. Additionally, participants who tried harder also reported more poignancy after the task, but this was limited to the control group. Perhaps after experiencing the good feelings from recalling a positive event, participants felt these feelings start to fade during the control task and therefore tried harder to maintain that affect with limited success. This explanation is plausible given that people typically are motivated to try to increase their PA if they do not feel as good as they would like (Scheibe et al., 2012).

\section{Savoring and the Broaden and Build Theory}

To date, little is known about the specific strategies that people may use to increase their positive feelings and how this relates to typical PA-related benefits. In the current study, there were no main effects in broadening outcomes by group, but an interaction between group and affect emerged. However, contrary to hypotheses, greater increases in general PA and higharousal PA after savoring actually predicted less global processing, and this was only the case for the savoring group. This finding contrasts a substantial body of evidence that suggests that increased PA leads to more global processing (Fredrickson \& Branigan, 2005; Gasper \& Clore, 2002; Schmitz, De Rosa, \& Anderson, 2009). However, emerging evidence suggests that PA high in emotional intensity may actually predict more narrowed attention, whereas low-arousal PA is more predictive of broadened attention (Gable \& Harmon-Jones, 2008; Harmon-Jones, Gable, \& Price, 2013). Although low-arousal PA was unrelated to processing, the current findings support these claims, as the narrowing effects in the current study were limited to general and high-arousal PA. 
Moreover, the savoring task itself may have promoted a narrowed processing style. Previous work that supports the notion that savoring broadens behavior and cognition has investigated behaviors such as expressing emotion through facial expressions (Johnson et al., 2010), sharing good news with someone else (Gable et al., 2004; Reis et al., 2010), or experimentally promoting other-oriented emotions such as gratitude (Tsang, 2006). Participants in the current study were asked to passively reflect on a past event, which involves an inward focus on personal thoughts, feelings, and behaviors. Consequently, because the focus on participants' thoughts may have been more self-focused and internal in nature, this may have led to more local processing. Future research should continue to examine the effect of not only the valence and arousal of the emotion on broadening, but also the task used to produce that emotion. The current findings suggest that while cognitively reminiscing on a positive event may be beneficial in increasing our PA, it may not provide typical PA benefits.

None of the affect subscales were linked to broadening effects in the control group, but this is likely due to more moderate levels of PA experienced by control participants. Preliminary correlations also indicated that participants engaged in greater global processing in the lab than at other locations. This finding is similar to previous research suggesting that people take in more information in unfamiliar and novel situations, which call for a broader cognitive processing style (Förster, Liberman, \& Shapira, 2009). Furthermore, males had a more broadened processing style. While literature on gender differences in global-local processing in sparse, this is consistent with studies that have found that women use more local processing when analyzing faces when compared to men (Schmid, Schmid Mast, Bombari, Mast, \& Lobmaier, 2011) and in children, boys generally use more global processing than do girls (Kramer, Ellenberg, Leonard, \& Share, 1996). 
The number of thought-action repertoires was linked to increases in PA. These findings did not differ by group, indicating that savoring does not predict increased willingness to engage in behaviors over and above the experience of PA. In other words, other than its tendency to increase our PA, there is nothing about the savoring process (at least as completed in the current task) that promotes or inhibits increased thought-action repertoires. Despite the lack of main effects by group, perhaps the type of behaviors listed differed. Notably, the current study only examined the number of activities that people listed, and not the activity level that would be involved in those actions (e.g., “go for a run” versus “relax on the couch”), the motivation to actually complete them, or the type of activity itself. For example, participants in the savoring group may be more likely to want to engage in behaviors to prolong PA or to experience something positive.

There are aspects of the control task that may have contributed to performance on the thought-action repertoire task, which may have contributed to nonsignificant group effects, despite savoring's increased PA overall. Perhaps thinking about a daily morning routine, which might be overflowing with daily responsibilities and tasks, prompted participants to think about things they needed to do, not just things they wanted to do. While types of activities listed were not explicitly analyzed, preliminary coding indicates that the number of morning-related behaviors listed was quite low. However, thinking about a daily morning routine still may have prompted other chore-like items.

It is important to note that only moderate levels of PA, but not high- or low-arousal PA, predicted thought-action repertoires. Although all participants in the savoring condition were reflecting on a past event, the extent to which this prompted them to think about the past, their good feelings in the moment, or related future events is unknown. Generally, high-arousal 
emotions, such as excitement, may be prompted when thinking about the future (Mogilner, Kamvar, \& Aaker, 2011), which may have resulted in their anticipation of very specific things. Conversely, low-arousal affective states are typically associated with an appreciation of the current moment (Mogilner et al., 2011), which may have prompted a desire to continue, not change, current behaviors.

The current study found links between savoring, affect, and cognitive broadening. However, emotions are typically short lived (Verduyn et al., 2009). The global-local task and the twenty statements test were completed immediately after the savoring task, but the deterioration of these emotions may have occurred rather rapidly, and it is difficult to predict if these same cognitive effects would have occurred if assessed after a lapse in time. Perhaps cognitively savoring a positive event leads to a more local, narrow focus immediately after these thoughts, but after some time this local focus may fade. This is a viable possibility given that the tasks were not counter-balanced. The thought-action repertoire task occurred after the global-local task, and the direction of the relationship suggested a broadened effect, not a narrowed one.

Research generally suggests that PA is associated with favorable outcomes (Fredrickson, 2001), and the results of the current study suggest that the way we achieve or maintain this PA may have implications for these benefits. Emotion scholars have begun to discuss some limitations to PA, and preliminary research suggests that while PA in moderation can be beneficial, there may be certain levels, times, and ways that positive emotions may cease to be adaptive (Gruber, Mauss, \& Tamir, 2011). However, more research is needed to fully understand when and how PA is good and when it may actually hinder adaptive outcomes.

\section{Individual Differences in Affect and Savoring}


Self-esteem. Self-reported trait savoring ability was related to higher levels of selfesteem, which is consistent with previous research (Bryant, 2003; Wood et al., 2003; Wood et al., 2005). However, contrary to hypotheses, self-esteem was not linked to greater PA or less NA after the savoring task. It is possible that the savoring task was easier than savoring in a daily, naturalistic context, because the current task included detailed instructions for participants based on empirically supported interventions to increase positive emotion. Notably, some of these instructions were specifically developed for those suffering from depression by attempting to inhibit typical dampening thoughts that may occur (McMakin et al., 2011). The ease of the instructions may have provided an opportunity to those with lower self-esteem to maintain their PA, even if they do not engage in those skills on a routine basis, or if they typically dampen their PA. In addition, self-esteem was related to higher reports of all types of PA, lower reports of NA, and lower poignancy both at baseline and after the positive event recall, with the exception of baseline low-arousal PA. These affect levels before the savoring task may have resulted in ceiling effects for some participants, and may have limited the variability in affect changes for those with high self-esteem.

Self-esteem was related to more general PA and high-arousal PA for the control group after the control task. This finding is consistent with previous work that suggests that those with higher self-esteem generally experience an overall, positive bias across a range of contexts (Baumeister, Campbell, Krueger, \& Vohs, 2003). Those with higher self-esteem may also have more enjoyable morning routines, which may have resulted in the control instructions actually serving as a pseudo-savoring task. However, these findings could also indicate that participants with higher self-esteem were better at maintaining or increasing their PA after the event recall, 
even when they were instructed to think about something else. However, there were no associations with self-esteem and self-reports of distraction during the control task.

Anxious attachment. Those reporting higher rates of anxious attachment reported lower rates of trait savoring ability, which is similar to other studies that have found links between attachment and savoring ability (Gentzler et al., 2010; Gentzler et al., 2014), potentially due to the tendency to interpret positive situations as threatening (Mikulincer \& Shaver, 2008). Furthermore, preliminary correlations indicated that anxious attachment was negatively related to mindfulness. It has been suggested that less mindfulness of current thoughts and feelings in those with high anxious attachment may be partially due to increased rumination on negative thoughts (Caldwell \& Shaver, 2013), which may lead to more dampening of PA. However, despite self-reported trait savoring differences, attachment did not predict any changes in affect after the savoring task. Again, it is possible that the savoring task was easier than savoring in a daily, naturalistic context, which may have allowed participants that may not typically savor to effectively employ these skills.

Higher reports of anxious attachment were associated with lower high-arousal PA, higher NA, and higher poignancy at baseline and after the positive event recall, and related to lower rates of low-arousal PA at baseline. Reports of anxious attachment were also associated with general PA, but only after the positive event recall, and not at baseline. Similar to the self-esteem model, these affect levels before the savoring task may have resulted in ceiling or floor effects for some participants, and may have limited the variability in affect changes for those with lower anxiety.

Age. Preliminary correlations indicated that older age was associated with less NA at baseline and less poignancy at baseline. Despite hypotheses that older adults are better at 
regulating PA (Isaacowitz \& Blanchard-Fields, 2012) and preliminary reports of age-related increases in savoring in adulthood (Bryant, 2003), the current study did not find a relationship between age and self-reported savoring ability. This is similar to findings by Ramsey and Gentzler (2014), who did not find main effects of age on savoring. In addition, the current study found no relation between age and affect after the savoring task. Potentially, providing participants with instructions may have prompted the pursuit or the intention to up-regulate PA in all participants, which may have obscured effects of any natural tendencies to seek out positive emotions. For example, previous research indicates that providing motivation may reduce age effects to focus on emotional content (Löckenhoff \& Carstensen, 2007). Nonetheless, these results are surprising given that older adults report more PA with age (Grühn et al., 2010), are more motivated to experience PA (Riediger et al., 2010), have longer lasting PA experiences (Carstensen et al., 2000), and are more likely to meet their PA goals (Scheibe et al., 2012).

However, if older adults are not better at savoring their PA, then where are these differences in affect with age coming from? As suggested by Ramsey and Gentzler (2014) and Bryant and colleagues (2011), older adults may lose savoring capacities with age with cognitive declines, which may lead to an inability to savor effectively. One explanation may be that older adults are more likely to engage in antecedent-focused savoring strategies as opposed to the response-focused strategies typically assessed by savoring researchers. The process model of emotion regulation outlines several ways that people can control what they feel (Gross, 1998). Antecedent-focused strategies occur before situations take place, like seeking out or avoiding certain experiences. Response-focused strategies involve suppressing or expressing emotion in ways that modify an emotion already felt. Older adults do focus their attention to positive information more often than younger adults (Scheibe \& Carstensen, 2010), and they may be 
more likely to seek out emotionally meaningful situations (Lang \& Carstensen, 2002), both of which would be considered antecedent-focused strategies. It is possible that if older adults are engaging in antecedent-focused strategies designed to seek out positive experiences or interpret experiences as positive more often, they may not need to up-regulate their PA in the moment. In fact, experiencing more frequent PA as opposed to more intense PA may be better suited for older adults, given that age-related decreases in physiological flexibility may reduce the desire to experience intense moods (Charles, 2010).

Future time perspective. A more expansive future time perspective and a focus on opportunities was associated with more high-arousal PA after the positive event recall, but was unrelated to all other affect variables at baseline, after the positive event recall, and after the savoring task. In addition, no findings emerged for overall future time perspective or a focus on opportunities and self-reported trait savoring. A focus on limitations was unrelated to all of the affect variables at baseline, after the positive event recall, and to reports of trait savoring. However, results indicated that a focus on limitations was marginally related to more NA after the savoring task. Preliminary analyses also indicated that a focus on limitations was associated with more effort during the task, but also more distraction, indicating that even though these participants were trying harder to savor, they may not have been doing so successfully.

These findings were surprising given the range of evidence that suggests that future time perspective profoundly impacts the decisions people make in regards to their happiness (Carstensen, 2006; Mogilner, Aaker, \& Kamvar, 2012) in that those with a more limited time perspective are more likely to pursue emotionally satisfying goals (Carstensen et al., 1999). These findings, in conjunction with other emerging research, suggest that despite hypotheses that a limited future time perspective should lead to more savoring (e.g., Bryant \& Veroff, 2007), 
those with a more limited future time perspective might actually struggle to savor their positive events (Gentzler \& Ramsey, 2014). Research suggests that valuing happiness to a greater extent might paradoxically reduce the PA gained from experiences because of increases in disappointment (e.g., Mauss et al., 2011). Possibly, the increased value placed on positive emotional experiences by those with focus on limitations may result in more negative feelings. However, the current study did not examine motivations for savoring or actual value placed on emotionally satisfying experiences.

Moreover, feeling like time is more limited may have led participants in the current study to feel distracted during the task if they felt like it was a waste of time. A study that manipulated participants to put a value on their time (by thinking about it in regards to its monetary worth) found that this led to more impatience and less savoring (DeVoe \& House, 2012). Participants were not encouraged to think of their time as money in the present study, but participants who view their time as being more valuable (because they see their time left as being more limited) may have been less likely to savor during the task.

Perceptions of free time. Bryant and Veroff (2007) hypothesized that free time would relate to greater savoring capacity. Savoring involves lingering on a positive feeling and calls for increased attentional resources (Bryant \& Veroff, 2007; Frijda \& Sundararajan, 2007; Linville \& Fischer, 1991), which may be more limited for those who are preoccupied with other tasks or responsibilities. This is the first known study to examine the relationship between free time and both self-reported and actual savoring ability. However, perception of free time was unrelated to all baseline emotions, all reports of emotion after the event recall, and to reports of trait savoring. Perception of greater free time was related to less NA after the task, but this was limited to participants in the control group. Free time was not related to savoring when provided with 
instructions, but this finding may suggest that those reporting less free time had difficulty maintaining their lower NA after the positive event recall. This finding may also be a function of the control task selected for the current project. Participants who generally feel like they do not have a lot of free time may have hectic, rushed morning routines, and therefore thinking about these daily morning activities may have promoted more negative feelings.

Although the current study did not find links between free time and savoring, free time may simply be linked to the tendency to seek out leisure activities, not necessarily the ability to enjoy them. Additionally, in the current study it was assumed that people who reported little free time would not be able to disengage from their daily schedule to savor. However, some people may be better able to disengage from a hectic life than others, regardless of actual free time available. Unfortunately, cognitive disengagement was not examined in the current study, and this may have been a better indicator of the attentional resources available to savor.

Trait savoring. Additional analyses also examined if self-reported savoring predicted affect after the savoring task. Trait savoring was related to less distraction during the savoring task, which provides evidence that those who report that they are better at savoring a past event may actually be better at focusing their attention while reminiscing. This provides some evidence for the validity of self-reported savoring ability. However, trait savoring was unrelated to affect after the savoring task, with the exception of increases in high-arousal PA for the control group only. Potentially, those high in trait savoring may have continued to savor their positive event, even during the control task, whereas the ease of the savoring induction may have promoted more savoring among those who may not generally have or utilize savoring skills. Although it was unrelated to affect after savoring, trait savoring was related to increased PA and decreased NA both at baseline and after the positive event recall. Potentially, this left minimal variability 
for affect changes for those who already reported high PA and low NA before the savoring task, and may have left less room for improvement.

Mindfulness. Generally, mindfulness was related to better affect (higher scores on the PA scales and lower scores on NA and poignancy) both at baseline and after the post-event recall, with the exception of general post-event recall PA. Furthermore, consistent with previous research and hypothesized relations, mindfulness was related to reports of trait savoring (Bryant \& Veroff, 2007) and to fewer distractions during the savoring task. However, after the savoring task, mindfulness was related to less increases in low-arousal PA. It is important to note that this is only in comparison to other participants, and on average participants experienced decreases in low-arousal PA after the positive event recall, then subsequent increases after savoring. However, mindfulness was related to more low-arousal PA after the positive event recall. This suggests that although overall, those high in mindfulness may have reported less increases in low-arousal PA after the savoring task, this may be contingent on the fact that they were already reporting relatively high levels. In addition, the current study only examined reports of trait mindfulness, and not actual mindfulness during the savoring task, which may be more predictive of savoring (Ritchie \& Bryant, 2012).

\section{Limitations and Future Directions}

This study contributes unique, novel information about who can savor and how this savoring ability impacts positive emotions and its related benefits. However, a few limitations must be considered when interpreting these results. First, although this study was the first to investigate cognitive broadening effects of savoring and individual differences in immediate, emotional benefits of savoring using a behavioral task, these results should be interpreted with caution until replicated. Certain aspects of the study or the study sample may have influenced the 
results. For example, all participants had the same experimenter during the in-person session. While this allowed for consistency across participants in the procedure, analyses to examine experimenter effects could not be examined. Furthermore, the study sample may not generalize to other populations. The majority of the participants in the current study were white, generally very well-educated, and on average did not report a difficult time paying their bills. Although little is known about the effects of race or education on savoring, there is some evidence that wealthier adults are less able to savor their positive events (Quoidbach, Dunn et al., 2010). Moreover, the older adults in the current study were still fairly young (see Table 1), which may have limited any age effects. For example, there were no differences in any of the affect subscales at baseline for age with the exception of NA and poignancy, which is counter to previous research that suggests that older adults experience more daily PA (e.g., Carstensen et al., 2011).

In the current study, individual differences existed in baseline affect and in typical, selfreported savoring capacity. However, nearly everyone in the current study was able to maintain their affect in the savoring task. As previously mentioned, the savoring task was designed based on theory (Bryant \& Veroff, 2007) and previous research that has produced success in improving affect for those who are suffering from depression (McMakin et al., 2011). By providing detailed instructions and a relatively quiet, uninterrupted space, participants who typically do not savor may have been able to do so in the current study. This may have masked individual differences in ability that may have emerged if a more challenging task had been used. A different task with no explicit savoring instructions (e.g., Gentzler et al., 2010) may have better elucidated natural momentary savoring tendencies. 
Alternatively, when individual differences did occur, they were often limited to the control group, which may have allowed for more variability in affect. Some participants may have simply enjoyed their daily morning routine more, or some participants may have continued to savor their positive event even during the savoring task. The current study also examined affect directly after the savoring task, and did not assess affect after a lapse in time. Perhaps examining duration of emotion may have provided slightly different information about the salutary effects of savoring experiences, beyond immediate, momentary benefits. For example, some research suggests that older adults experience more long-lasting PA, despite not experiencing any differences in the amount (Carstensen et al., 2000).

In addition, by controlling for affect before the task, this limited any results to actual increases or decreases in affect, and these results do not necessarily provide any information about mean levels. Participants high or low on the individual difference variables of interest may have experienced different levels of affect overall, because the savoring task did not necessarily promote similar levels of affect, but did allow similar levels of maintenance. Ceiling effects in the measurement of affect may have had an adverse impact on the ability to detect individual differences in affect changes at each assessment point. Some participants had maximum (or close to the maximum) PA scores at baseline or after the positive event recall and this may have masked effects when comparing increases to participants who started much lower. In other words, participants who started off with maximum scores (or close to the maximum score) may not have been accurately assessed if they did actually experience increases in their affect at each time point, whereas others who started with a lower baseline may have appeared to actually experience greater increases. Ceiling effects (or floor effects) such as this may lead to misleading results when variables are related to different variations in ceiling effects, and this may be is 
especially dangerous when it occurs in longitudinal analyses where participants reach the maximum values before the last assessment (e.g., after the positive event recall, Wang, Zhang, McArdle, \& Salthouse, 2009).

The current study expanded on research examining individual differences in savoring by using a behavioral savoring task to assess its immediate, affect benefits. This is critical to examine savoring ability, as self-reported surveys typically examine prospective or retrospective evaluations (Bryant, 2003; Gentzler, Palmer, \& Ramsey, 2014) which may be subject to bias. However, current levels of affect were still assessed using a self-reported measure. Although the PANAS is well-validated, it is possible that there were meaningful patterns of bias that influenced results. By assessing emotion in a way that asks participants to consciously think about how they are feeling, use of these scales may have subsequently altered participants' reports. However, some research suggests that this may impact NA more than PA (Thompson, Mata, Jaeggi, Buschkuehl, Jonides, \& Gotlib, 2011). Furthermore, there is evidence that multiple, repetitive emotion assessments may mask affect-cognition processes (Keltner, Ellsworth, \& Edwards, 1993). Other forms of emotion assessment may prevent these biases and may be able to capture affect changes in real time, throughout the task as opposed to just after completion of the task. Future research should explore these other forms of assessment, including physiological indicators of positive mood (e.g., heart rate variability), facial expressions (e.g., through facial coding or facial electromyography), or neurological correlates.

In addition to meaningful patterns of bias that may have emerged from the emotion assessment, participants chose the positive event that they wanted to discuss for the positive event recall, and subsequently the event they savored, which may have introduced some confounding effects. While allowing participants to choose their own event ensured that the 
event would be one that made them happy, there still may have been differences in the quality of the event chosen. There may also have been differences in the type of event chosen (e.g., interpersonal, personal achievement), which may have led to systematic differences in how well participants could savor these events. For example, self-esteem might predict PA in self-relevant situations, but not others (Brown \& Dutton, 1995).

Furthermore, the majority of participants thought about major, life-defining positive events in the current study (e.g., graduating, meeting their spouse, birth of a child). Due to the importance of major life events, participants may be more likely to savor and remember these experiences. However, people generally do not feel as positive as they would like (Scheibe et al., 2012), and this may occur more often during daily, necessary tasks like work (Mannell, Walker, \& Ito, 2014). Investigating more minor events may have further exposed individual differences in savoring ability. For example, some research suggests that older adults may take more joy out of everyday experiences when compared to younger adults (Bhattacharjee \& Mogilner, 2014), and future research would benefit from looking at the savoring of everyday events using behavioral tasks. For example, Quoidbach, Dunn, and colleagues (2010) examined how much participants savored a piece of chocolate, Gentzler and colleagues (2010) investigated natural savoring tendencies after a positive social interaction, and DeVoe and House (2012) examined affect after spending leisure time on the internet or listening to positively valenced music. Future research should examine momentary affect after savoring more minor, daily events, because these are more frequent and therefore may have more implications for well-being (e.g., Wagner, Compas, \& Howell, 1988).

The current study also examined savoring in a very narrow, specific way (cognitive reflection on a past event). Keeping the type of savoring consistent across participants was 
beneficial for examining this specific strategy. However, there are many other ways to upregulate PA, such as expressing positive emotion (e.g., Wong, Tschan, Messerli, \& Semmer, 2013), sharing with others (e.g., Gable et al., 2004), or doing things to create more instances of positive emotion like seeking out friends or family (Livingstone \& Srivastava, 2012).

Additionally, this type of savoring may not be the preferred method of PA up-regulation for some participants. As previously discussed, some strategies may be aimed at choosing more positive situations or interpreting experiences as being more positive, as opposed to trying to create or maintain more positive feelings in the moment. This is supported by research that suggests that some people may be more likely to engage in more rewarding activities than others (Oerlemans \& Bakker, 2014). Future research should examine how participants might engage in these antecedent versus response-focused savoring strategies (Gross, 1998). As previously discussed, older adults may be more likely to engage in antecedent savoring strategies such as situation selection (selecting more positive experiences, Lang \& Carstensen 2002) and attention deployment (focusing on more positive aspects of the situation, Scheibe \& Carstensen, 2010), as opposed to response-focused strategies. These proposed differences should be examined empirically, along with any mediating effects of cognitive and physiological changes that may limit the ability to up-regulate PA in the moment.

Research should continue to examine the ways that people can savor their positive experiences, but with an understanding that some strategies may promote some benefits over others. Up-regulating specific types of positive emotion may differentially relate to various forms of well-being. For example, gratitude may be more beneficial for relationship outcomes, elevation for prosocial behavior, and admiration for self-improvement (Algoe \& Haidt, 2009). Furthermore, it is also important to consider the idea of optimal levels of PA or matching the 
savoring strategy to the situation. Sometimes the up-regulation of PA may not be optimal depending on the circumstance, such as expressing PA after winning (Kalokerinos, Greenaway, Pedder, \& Margetts, 2014). It is also important to note that increasing affect may not always be an end goal. Although people generally pursue happiness (Diener, 2000), some cultures may value the up-regulation of PA more than others (Miyamoto \& Ma, 2011).

The motivation for savoring and its related benefits should also be examined. Some research states that trying to make yourself happy (Cupchik \& Leventhal, 1974; Schooler et al., 2003) or overvaluing happiness might be counterproductive and may actually result in less happiness (Mauss et al., 2011). Therefore, investigating how motivation impacts when and how savoring PA is beneficial is an important next step. In addition, some research suggests that people are most likely to reminisce when they are feeling down (Bryant et al., 2005). If negative mood is a motivating factor to savor, investigating savoring's impact on recovery from negative emotions might be an important avenue of research. Fredrickson and colleagues (2000) found that positive emotion assisted in physiological recovery from stress. However, this study used induced PA to undo these effects, so savoring should be further investigated as an undoing agent for NA.

In addition, people likely savor the same event in multiple ways, but the cumulative effects of savoring strategies are relatively uninvestigated (for an exception, see Palmer, Ramsey, Morey, \& Gentzler, 2014). Using multiple savoring strategies may counteract any benefits derived from one another, or may serve additive, or synergistic effects. For example, cognitively reminiscing on a past positive event may lead to emotional benefits, but this may not result in any social benefits if the event is not shared with other people. However, reminiscing on a past positive event and sharing it with another may result in both emotional and social benefits. 
There may also be individual differences in the ability to reap benefits from PA and savoring. People have a limited amount of attentional resources that they can devote to their emotional experiences (Linville \& Fischer, 1991), and therefore may see less of a benefit from the PA. For example, although it was not examined in the current study, it has been suggested that those who are higher on anxious attachment may be more likely to interpret a positive situation as threatening and they may be less likely to experience any broadening effects (Mikulincer \& Sheffi, 2000).

\section{Conclusions}

Using a behavioral savoring task and random assignment, the current study investigated the momentary emotional benefits of savoring a past positive event, its related cognitive and behavioral benefits, and individual differences in savoring ability. The current findings suggest that savoring a past positive event is generally associated with the maintenance of affect if one is already experiencing good feelings. Furthermore, savoring impacts attentional processing styles and this may differ from typical PA benefits. However, beyond simply increasing PA, the savoring process itself does not impact the relationship between PA and thought-action repertoires. Very few individual differences emerged in savoring ability, despite differences in self-reported trait savoring. Although the current study did not assess any emotional benefits beyond the immediate effects of the savoring task, these findings suggest that providing people with detailed instructions on how to savor may preclude any natural savoring tendencies that may emerge in daily life and promote the maintenance of high PA and low NA.

Future research should continue to assess savoring in real time (Bryant et al., 2011) and investigate its momentary benefits in different populations, using multiple forms of emotion assessments, a variety of savoring tasks, and a range of savoring strategies for a variety of event types. Furthermore, future research should explore individual differences in the cognitive and 
behavioral benefits of savoring. Despite only recent empirical attention to PA and its related processes, an impressive body of research suggests that experiencing PA is beneficial for overall success and well-being (Fredrickson, 2001; Lyubomirsky, King et al., 2005). Therefore, finding ways to maximize it through savoring processes is a critical area of research that needs to be further considered and explored. 


\section{References}

Alessandri, G., Zuffianò, A., Fabes, R., Vecchione, M., \& Martin, C. (2013). Linking positive affect and positive self-beliefs in daily life. Journal of Happiness Studies. Advanced online publication.

Algoe, S. B., \& Haidt, J. (2009). Witnessing excellence in action: The 'other-praising'emotions of elevation, gratitude, and admiration. The Journal of Positive Psychology, 4(2), 105127.

Boehm, J. K., \& Lyubomirsky, S. (2008). Does happiness lead to career success? Journal of Career Assessment, 16, 101-116.

Baer, R. A., Smith, G. T., Hopkins, J., Krietemeyer, J., \& Toney, L. (2006). Using self-report assessment methods to explore facets of mindfulness. Assessment, 13(1), 27-45.

Baumeister, R. F., Campbell, J. D., Krueger, J. I., \& Vohs, K. D. (2003). Does high self-esteem cause better performance, interpersonal success, happiness, or healthier lifestyles? Psychological Science in the Public Interest, 4(1), 1-44.

Baumeister, R. F., Tice, D. M., \& Hutton, D. G. (1989). Self-presentation motivations and personality differences in self-esteem. Journal of Personality, 57, 547-579.

Bhattacharjee, A., \& Mogilner, C. (2014). Happiness from ordinary and extraordinary experiences. Journal of Consumer Research. Advanced online publication.

Bishop, S. R., Lau, M., Shapiro, S., Carlson, L., Anderson, N. D., Carmody, J., ... \& Devins, G. (2004). Mindfulness: A proposed operational definition. Clinical psychology: Science and Practice, 11(3), 230-241.

Blanchard-Fields, F. (2007). Everyday problem solving and emotion: An adult developmental perspective. Current Directions in Psychological Science, 16, 26-31. 
Brennan, K. A., Clark, C. L., \& Shaver, P. R. (1998). Self-report measurement of adult attachment: An integrative overview. In J. A. Simpson \& W. S. Rholes (Eds.), Attachment theory and close relationships (pp. 46-76). New York, NY: Guilford.

Brown, J. D., \& Dutton, K. A. (1995). The thrill of victory, the complexity of defeat: Self-esteem and people's emotional reactions to success and failure. Journal of Personality and Social Psychology, 68(4), 712-722.

Brown, K. W., \& Ryan, R. M. (2003). The benefits of being present: mindfulness and its role in psychological well-being. Journal of Personality and Social Psychology, 84(4), 822-848.

Bryant, F. B. (2003). Savoring Beliefs Inventory (SBI): A scale for measuring beliefs about savouring. Journal of Mental Health, 12(2), 175-196.

Bryant, F. B., Chadwick, E. D., \& Kluwe, K. (2011). Understanding the processes that regulate positive emotional experience: Unsolved problems and future directions for theory and research on savoring. International Journal of Wellbeing, 1, 107-126.

Bryant, F. B., Smart, C. M., \& King, S. P. (2005). Using the past to enhance the present: Boosting happiness through positive reminiscence. Journal of Happiness Studies, 6, 227260.

Bryant, F. B., \& Veroff, J. (2007). Savoring: A new model of positive experience. Mahwah, New Jersey: Lawrence Erlbaum Associates, Inc.

Burton, C. M., \& King, L A. (2004). The health benefits of writing about intensely positive experiences. Journal of Research in Personality, 38, 150-163.

Caldwell, J. G., \& Shaver, P. R. (2013). Mediators of the link between adult attachment and mindfulness. Interpersona: An International Journal on Personal Relationships, 7(2), 299-310. 
Cardaciotto, L., Herbert, J. D., Forman, E. M., Moitra, E., \& Farrow, V. (2008). The assessment of present-moment awareness and acceptance: The Philadelphia Mindfulness Scale. Assessment, 15(2), 204-223.

Carroll, J. (2008). Time pressures, stress common for Americans. Retrieved May 24, 2012, from http:/www.gallup.com/poll/103456/Time-Pressures-Stress-Common-Americans.aspx.

Carstensen, L. L. (2006). The influence of a sense of time on human development. Science, 312(5782), 1913-1915.

Carstensen, L. L., Fung, H. H., \& Charles, S. T. (2003). Socioemotional selectivity theory and the regulation of emotion in the second half of life. Motivation and Emotion, 27(2), 103123.

Carstensen, L. L., Isaacowitz, D. M., \& Charles, S. T. (1999). Taking time seriously: A theory of socioemotional selectivity. American Psychologist, 54(3), 165-181.

Carstensen, L. L. \& Mikels, J. A. (2005). At the intersection of emotion and cognition: Aging and the positivity effect. Current Directions in Psychological Science, 14, 117-121.

Carstensen, L. L., Pasupathi, M., Mayr, U., \& Nesselroade, J. R. (2000). Emotional experience in everyday life across the adult life span. Journal of Personality and Social Psychology, 79(4), 644-655.

Carstensen, L. L., Turn, B., Scheibe, S., Ram, N., Ersner-Hershfield, H., Samanez-Larkin, G. R., Brooks, K. P., \& Nesselroade, J. R. (2011). Emotional experience improves with age: Evidence based on over 10 years of experience sampling. Psychology and Aging, 26, 2133.

Carver, C. .S. (2003). Pleasure as a sign you can attend to something else: Placing positive feelings within a general model of affect. Cognition and Emotion, 17, 241-261. 
Catalino, L. I., \& Fredrickson, B. L. (2011). Tuesdays in the lives of flourishers: The role of positive emotional reactivity in optimal mental health. Emotion, 11, 938-950.

Cate, R. A., \& John, O. P. (2007). Testing models of the structure and development of future time perspective: Maintaining a focus on opportunities in middle age. Psychology and Aging, 22(1), 186-201.

Charles, S. T. (2010). Strength and vulnerability integration: A model of emotional well-being across adulthood. Psychological Bulletin, 136(6), 1068-1091.

Charles, S. T., \& Carstensen, L. L. (2007). Emotion regulation and aging. In J.J. Gross (Ed.), Handbook of emotion regulation (pp. 307-327), New York, NY: Guilford Press.

Charles, S. T., \& Carstensen, L. L. (2010). Social and emotional aging. Annual Review of Psychology, 61, 383-409.

Charles, S., Mather, M., \& Carstensen, L. L. (2003). Aging and emotional memory: The forgettable nature of negative images for older adults. Journal of Experimental Psychology: General, 132, 310-324.

Compton, R. J., Wirtz, D., Pajoumand, G., Claus, E., \& Heller, W. (2004). Association between positive affect and attentional shifting. Cognitive Therapy and Research, 28, 733-744.

Cunningham, M. R. (1988). What do you do when you're happy or blue? Mood, expectancies, and behavioral interest. Motivation and Emotion, 12, 309-331.

Cupchik, G. C., \& Leventhal, H. (1974). Consistency between expressive behavior and the evaluation of humorous stimuli: The role of sex and self-observation. Journal Personality and Social Psychology, 30, 429-442. 
Danner, D., Snowdon, D., \& Friesen W. (2001). Positive emotions in early life and longevity: Findings from the Nun Study. Journal of Personality and Social Psychology, 80, 804813.

de Bloom, J., Geurts, S. A., \& Kompier, M. A. (2013). Vacation (after-) effects on employee health and well-being, and the role of vacation activities, experiences and sleep. Journal of Happiness Studies, 14(2), 613-633.

Derryberry, D., \& Tucker, D. M. (1994). Motivating the focus of attention. In P. M. Niedenthal \& S. Kitayama (Eds.), The heart's eye: Emotional influences in perception and attention (pp.167-196), San Diego, California: Academic Press.

DeVoe, S. E., \& House, J. (2012). Time, money, happiness: How does putting a price on time affect our ability to smell the roses? Journal of Experimental Social Psychology, 48, 466474.

DeVoe, S. E., House, J., \& Zhong, C. B. (2013). Fast food and financial impatience: A socioecological approach. Journal of Personality and Social Psychology, 105(3), 476494.

Diamond, L. M., \& Aspinwall, L. G. (2003). Integrating diverse developmental perspectives on emotion regulation. Motivation and Emotion, 27, 1-6.

Diener, E. (2000). Subjective well-being: The science of happiness, and a proposal for a national index. American Psychologist, 55, 34-43.

Diener, E., \& Seligman, M. E. (2002). Very happy people. Psychological Science, 13, 81-84.

Dreisbach, G., \& Goschke, T. (2004). How positive affect modulates cognitive control: Reduced perseveration at the cost of increased distractibility. Journal of Experimental Psychology: Learning, Memory, and Cognition, 30, 343-353. 
Emmons, R. A., \& McCullough, M. E. (2003). Counting blessings versus burdens: An experimental investigation of gratitude and subjective well-being in daily life. Journal of Personality and Social Psychology, 84, 377-389.

Ersner-Hershfield, H., Mikels, J. A., Sullivan, S. J., \& Carstensen, L. L. (2008). Poignancy: mixed emotional experience in the face of meaningful endings. Journal of Personality and Social Psychology, 94(1), 158-167.

Estrada, C. A., Isen, A. M., \& Young, M. J. (1997). Positive affect facilitates integration of information and decreases anchoring in reasoning among physicians. Organizational Behavior and Human Decision Processes, 72, 117-135.

Falkenstern, M., Schiffrin, H. H., Nelson, S. K., Ford, L., \& Keyser, C. (2009). Mood over matter: Can happiness be your undoing? Journal of Positive Psychology, 4, 365-371.

Faul, F., Erdfelder, E., Buchner, A., \& Lang, A. G. (2009). Statistical power analyses using G*Power 3.1: Tests for correlation and regression analyses. Behavior Research Methods, 41, 1149-1160.

Faul, F., Erdfelder, E., Lang, A. G., \& Buchner, A. (2007). G*Power 3: A flexible statistical power analysis program for the social, behavioral, and biomedical sciences. Behavior Research Methods, 39, 175-191.

Fava, G. A., Rafanelli, C., Cazzaro, M., Conti, S., \& Grandi, S. (1998). Well-being therapy: A novel psychotherapeutic approach for residual symptoms of affective disorders. Psychological Medicine, 28, 475-480.

Feldman, G., Joormann, J., \& Johnson, S. L. (2008). A self-report measure of responses to positive affect: Rumination and Dampening. Cognitive Therapy and Research, 32, 507525. 
Ferguson, Y. L., \& Sheldon, K. M. (2013). Trying to be happier really can work: Two experimental studies. The Journal of Positive Psychology, 8(1), 23-33.

Folkman, S., \& Moskowitz, J. T. (2000). Stress, positive emotion, and coping. Current Directions in Psychological Science, 9, 115-118.

Förster, J., Liberman, N., \& Shapira, O. (2009). Preparing for novel versus familiar events: Shifts in global and local processing. Journal of Experimental Psychology: General, 138(3), 383-399.

Fraley, R. C., \& Shaver, P. R. (2000). Adult romantic attachment: Theoretical developments, emerging controversies, and unanswered questions. Review of General Psychology, 4(2), 132-154.

Fredrickson, B. L. (1998). What good are positive emotions? Review of General Psychology, 2, 300-319.

Fredrickson, B. L. (2001). The role of positive emotions in positive psychology: The broadenand-build theory of positive emotions. American Psychologist, 56, 218-226.

Fredrickson, B. L., \& Branigan, C. (2005). Positive emotions broaden the scope of attention and thought-action repertoires. Cognition and Emotion, 19, 313-332.

Fredrickson, B. L., Cohn, M. A., Coffey, K., Pek, J., \& Finkel, S. M. (2008). Open hearts build lives: Positive emotions, induced through meditation, build consequential personal resources. Journal of Personality and Social Psychology, 95, 1045-1062.

Fredrickson, B. L., \& Joiner, T. (2002). Positive emotions trigger upward spirals toward emotional well-being. Psychological Science, 13, 172-175.

Fredrickson, B. L., Mancuso, R. A., Branigan, C., \& Tugade, M. M. (2000). The undoing effect of positive emotions. Motivation and Emotion, 24, 237-258. 
Friedman, R., \& Förster, J. (2010). Implicit affective cues and attentional tuning: An integrative review. Psychological Bulletin, 136, 875-893.

Friedman, M., \& Ulmer, N. (1985). Treating Type A behavior and your heart. New York, NY: Knopf.

Frijda, N. H., \& Sundararajan, L. (2007). Emotion refinement: A theory inspired by Chinese poetics. Perspectives on Psychological Science, 2, 227-241.

Froh, J. J., Emmons, R. A., Card, N. A., Bono, G., \& Wilson, J. (2011). Gratitude and the reduced costs of materialism in adolescents. Journal of Happiness Studies, 12, 289-302.

Froh, J. J., Sefick, W. J., \& Emmons, R. A. (2008). Counting blessings in early adolescents: An experimental study of gratitude and subjective well-being. Journal of School Psychology, 46, 213-233.

Froh, J. J., Yurkewicz, C., \& Kashdan, T.B. (2009). Gratitude and subjective well-being in early adolescence: Examining gender differences. Journal of Adolescence, 32, 633-650.

Fung, H. H., \& Carstensen, L. L. (2006). Goals change when life's fragility is primed: Lessons learned from older adults, the September 11th attacks and SARS. Social Cognition, 24, 248-278.

Gable, P. A., \& Harmon-Jones, E. (2008). Approach-motivated positive affect reduces breadth of attention. Psychological Science, 19, 476-482.

Gable, S. L., Reis, H. T., Impett, E. A., \& Asher, E. R. (2004). What do you do when things go right? The intrapersonal and interpersonal benefits of sharing positive events. Journal of Personality and Social Psychology, 87, 228-245.

Gasper, K., \& Clore, G. L. (2002). Attending to the big picture: Mood and global versus local processing of visual information. Psychological Science, 13, 33-39. 
Gentzler, A. L., Kerns, K. A., \& Keener, E. (2010). Emotional reactions and regulatory responses to negative and positive events: Associations with attachment and gender. Motivation and Emotion, 34, 78-92.

Gentzler, A. L., Morey, J. N., Palmer, C. A., \& Yi, C. Y. (2013). Young adolescents’ responses to positive events: Associations with positive affect and adjustment. The Journal of Early Adolescence, 33(5), 663-683.

Gentzler, A. L., Palmer, C. A., \& Ramsey, M. A. (2014). The Positive Events and Responses Survey (PEARS). Manuscript in preparation.

Gentzler, A. L., Ramsey, M. A., Yi, C. Y., Palmer, C. A., \& Morey, J. (in press). Young adolescents’ emotional and regulatory responses to positive events: Investigating temperament, attachment, and event characteristics. Journal of Positive Psychology.

Girden, E. R. (1992). ANOVA: Repeated measures. Newbury Park, CA: Sage.

Giuliani, N. R., McRae, K., \& Gross, J. J. (2008). The up- and down-regulation of amusement: Experiential, behavioral, and autonomic consequences. Emotion, 8, 714-719.

Griffin, D. W., \& Bartholomew, K. (1994). Models of the self and other: Fundamental dimensions underlying measures of adult attachment. Journal of Personality and Social Psychology, 67(3), 430-445.

Gross, J. J. (1998). Antecedent-and response-focused emotion regulation: Divergent consequences for experience, expression, and physiology. Journal of Personality and Social Psychology, 74(1), 224-237.

Gross, J. J., Carstensen, L. L., Pasupathi, M., Tsai, J., Skorpen, C. G., \& Hsu, A. Y. C. (1997). Emotion and aging: Experience, expression, and control. Psychology and Aging, 12, 590-599. 
Gruber, J., Mauss, I. B., \& Tamir, M. (2011). A dark side of happiness? How, when, and why happiness is not always good. Perspectives on Psychological Science, 6(3), 222-233.

Grühn, D., Kotter-Grühn, D., \& Röcke, C. (2010). Discrete affects across the adult lifespan: Evidence for multidimensionality and multi-directionality of affective experiences in young, middle-aged and older adults. Journal of Research in Personality, 44, 492-500.

Harmon-Jones, E., Gable, P. A., \& Price, T. F. (2013). Does negative affect always narrow and positive affect always broaden the mind? Considering the influence of motivational intensity on cognitive scope. Current Directions in Psychological Science, 22(4), 301307.

Hayes, A. F. (2009). Beyond Baron and Kenny: Statistical mediation analysis in the new millennium. Communication Monographs, 76, 408-420.

Hayes, A. F. (2013). Introduction to mediation, moderation, and conditional process analysis: a regression-based approach: Methodology in the social sciences. New York: NY: Guilford Press.

Hazan, C., \& Shaver, P. (1987). Romantic love conceptualized as an attachment process. Journal of Personality and Social Psychology, 52(3), 511-524.

Helliwell, J. F., Layard, R., \& Sachs, J. (2012). World Happiness Report. New York, NY: The Earth Institute.

Huang, C., \& Dong, N. (2012). Factor structures of the Rosenberg Self-Esteem Scale. European Journal of Psychological Assessment, 28(2), 132-138.

Hurley, D. B., \& Kwon, P. (2012). Results of a study to increase savoring the moment: Differential impact on positive and negative outcomes. Journal of Happiness Studies, 13(4), 579-588. 
Huynh, H., \& Feldt, L.S. (1976) Estimation of the Box correction for degrees of freedom from sample data in randomized block and split-plot designs. Journal of Educational Statistics, 1, 69-82.

Isaacowitz, D. M., \& Blanchard-Fields, F. (2012). Linking process and outcome in the study of emotion and aging. Perspectives on Psychological Science, 7, 3-17.

Isaacowitz, D. M., Wadlinger, H. A., Goren, D., \& Wilson, H. (2006a). Is there an age-related positivity effect in visual attention? A comparison of two methodologies. Emotion, 6, $511-516$.

Isaacowitz, D. M., Wadlinger, H. A., Goren, D., \& Wilson, H. (2006b). Selective bias in visual fixation to negative images in old age: An eye tracking study. Psychology and Aging, 21, 40-48.

Isen, A. M., Johnson, M. M. S., Mertz, E., \& Robinson, G. F. (1985). The influence of positive affect on the unusualness of word associations. Journal of Personality and Social Psychology, 48, 1413-1426.

Isen A., Rosenzweig A., \& Young M. (1991). The influence of positive affect on clinical problem solving. Medical Decision Making, 11, 221-227.

Izard, C. (1977). Human Emotions. New York, NY: Plenum Press.

John, O. P., \& Gross, J. J. (2007). Individual differences in emotion regulation. In J.J. Gross (Ed.), Handbook of emotion regulation (pp. 351-373). New York, NY: Guilford.

Johnson, K. J., \& Fredrickson, B. L. (2005). "We all look the same to me:" Positive emotions eliminate the own-race bias in face recognition. Psychological Science, 16, 875-881.

Johnson, K. J., Waugh, C. E., \& Fredrickson, B. L. (2010). Smile to see the forest: Facially expressed positive emotions broaden cognition. Cognition and Emotion, 24, 299-321. 
Jose, P. E., Lim, B. T., \& Bryant, F. B. (2012). Does savoring increase happiness? A daily dairy study. Journal of Positive Psychology, 7, 176-187.

Kalokerinos, E. K., Greenaway, K. H., Pedder, D. J., \& Margetts, E. A. (2014). Don’t grin when you win: The social costs of positive emotion expression in performance situations. Emotion, 14(1), 180-186.

Kashdan, T. B., Uswatte, G., \& Julian, T. (2006). Gratitude and hedonic and eudaimonic wellbeing in Vietnam War veterans. Behaviour Research and Therapy, 44, 177-199.

Keltner, D., Ellsworth, P. C., \& Edwards, K. (1993). Beyond simple pessimism: Effects of sadness and anger on social perception. Journal of Personality and Social Psychology, 64(5), 740-752.

Kerns, K. A., Abraham, M. M., Schlegelmilch, A., \& Morgan, T. A. (2007). Mother-child attachment in later middle childhood: Assessment approaches and associations with mood and emotion regulation. Attachment and Human Development, 9, 33-53.

Killingsworth, M. A., \& Gilbert, D. T. (2010). A wandering mind is an unhappy mind. Science, 330(6006), 932-932.

Kimchi, R., \& Palmer, S. E. (1982). Form and texture in hierarchically constructed patterns. Journal of Experimental Psychology: Human Perception and Performance, 8, 521-535.

King, L. (2001). The health benefits of writing about life goals. Personality and Social Psychology Bulletin, 27, 798-807.

King, L. A., \& Napa, C. K. (1998). What makes a life good? Journal of Personality and Social Psychology, 75, 156-165.

Kramer, J. H., Ellenberg, L., Leonard, J., \& Share, L. J. (1996). Developmental sex differences in global-local perceptual bias. Neuropsychology, 10, 402-407. 
Kryla-Lighthall, N., \& Mather, M. (2009). The role of cognitive control in older adults' emotional well-being. In V. Berngtson, D. Gans, N. Putney, M. \& Silverstein (Eds.), Handbook of Theories of Aging ( $2^{\text {nd }}$ edition, pp. 323-344). Springer Publishing,

Labouvie-Vief, G., DeVoe, M., \& Bulka, D. (1989). Speaking about feelings: Conceptions of emotion across the life span. Psychology and Aging, 4(4), 425-437.

Lambert, N., Gwinn, A. M., Stillman, T. F., \& Fincham, F. D. (2011). Feeling tired?: How sharing positive experiences can boost vitality. International Journal of Wellbeing, 1(3), 307-314.

Larsen, J. T., McGraw, A. P., Mellers, B. A., \& Cacioppo, J. T. (2004). The agony of victory and thrill of defeat mixed emotional reactions to disappointing wins and relieving losses. Psychological Science, 15(5), 325-330.

Lang, F. R., \& Carstensen, L.L. (2002). Time counts: Future time perspective, goals and social relationships. Psychology and Aging, 17, 125-139.

Langston, C. A. (1994). Capitalizing on and coping with daily-life events: Expressive responses to positive events. Journal of Personality and Social Psychology, 67, 1112-1125.

Levenson, R. W., Ekman, P., \& Friesen, W. V. (1990). Voluntary facial action generates emotion-specific autonomic nervous system activity. Psychophysiology, 27(4), 363-384.

Linville, P. W., \& Fischer, G. W. (1991) Preferences for separating or combining events. Journal of Personality and Social Psychology, 60, 5-23.

Livingstone, K. M., \& Srivastava, S. (2012). Up-regulating positive emotions in everyday life: Strategies, individual differences, and associations with positive emotion and well-being. Journal of Research in Personality, 46(5), 504-516. 
Löckenhoff, C. E., \& Carstensen, L. L. (2007). Aging, emotion, and health-related decision strategies: Motivational manipulations can reduce age differences. Psychology and Aging, 22(1), 134-146.

Lyubomirsky, S., Dickerhoof, R., Boehm, J. K., \& Sheldon, K. M. (2011). Becoming happier takes both a will and a proper way: An experimental longitudinal intervention to boost well-being. Emotion, 11, 391-402.

Lyubomirsky, S., King, L. A., \& Diener, E. (2005). The benefits of frequent positive affect. Psychological Bulletin, 131, 803-855.

Lyubomirsky, S. \& Lepper, H. (1999). A measure of subjective happiness: Preliminary reliability and construct validation. Social Indicators Research, 46, 137-155.

Lyubomirsky, S., Sheldon, K. M., \& Schkade, D. (2005). Pursuing happiness: The architecture of sustainable change. Review of General Psychology, 9(2), 111-131.

Lyubomirsky, S., Sousa, L., Dickerhoof, R. (2006). The costs and benefits of writing, talking, and thinking about life's triumphs and defeats. Journal of Personality and Social Psychology, 90, 692-708.

Mannell, B., Walker, G. J., \& Ito, E. (2014). Ideal affect, actual affect, and affect discrepancy during leisure and paid work. Journal of Leisure Research, 46, 13-37.

Mannell, R.C., \& Zuzanek, J. (1991). The nature and variability of leisure constraints in daily life: The case of the physically active leisure of older adults. Leisure Sciences, 13, 337351.

Maruta, T., Colligan, R. C., Malinchoc, M., \& Offord, K. P. (2000). Optimists vs pessimists: survival rate among medical patients over a 30-year period. Mayo Clinic Proceedings, $75,140-143$. 
Mather, M. \& Carstensen, L.L. (2003). Aging and attentional biases for emotional faces. Psychological Science, 14, 409-415.

Mauss, I. B., Tamir, M., Anderson, C. L., \& Savino, N. S. (2011). Can seeking happiness make people unhappy? Paradoxical effects of valuing happiness. Emotion, 11, 807-815.

Mayer, J. D., \& Stevens, A. (1994). An emerging understanding of the reflective (meta-) experience of mood. Journal of Research in Personality, 28, 351-373.

McMakin, D. L., Siegle, G. J., \& Shirk, S. R. (2011). Positive Affect Stimulation and Sustainment (PASS) Module for depressed mood: A preliminary investigation of treatment-related effects. Cognitive Therapy Research, 35, 217-226.

Mikels, J. A., Larkin, G. R., Reuter-Lorenz, P. A., \& Carstensen, L. L. (2005). Divergent trajectories in the aging mind: Changes in working memory for affective versus visual information with age. Psychology and Aging, 20, 542-553.

Mikulincer, M., \& Shaver, P. R. (2007). Boosting attachment security to promote mental health, prosocial values, and inter-group tolerance. Psychological Inquiry, 18(3), 139-156.

Mikulincer, M., \& Shaver, P. R. (2008). Adult attachment and affect regulation. In J. Cassidy \& P. R. Shaver (Eds.), Handbook of attachment: Theory, research, and clinical applications (pp. 503-531). New York, NY: Guilford Press.

Mikulincer, M., \& Sheffi, E. (2000). Adult attachment style and cognitive reactions to positive affect: A test of mental categorization and creative problem solving. Motivation and Emotion, 24(3), 149-174.

Miyamoto, Y., \& Ma, X. (2011). Dampening or savoring positive emotions: A dialectical cultural script guides emotion regulation. Emotion, 11(6), 1346-1357. 
Mogilner, C., Aaker, J., \& Kamvar, S. D. (2012). How happiness affects choice. Journal of Consumer Research, 39(2), 429-443.

Mogilner, C., Kamvar, S. D., \& Aaker, J. (2011). The shifting meaning of happiness. Social Psychological and Personality Science, 2(4), 395-402.

Mrazek, M. D., Smallwood, J., \& Schooler, J. W. (2012). Mindfulness and mind-wandering: Finding convergence through opposing constructs. Emotion, 12(3), 442-448.

Mroczek, D. K., \& Almeida, D. M. (2004). The effect of daily stress, personality, and age on daily negative affect. Journal of Personality, 72(2), 355-378.

Mroczek, D. K., \& Kolarz, C. M. (1998). The effect of age on positive and negative affect: A developmental perspective on happiness. Journal of Personality and Social Psychology, 75, 1333-1349.

Nélis, D., Quoidbach, J., Hansenne, M., \& Mikolajczak, M. (2011). Measuring individual differences in emotion regulation: The Emotion Regulation Profile-Revised (ERP-R). Psychologica Belgica, 51, 49-91.

Oerlemans, W. G., \& Bakker, A. B. (2014). Why extravert are happier: A day reconstruction study. Journal of Research in Personality, 50, 11-22.

Ong, A. D., \& Bergeman, C. S. (2004). The complexity of emotions in later life. The Journals of Gerontology Series B: Psychological Sciences and Social Sciences, 59(3), P117-P122.

Orth, U., Robins, R. W., \& Widaman, K. F. (2012). Life-span development of self-esteem and its effects on important life outcomes. Journal of Personality and Social Psychology, 102(6), 1271-1288. 
Ostir, G. V., Markides, K. S., Black, S. A., \& Goodwin, J. S. (2000). Emotional well-being predicts subsequent functional independence and survival. Journal of the American Geriatrics Society, 48, 473-478.

Palmer, C. A., Ramsey, R. A., Morey, J. N., \& Gentzler, A. L. (2014). How do you share your positive events? Individual differences in capitalizing, bragging, and mass-sharing. Manuscript in preparation.

Parrot, G. W. (1993). Beyond hedonism: Motives for inhibiting good moods and for maintaining bad moods. In D. M. Wegner, \& J. W. Pennebaker (Eds.), Handbook of mental control (pp. 278-305). Upper Saddle River, NJ: Prentice-Hall.

Pettit, J. W., Kline, J., Gencoz, T., Gencoz, F., \& Joiner, T. (2001). Are happier people healthier? The specific role of positive affect in predicting self-reported health symptoms. Journal of Research in Personality, 35, 521-536.

Phillips, L. H., Bull, R., Adams, E., \& Fraser, L. (2002). Positive mood and executive function: Evidence from Stroop and fluency tasks. Emotion, 2, 21-22.

Phillips, L. H., Henry, J. D., Hosie, J. A., \& Milne, A. B. (2008). Effective regulation of the experience and expression of negative affect in old age. The Journals of Gerontology Series B: Psychological Sciences and Social Sciences, 63(3), P138-P145.

Pinquart, M. (2001). Correlates of subjective health in older adults: a meta-analysis. Psychology and Aging, 16, 414-26.

Quoidbach, J., Berry, E. V., Hansenne, M., \& Mikolajczak, M. (2010). Positive emotion regulation and well-being: Comparing the impact of eight savoring and dampening strategies. Personality and Individual Differences, 49(5), 368-373. 
Quoidbach, J., Dunn, E. W., Petrides, K. V., \& Mikolajczak, M. (2010). Money giveth, money taketh away: The dual effect of wealth on happiness. Psychological Science, 21, 759-763.

Ramsey, M. A., \& Gentzler, A. L. (2014). Age differences in subjective well-being across adulthood: The roles of savoring and future time perspective. The International Journal of Aging and Human Development, 78(1), 3-22.

Reis, H .T., Smith, S. M., Carmichael, C. L., Caprariello, P. A., Tsai, F. F., Rodrigues, A., \& Maniaci, M. R. (2010). Are you happy for me? How sharing positive events with others provides personal and interpersonal benefits. Journal of Personality and Social Psychology, 99, 311-329.

Riediger, M., Schmiedek, F., Wagner, G. G., \& Lindenberger, U. (2010). Seeking pleasure and seeking pain: Differences in prohedonic and contra-hedonic motivation from adolescence to old age. Psychological Science, 20(12), 1529-1535.

Ritchie, T. D., \& Bryant, F. B. (2012). Positive state mindfulness: A multidimensional model of mindfulness in relation to positive experience. International Journal of Wellbeing, 2(3), $150-181$.

Robinson, J. P., \& Godbey, G. (1997). Time for life: The surprising ways Americans use their time. University Park, PA: The Pennsylvania University Press.

Rosenberg, M. (1965). Society and the adolescent self-image. Princeton, NJ: Princeton University Press.

Rowe, G., Hirsh, J. B., \& Anderson, A. K. (2007). Positive affect increases the breadth of attentional selection. Proceedings of the National Academy of Sciences, 104(1), 383-388.

Rudd, M., Vohs, K. D., \& Aaker, J. (2012). Awe expands people’s perception of time, alters decision making, and enhances well-being. Psychological Science, 23(10), 1130-1136. 
Scheibe, S., \& Carstensen, L. L. (2010). Emotional aging: Recent findings and future trends. Journal of Gerontology: Psychological Sciences, 65, 135-144.

Scheibe, S., English, T., Tsai, J. L., \& Carstensen, L. L. (2013). Striving to feel good: Ideal affect, actual affect, and their correspondence across adulthood. Psychology and Aging, 28(1), 160-171.

Schmid, P. C., Schmid Mast, M., Bombari, D., Mast, F. W., \& Lobmaier, J. S. (2011). How mood states affect information processing during facial emotion recognition: An eye tracking study. Swiss Journal of Psychology, 70(4), 223-231.

Schmitt, D. P., \& Allik, J. (2005). Simultaneous administration of the Rosenberg Self-Esteem Scale in 53 nations: Exploring the universal and culture-specific features of global selfesteem. Journal of Personality and Social Psychology, 89(4), 623-642.

Schmitz, T. W., De Rosa, E., \& Anderson, A. K. (2009). Opposing influences of affective state valence on visual cortical encoding. Journal of Neuroscience, 29, 7199-207.

Schooler, J. W., Ariely, D., \& Loewenstein, G. (2003). The pursuit and assessment of happiness may be self-defeating. In I. Brocas \& J. D. Carillo (Eds.), The psychology of economic decisions. Volume 1: Rationality and well-being (pp. 41-70). New York: Oxford University Press.

Segel-Karpas, D., Bamberger, P. A., \& Bacharach, S. B. (2013). Income decline and retiree wellbeing: The moderating role of attachment. Psychology and Aging, 28(4), 1098-1107.

Seligman, M. E. P., Steen, T., Park, N., \& Peterson, C. (2005). Positive psychology progress: Empirical validation of interventions. American Psychologist, 60, 410-421. 
Shaver, P. R., \& Hazan, C. (1993). Adult romantic attachment: Theory and evidence. In D. Perlman \& W. Jones (Eds.), Advances in personal relationships (Vol. 4, pp. 29-70). London, England: Kingsley.

Shrout, P. E., \& Bolger, N. (2002). Mediation in experimental and nonexperimental studies: New procedures and recommendations. Psychological Methods, 7, 422-445.

Shiota, M. N., Keltner, D., \& John, O. P. (2006). Positive emotion dispositions differentially associated with Big Five Personality and Attachment Style. Journal of Positive Psychology, 1, 61-71.

Sin, N. L., \& Lyubomirsky, S. (2009). Enhancing well-being and alleviating depressive symptoms with positive psychology interventions: A practice-friendly meta-analysis. Journal of Clinical Psychology: In Session, 65, 467-487.

Smallwood, J., Fitzgerald, A., Miles, L. K., \& Phillips, L. H. (2009). Shifting moods, wandering minds: Negative moods lead the mind to wander. Emotion, 9(2), 271-276.

Sonnentag, S. (2012). Psychological detachment from work during leisure time: The benefits of mentally disengaging from work. Current Directions in Psychological Science, 21, 114118.

Stanley, J. T., \& Isaacowitz, D. M. (2011). Age-related differences in profiles of mood-change trajectories. Developmental Psychology, 47, 318-330.

Swann, W. B., Jr. (2011). Self-verification theory. In P. Van Lang, A. Kruglanski, \& E. T. Higgins (Eds.), Handbook of theories of social psychology (pp. 23-42). London, England: Sage. 
Swann, W. B., Jr., \& Schroeder, D.G. (1995). The search for beauty and truth: A framework for understanding reactions to evaluations. Personality and Social Psychology Bulletin, 21, 1307-1318.

Talarico, J. M., Berntsen, D., \& Rubin, D. C. (2009). Positive emotions enhance recall of peripheral details. Cognition and Emotion, 23, 380-398.

Tamir, M. (2009). Differential preferences for happiness; Extraversion and trait-consistent emotion regulation. Journal of Personality, 77, 447-470.

Teper, R., Segal, Z. V., \& Inzlicht, M. (2013). Inside the mindful mind: How mindfulness enhances emotion regulation through improvements in executive control. Current Directions in Psychological Science, 22(6), 449-454.

Thoman, D. B. (2011). The resource replenishment function of interest. Social Psychological and Personality Science, 2, 592-599.

Mata, J., Thompson, R. J., Jaeggi, S. M., Buschkuehl, M., Jonides, J., \& Gotlib, I. H. (2012). Walk on the bright side: Physical activity and affect in major depressive disorder. Journal of Abnormal Psychology, 121(2), 297.

Tidwell, M., Reis, H. T., \& Shaver, P. R. (1996). Attachment styles, attractiveness, and emotions in social interactions: A diary study. Journal of Personality and Social Psychology, 71, 729-745.

Tooby, J., \& Cosmides, L. (2008). The evolutionary psychology of the emotions and their relationship to internal regulatory variables. In M. Lewis, J. M. Haviland-Jones, \& L. F. Barrett (Eds.), Handbook of emotions (3nd ed., pp. 114-137). New York, NY: Guilford Press. 
Tsang, J. (2006). Gratitude and prosocial behavior: An experimental test of gratitude. Cognition and Emotion, 20, 138-148.

Urry, H. L., \& Gross, J. J. (2010). Emotion regulation in older age. Current Directions in Psychological Science, 19, 352-357.

Veenhoven, R. (1988). The utility of happiness. Social Indicators Research, 20, 333-354.

Veenhoven, R. (2008). Healthy happiness: Effects of happiness on physical health and the consequences for preventive health care. Journal of Happiness Studies, 9, 449-464.

Verduyn, P., Delvaux, E., Van Coillie, H., Tuerlinckx, F., \& Van Mechelen, I. (2009). Predicting the duration of emotional experience: Two experience sampling studies. Emotion, 9, 8391.

Verduyn, P., Van Mechelen, I., \& Tuerlinckx, F. (2011). The relation between event processing and the duration of emotional experience. Emotion, 11, 20-28.

Wagner, B. M., Compas, B. E., \& Howell, D. C. (1988). Daily and major life events: A test of an integrative model of psychosocial stress. American Journal of Community Psychology, 16(2), 189-205.

Wang, L., Zhang, Z., McArdle, J. J., \& Salthouse, T. A. (2008). Investigating ceiling effects in longitudinal data analysis. Multivariate Behavioral Research, 43(3), 476-496.

Warner, R. M., \& Vroman, K. G. (2011). Happiness inducing behaviors in everyday life: An empirical assessment of "the how of happiness". Journal of Happiness Studies, 12(6), 1063-1082.

Watkins, P. C., Woodward, K., Stone, T., \& Kolts, R. L. (2003). Gratitude and happiness: Development of a measure of gratitude, and relationships with subjective well-being. Social Behavior and Personality, 31, 431-452. 
Watson, D., \& Clark, L. A. (1994). Manual for the Positive and Negative Affect Schedule (Expanded Form). Unpublished manuscript. University of Iowa, Iowa City.

Watson, D., Clark, L. A., \& Tellegen, A. (1988). Development and validation of brief measures of positive and negative affect: The PANAS scales. Journal of Personality and Social Psychology, 54, 1963-1070.

Weiner, B. (1985). An attributional theory of achievement motivation and emotion. Psychological Review, 92, 548-573.

Werner-Seidler, A., Banks, R., Dunn, B. D., \& Moulds, M. L. (2013). An investigation of the relationship between positive affect regulation and depression. Behaviour Research and Therapy, 51(1), 46-56.

Wilson, T. D., Centerbar, D. B., Kermer, D. A., \& Gilbert, D. T. (2005). The pleasures of uncertainty: Prolonging positive moods in ways people do not anticipate. Journal of Personality and Social Psychology, 88, 5-21.

Wohlwill, J. (1970). The age variable in psychological research. Psychological Review, 77, 4964.

Wong, E., Tschan, F., Messerli, L., \& Semmer, N. K. (2013). Expressing and amplifying positive emotions facilitate goal attainment in workplace interactions. Frontiers in Psychology, 4, 188-227.

Wood, J. V., Heimpel, S. A., \& Michela, J. L. (2003). Savoring versus dampening: Self-esteem differences in regulating positive affect. Journal of Personality and Social Psychology, 85(3), 566-580. 
Wood, J., Heimpel, S., Newby-Clark, I., \& Ross, M. (2005). Snatching defeat from the jaws of victory: Self-esteem differences in the experience and anticipation of success. Journal of Personality and Social Psychology, 89, 764-780.

Zimbardo, P. G., \& Boyd, J. N. (1999). Putting time into perspective: A valid, reliable individual-differences metric. Journal of Personality and Social Psychology, 77, 12711288. 
Table 1

Demographics by Age

\begin{tabular}{|c|c|c|c|}
\hline & $\begin{array}{l}\text { Younger Adults } \\
(n=38)\end{array}$ & $\begin{array}{l}\text { Middle-Aged Adults } \\
(n=48)\end{array}$ & $\begin{array}{l}\text { Older Adults } \\
(n=44)\end{array}$ \\
\hline Age & $\begin{array}{l}M=20.92 S D=2.96 \\
\text { Range }=18-27\end{array}$ & $\begin{array}{l}M=42.87 S D=10.29 \\
\text { Range }=30-59\end{array}$ & $\begin{array}{l}M=66.58 S D=7.17 \\
\text { Range }=60-94\end{array}$ \\
\hline Gender & $60.5 \%$ female $(n=23)$ & $57.9 \%$ female $(n=22)$ & $68.2 \%$ female $(n=30)$ \\
\hline $\begin{array}{l}\text { Marital } \\
\text { Status }\end{array}$ & $\begin{array}{l}\text { Single }(\mathrm{n}=33) \\
\text { Married }(\mathrm{n}=1) \\
\text { Cohabiting }(\mathrm{n}=3) \\
\text { Widowed }(\mathrm{n}=0) \\
\text { Divorced/Separated }(\mathrm{n}=0) \\
\text { Prefer not to answer }(\mathrm{n}=1)\end{array}$ & $\begin{array}{l}\text { Single }(n=10) \\
\text { Married }(n=23) \\
\text { Cohabiting }(n=3) \\
\text { Widowed }(n=0) \\
\text { Divorced/Separated }(n=2) \\
\text { Prefer not to answer }(n=0)\end{array}$ & $\begin{array}{l}\text { Single }(n=5) \\
\text { Married }(n=24) \\
\text { Cohabiting }(n=0) \\
\text { Widowed }(n=5) \\
\text { Divorced/Separated }(n=9) \\
\text { Prefer not to answer }(n=0)\end{array}$ \\
\hline Ethnicity & 84.2\% White/Caucasian & 89.5\% White/Caucasian & 88.6\% White/Caucasian \\
\hline Education & $M=$ Some college & $M=$ Graduated college & $M=$ Some graduate school \\
\hline $\begin{array}{l}\text { Difficulty } \\
\text { Paying } \\
\text { Bills }\end{array}$ & A little & Not at all & Not at all \\
\hline $\begin{array}{l}\text { Retirement } \\
\text { Status }\end{array}$ & $n=0$ & $n=1$ & $n=20$ \\
\hline
\end{tabular}


Table 2

Preliminary Correlations, Means, and Standard Deviations for all Demographic and Individual Difference Variables and Baseline Emotions

\begin{tabular}{|c|c|c|c|c|c|c|}
\hline & $\begin{array}{l}M(S D) \\
\text { Range }\end{array}$ & Age & Gender & $\begin{array}{c}\text { Difficulty } \\
\text { Paying } \\
\text { Bills } \\
\end{array}$ & Education & $\begin{array}{c}\text { Retirement } \\
\text { Status }\end{array}$ \\
\hline BL PA & $\begin{array}{c}5.76(1.58) \\
1.4-14.1\end{array}$ & .14 & $.21^{*}$ & .07 & .05 & -.17 \\
\hline BL HAP & $\begin{array}{c}5.61(1.59) \\
1.6-9\end{array}$ & .13 & .15 & -.02 & .08 & -.17 \\
\hline BL LAP & $\begin{array}{c}7.08(1.41) \\
3.67-9\end{array}$ & .03 & .15 & .05 & -.04 & -.04 \\
\hline BL NA & $\begin{array}{c}1.43(.82) \\
1-6.8\end{array}$ & $-.27 * *$ & .05 & $.22 *$ & -.11 & $.19 *$ \\
\hline BL Poignancy & $\begin{array}{c}1.41(.74) \\
1-5\end{array}$ & $-.27 * *$ & .07 & $.21^{*}$ & -.13 & .18 \\
\hline PPE PA & $\begin{array}{c}6.45(1.36) \\
2.3-9\end{array}$ & .14 & .16 & -.07 & .11 & -.15 \\
\hline PРE HAP & $\begin{array}{c}6.62(1.55) \\
2.5-9\end{array}$ & .03 & .07 & -.07 & .07 & -.09 \\
\hline PPE LAP & $\begin{array}{c}6.83(1.65) \\
2-9\end{array}$ & .08 & $.28 * *$ & -.06 & .04 & -.08 \\
\hline PPA NA & $\begin{array}{c}1.25(.62) \\
1-4.4\end{array}$ & -.13 & .11 & .17 & -.09 & .04 \\
\hline PPE Poignancy & $\begin{array}{c}1.25(.61) \\
1-4\end{array}$ & -.13 & .11 & .16 & -.09 & .05 \\
\hline $\begin{array}{l}\text { Anxious } \\
\text { Attachment }\end{array}$ & $\begin{array}{c}2.67(1.31) \\
1-6.44\end{array}$ & $-.21 *$ & .06 & $.35^{* * *}$ & -.18 & .16 \\
\hline Self-Esteem & $\begin{array}{c}3.39(.47) \\
2.3-4\end{array}$ & .18 & .02 & $-.31 * *$ & $.21^{*}$ & $-.21^{*}$ \\
\hline FTP & $\begin{array}{c}4.94(1.2) \\
2-7\end{array}$ & $-.52 * * *$ & -.02 & -.01 & $-.19 *$ & $.31^{* *}$ \\
\hline FTP: Limitations & $\begin{array}{c}3.57(1.5) \\
1-7\end{array}$ & $.26^{* *}$ & .09 & .08 & .07 & $-.26 * *$ \\
\hline $\begin{array}{l}\text { FTP: } \\
\text { Opportunities }\end{array}$ & $\begin{array}{c}5.17(1.28) \\
2-7\end{array}$ & $-.58^{* * *}$ & .01 & .04 & $-.22 * *$ & $.29 * *$ \\
\hline $\begin{array}{l}\text { Perceptions of } \\
\text { Free Time }\end{array}$ & $\begin{array}{c}3.76(1.40) \\
1-7\end{array}$ & $.22^{*}$ & .17 & -.13 & .07 & .16 \\
\hline Trait Savoring & $\begin{array}{c}5.80(.91) \\
3-7\end{array}$ & .16 & -.06 & -.17 & .05 & -.17 \\
\hline Mindfulness & $\begin{array}{c}4.02(.86) \\
2-7\end{array}$ & $.23^{*}$ & -.05 & -.14 & .08 & $-.25 * *$ \\
\hline
\end{tabular}

Note. ${ }^{*} p<.05,{ }^{* *} p<.01,{ }^{* * *} p<.001$. Gender is coded as $1=$ female and $2=$ male. Retirement status is coded as $1=$ yes and $2=$ no. $\mathrm{BL}=$ baseline, $\mathrm{PPE}=$ post-positive event recall, $\mathrm{HAP}=$ high-arousal PA, LAP = low-arousal PA, FTP = future time perspective. 
Table 3

Preliminary Bivariate and Partial Correlations, Means, and Standard Deviations for all PostTask Variables and Demographics for the Savoring Group

\begin{tabular}{|c|c|c|c|c|c|c|}
\hline & $\begin{array}{c}M(S D) \\
\text { Range }\end{array}$ & Age & Gender & $\begin{array}{c}\text { Difficult } \\
\text { Paying } \\
\text { Bills }\end{array}$ & Education & $\begin{array}{c}\text { Retirement } \\
\text { Status }\end{array}$ \\
\hline PT PA & $\begin{array}{c}6.44(1.52) \\
1.3-9\end{array}$ & .07 & .01 & -.07 & .07 & .002 \\
\hline PT HAP & $\begin{array}{c}6.78(1.67) \\
1.63-9\end{array}$ & .15 & .19 & -.04 & .17 & -.04 \\
\hline PT LAP & $\begin{array}{c}7.43(1.44) \\
3.67-9\end{array}$ & -.08 & $.27 *$ & .03 & -.07 & .16 \\
\hline PT NA & $\begin{array}{c}1.16(.51) \\
1-3.8\end{array}$ & .02 & -.17 & .19 & .12 & .04 \\
\hline PT Poignancy & $\begin{array}{c}1.16(.51) \\
1-4\end{array}$ & .02 & -.16 & .19 & .12 & .04 \\
\hline Impatience & $\begin{array}{l}2.32(.81) \\
1.13-4.13\end{array}$ & -.19 & -.23 & -.03 & -.20 & .08 \\
\hline Effort & $\begin{array}{c}66.17(30.34) \\
0-100\end{array}$ & -.05 & $.26^{*}$ & -.01 & -.12 & -.18 \\
\hline Distraction & $\begin{array}{c}27.08(26.51) \\
0-90\end{array}$ & -.19 & .04 & -.08 & -.20 & 1.5 \\
\hline Global-Local & $\begin{array}{c}.72(.31) \\
0-1\end{array}$ & -.17 & $.29 *$ & .25 & -.15 & .01 \\
\hline TAR & $\begin{array}{c}10.30(5.38) \\
2-20\end{array}$ & .02 & -.15 & .05 & .07 & .19 \\
\hline
\end{tabular}

Note. ${ }^{*} p<.05,{ }^{* *} p<.01,{ }^{* * *} p<.001$. Gender is coded as $1=$ female and $2=$ male. Retirement status is coded as $1=$ yes and $2=$ no. All analyses concerning the affect subscales controlled for the post-event recall affect score for that respective scale. $\mathrm{PT}=$ post-task, HAP $=$ high-arousal $\mathrm{PA}, \mathrm{LAP}=$ low-arousal PA, TAR $=$ thought-action repertoires. 
Table 4

Preliminary Bivariate and Partial Correlations, Means, and Standard Deviations for all PostTask Variables and Demographics for the Control Group

\begin{tabular}{|c|c|c|c|c|c|c|}
\hline & $\begin{array}{l}M(S D) \\
\text { Range }\end{array}$ & Age & Gender & $\begin{array}{c}\text { Difficulty } \\
\text { Paying } \\
\text { Bills }\end{array}$ & Education & $\begin{array}{l}\text { Retirement } \\
\text { Status }\end{array}$ \\
\hline PT PA & $\begin{array}{c}5.80(1.57) \\
2.3-8.3\end{array}$ & .17 & .23 & $-.34^{*}$ & .14 & -.20 \\
\hline PT HAP & $\begin{array}{c}5.60(1.62) \\
1.88-8.63\end{array}$ & .21 & .27 & $-.29 *$ & .21 & -.21 \\
\hline PT LAP & $\begin{array}{c}7.07(1.64) \\
1.67-9\end{array}$ & .06 & -.16 & -.09 & -.03 & -.06 \\
\hline PT NA & $\begin{array}{c}1.41(1.06) \\
1-7.6\end{array}$ & -.11 & .08 & -.10 & .003 & .02 \\
\hline PT Poignancy & $\begin{array}{c}1.36(.80) \\
1-5\end{array}$ & -.11 & .08 & -.10 & .003 & .02 \\
\hline Impatience & $\begin{array}{c}2.70(.92) \\
1-5.25\end{array}$ & -.13 & -.13 & -.04 & .06 & .04 \\
\hline Effort & $\begin{array}{c}71.83(27.06) \\
0-100\end{array}$ & -.03 & -.07 & .10 & -.04 & .10 \\
\hline Distraction & $\begin{array}{c}25.75(24.65) \\
0-100\end{array}$ & -.14 & -.09 & .00 & .02 & .23 \\
\hline Global-Local & $\begin{array}{c}.73(.29) \\
0-1\end{array}$ & -.002 & -.15 & $.27^{*}$ & .02 & .03 \\
\hline TAR & $\begin{array}{c}10.98(5.47) \\
3-20 \\
\end{array}$ & .19 & -.13 & $-.30 *$ & .22 & .09 \\
\hline
\end{tabular}

Note. ${ }^{*} p<.05,{ }^{* *} p<.01,{ }^{* * *} p<.001$. Gender is coded as $1=$ female and $2=$ male. Retirement status is coded as $1=$ yes and $2=$ no. All analyses concerning the affect subscales controlled for the post-event recall affect score for that respective scale. $\mathrm{PT}=$ post-task, $\mathrm{HAP}=$ high-arousal PA, LAP = low-arousal PA, TAR = thought-action repertoires. 
Table 5

Preliminary Correlations between all Individual Difference Variables and Baseline Emotions

\begin{tabular}{|c|c|c|c|c|c|c|c|c|c|c|c|c|c|c|c|c|c|}
\hline & 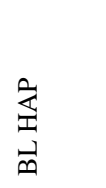 & $\begin{array}{l}\stackrel{\overbrace{}}{\leftrightarrows} \\
\vec{m}\end{array}$ & $\begin{array}{l}\overleftrightarrow{z} \\
\vec{n}\end{array}$ & 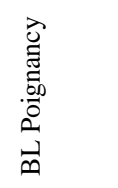 & $\begin{array}{l}\mathbb{a} \\
\text { 新 } \\
\text { a. }\end{array}$ & 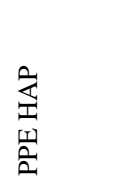 & 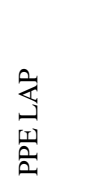 & $\begin{array}{l}\mathbb{z} \\
\text { cry } \\
\text { a }\end{array}$ & 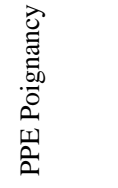 & 空 & 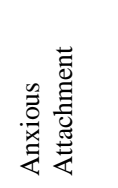 & 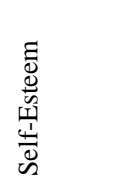 & 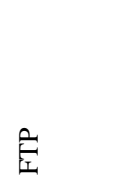 & : & 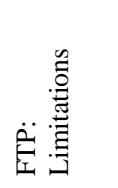 & 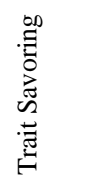 & 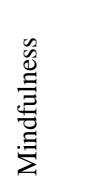 \\
\hline BL PA & $.75^{* * *}$ & $.37 * * *$ & -.15 & -.15 & $.73^{* * *}$ & $.58^{* * *}$ & $.51^{* * *}$ & -.10 & -.10 & .08 & -.18 & $.34 * * *$ & .10 & .08 & -.08 & $.28 * * *$ & $.27 * *$ \\
\hline BL HAP & & $.57^{* * *}$ & $-.29 * *$ & $-.30 * *$ & $.68^{* * *}$ & $.75^{* * *}$ & $.63^{* * *}$ & $-.22^{* *}$ & $-.22^{*}$ & .05 & $-.34 * * *$ & $.30 * *$ & .07 & .05 & -.05 & $.37 * * *$ & $.22 *$ \\
\hline BL LAP & & & $-.42 * * *$ & $-.43^{* * *}$ & $.31 * *$ & $.52 * * *$ & $.72 * * *$ & $-.33^{* * *}$ & $-.33^{* * *}$ & .07 & $-.24 *$ & .17 & .05 & .06 & -.002 & $.32 * * *$ & $.19 *$ \\
\hline BL NA & & & & $.99 * * *$ & -.18 & $-.31^{* *}$ & $-.31^{* *}$ & $.82 * * *$ & $.82^{* * *}$ & -.13 & $.46^{* * *}$ & $-.27 * *$ & -.01 & .05 & .10 & $-.21^{*}$ & $-.27 * *$ \\
\hline BL Poignancy & & & & & -.18 & $-.33^{* * *}$ & $-.31^{* *}$ & $.84 * * *$ & $.84 * * *$ & -.13 & $.49 * * *$ & $-.27 * *$ & -.01 & .04 & .07 & $-.22 *$ & $-.31^{* *}$ \\
\hline PPE PA & & & & & & $.84^{* * *}$ & $.42^{* * *}$ & -.12 & -.12 & -.03 & $-.22 *$ & $.28 * *$ & .10 & .13 & -.01 & $.38 * * *$ & $.20^{*}$ \\
\hline PPE HAP & & & & & & & $.51^{* * *}$ & $-.28 * *$ & $-.28 * *$ & -.02 & $-.30^{* *}$ & $.23 *$ & $.18^{*}$ & $.19 *$ & -.08 & $.42^{* * *}$ & .18 \\
\hline PPE LAP & & & & & & & & $-.25^{* *}$ & $-.25^{*}$ & .15 & -.17 & $.20^{*}$ & .03 & .04 & .00 & $.38^{* * *}$ & $.24 *$ \\
\hline PPE NA & & & & & & & & & $1^{* * *}$ & -.004 & $.35^{* * *}$ & $-.23^{*}$ & -.07 & -.03 & .11 & $-.21^{*}$ & $-.29 * *$ \\
\hline $\begin{array}{l}\text { PPE } \\
\text { Poignancy }\end{array}$ & & & & & & & & & & -.01 & $.36^{* * *}$ & $-.23^{*}$ & -.07 & -.03 & .11 & $-.21^{*}$ & $-.29 * *$ \\
\hline PFT & & & & & & & & & & & .002 & .04 & -.14 & -.16 & .05 & .14 & $.26 * *$ \\
\hline $\begin{array}{l}\text { Anxious } \\
\text { Attachment }\end{array}$ & & & & & & & & & & & & $-.50^{* * *}$ & $-.20^{* * *}$ & -.08 & $.36^{* * *}$ & $-.28^{* *}$ & $-.22^{*}$ \\
\hline Self-Esteem & & & & & & & & & & & & & $.26 * *$ & $.25^{* *}$ & $-.21^{*}$ & $.41^{* * *}$ & $.40^{* * *}$ \\
\hline FTP & & & & & & & & & & & & & & $.94^{* * *}$ & $-.77 * * *$ & .16 & .01 \\
\hline $\begin{array}{l}\text { FTP: } \\
\text { Opportunities }\end{array}$ & & & & & & & & & & & & & & & $-.50^{* * *}$ & .12 & -.003 \\
\hline $\begin{array}{l}\text { FTP: } \\
\text { Limitations }\end{array}$ & & & & & & & & & & & & & & & & -.06 & -.02 \\
\hline Trait Savoring & & & & & & & & & & & & & & & & & $.31^{* *}$ \\
\hline
\end{tabular}


Table 6

Preliminary Correlations between Individual Difference Variables, Emotion Difference Scores, and Post-Task Variables for the Savoring Group

\begin{tabular}{|c|c|c|c|c|c|c|c|c|c|c|}
\hline & 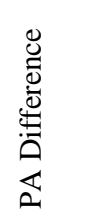 & 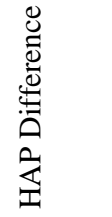 & 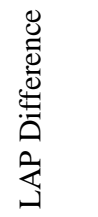 & 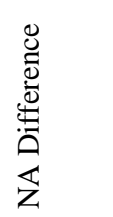 & 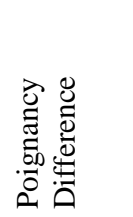 & $\begin{array}{l}\overline{\widetilde{U}} \\
0 \\
\frac{1}{\pi} \\
\frac{1}{\pi} \\
0 \\
0 \\
0\end{array}$ & 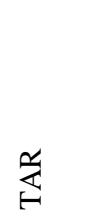 & 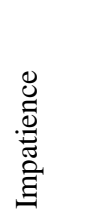 & $\underset{\text { 壳 }}{\stackrel{5}{0}}$ & 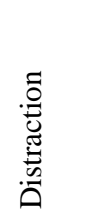 \\
\hline Perceptions of Free Time & .17 & .13 & -.22 & .16 & .16 & $-.26^{*}$ & .01 & .05 & .07 & .11 \\
\hline Anxious Attachment & .07 & .15 & -.002 & .13 & .13 & -.01 & .13 & .14 & .09 & .23 \\
\hline Self-Esteem & -.20 & -.14 & -.03 & .05 & .05 & .01 & -.17 & -.18 & .09 & -.22 \\
\hline FTP & -.06 & -.08 & .003 & .01 & .01 & -.02 & .22 & -.04 & -.13 & $-.29 *$ \\
\hline FTP: Opportunities & -.09 & -.04 & -.05 & .01 & .01 & -.03 & .19 & -.04 & .01 & -.25 \\
\hline FTP: Limitations & -.01 & .12 & -.11 & .01 & .01 & -.01 & -.19 & .03 & $.35^{* *}$ & $.26 *$ \\
\hline Trait savoring & -.16 & -.23 & -.20 & .09 & .09 & -.03 & -.09 & -.23 & .07 & $-.34 * *$ \\
\hline Mindfulness & -.17 & -.10 & $-.32 *$ & .19 & .19 & -.12 & -.06 & -.01 & -.04 & $-.36 * *$ \\
\hline PA Difference & & $.68 * * *$ & .07 & -.12 & -.12 & $-.37 * *$ & -.02 & -.02 & $-.25 *$ & .03 \\
\hline HAP Difference & & & .03 & $-.33^{*}$ & $-.33^{*}$ & $-.31 *$ & .001 & -.04 & -.02 & .05 \\
\hline LAP Difference & & & & $-.52 * *$ & $-.52 * * *$ & .13 & -.03 & .03 & -.06 & $-.26 *$ \\
\hline NA Difference & & & & & $1^{* * *}$ & -.01 & .12 & -.08 & -.13 & -.10 \\
\hline Poignancy Difference & & & & & & -.01 & .12 & -.08 & -.13 & -.10 \\
\hline Global-Local & & & & & & & -.06 & -.004 & .18 & .06 \\
\hline TAR & & & & & & & & -.12 & -.18 & -.14 \\
\hline Impatience & & & & & & & & & -.06 & $.56 *$ \\
\hline Effort & & & & & & & & & & .11 \\
\hline
\end{tabular}


Table 7

Preliminary Correlations between Individual Difference Variables, Emotion Difference Scores, and Post-Task Variables for the Control Group

\begin{tabular}{|c|c|c|c|c|c|c|c|c|c|c|}
\hline & 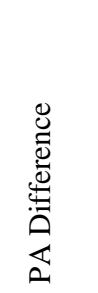 & 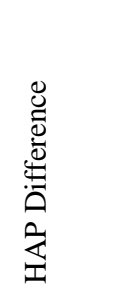 & 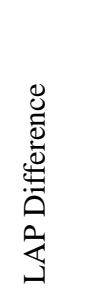 & 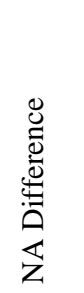 & 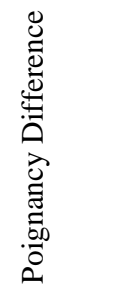 & $\begin{array}{l}\bar{\Xi} \\
0 \\
0 \\
\frac{1}{\pi} \\
0 \\
0 \\
0\end{array}$ & 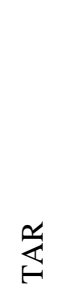 & 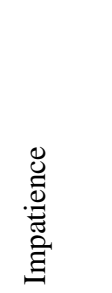 & 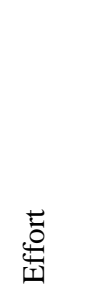 & 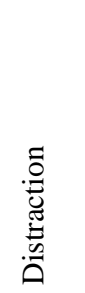 \\
\hline Perceptions of Free Time & .15 & .13 & .05 & -.19 & -.13 & .03 & .05 & -.03 & -.02 & -.12 \\
\hline Anxious Attachment & .03 & -.02 & -.13 & .09 & -.06 & .01 & -.18 & -.003 & .00 & -.06 \\
\hline Self-Esteem & $.26 *$ & $.31 *$ & -.03 & -.17 & -.01 & .13 & .19 & -.02 & -.11 & -.02 \\
\hline FTP & -.14 & -.10 & .04 & .03 & .12 & .001 & .02 & .18 & .03 & -.04 \\
\hline FTP: Opportunities & -.17 & -.15 & -.001 & .14 & .08 & .01 & -.02 & .17 & .08 & -.05 \\
\hline FTP: Limitations & .01 & -.04 & -.07 & .19 & .02 & .004 & -.10 & -.11 & .08 & -.08 \\
\hline Trait savoring & .08 & .16 & .10 & -.25 & -.20 & .01 & .10 & -.20 & -.07 & -.08 \\
\hline Mindfulness & .18 & .20 & -.08 & -.11 & -.11 & .12 & -.01 & $-.30 *$ & .002 & -.04 \\
\hline PA Difference & & $.86^{* * *}$ & $-.37 * *$ & -.07 & -.01 & .001 & $.26 *$ & $-.41 * *$ & .04 & -.07 \\
\hline HAP Difference & & & -.24 & -.25 & -.16 & .04 & .17 & $-.37 * *$ & .05 & -.05 \\
\hline LAP Difference & & & & -.10 & -.08 & .17 & -.08 & .13 & .05 & .02 \\
\hline NA Difference & & & & & $.77 * * *$ & -.15 & .01 & .16 & .09 & .21 \\
\hline Poignancy Difference & & & & & & -.08 & .01 & .20 & .25 & .12 \\
\hline Global-Local & & & & & & & -.14 & -.01 & .12 & .05 \\
\hline TAR & & & & & & & & -.15 & -.16 & .15 \\
\hline Impatience & & & & & & & & $a$ & .01 & $.31 *$ \\
\hline Effort & & & & & & & & & & .04 \\
\hline
\end{tabular}


Table 8

Self-Esteem Predicting Post-Task Affect

\begin{tabular}{|c|c|c|c|c|c|c|c|c|c|c|c|c|c|c|c|}
\hline \multirow[b]{3}{*}{ Predictor } & \multicolumn{3}{|c|}{ Positive Affect } & \multicolumn{3}{|c|}{ High-Arousal Positive Affect } & \multicolumn{3}{|c|}{ Low-Arousal Positive Affect } & \multicolumn{3}{|c|}{ Negative Affect } & \multicolumn{3}{|c|}{ Poignancy } \\
\hline & & Beta & & & Beta & & & Beta & & & Beta & & & Beta & \\
\hline & $R^{2}$ & (SE) & $95 \%$ CI & $R^{2}$ & (SE) & $95 \% \mathrm{CI}$ & $R^{2}$ & (SE) & $95 \%$ CI & $R^{2}$ & (SE) & $95 \% \mathrm{CI}$ & $R^{2}$ & (SE) & $95 \%$ CI \\
\hline Group & $.66^{* * *}$ & $\begin{array}{l}4.12 * * * \\
(1.03)\end{array}$ & 2.09, 6.15 & $.67 * * *$ & $\begin{array}{l}4.84 * * * \\
(1.24)\end{array}$ & $2.38,7.29$ & $.64^{* * *}$ & $\begin{array}{l}1.72 \\
(1.71)\end{array}$ & $-1.67,5.11$ & $.71^{* * *}$ & $\begin{array}{l}-.94 \\
(1.24)\end{array}$ & $-3.40,1.52$ & $.79 * * *$ & $\begin{array}{l}-.17 \\
(.42)\end{array}$ & $-1.02,1.07$ \\
\hline SE & & $\begin{array}{l}1.72^{* *} \\
(.53)\end{array}$ & $.66,2.77$ & & $\begin{array}{l}2.03^{* * *} \\
(.59)\end{array}$ & $.87,3.19$ & & $\begin{array}{l}.64 \\
(.84)\end{array}$ & $-1.03,2.30$ & & $\begin{array}{l}-.42 \\
(.62)\end{array}$ & $-1.64, .80$ & & $\begin{array}{l}-.05 \\
(.20)\end{array}$ & $-.44, .34$ \\
\hline $\begin{array}{l}\text { Post Event } \\
\text { Affect }\end{array}$ & & $\begin{array}{l}.87^{* * *} \\
(.05)\end{array}$ & $.76, .98$ & & $\begin{array}{l}.79 * * * \\
(.06)\end{array}$ & $.66, .91$ & & $\begin{array}{l}.74 * * * \\
(.07)\end{array}$ & $.59, .89$ & & $\begin{array}{l}1.13^{* * *} \\
(.23)\end{array}$ & $.68,1.58$ & & $\begin{array}{l}.96^{* * *} \\
(05)\end{array}$ & $.87,1.06$ \\
\hline SE X Group & & $\begin{array}{l}-.93^{* *} \\
(.29)\end{array}$ & $-1.51,-.36$ & & $\begin{array}{l}-1.05^{* *} \\
(.35)\end{array}$ & $-1.74,-.35$ & & $\begin{array}{l}-.44 \\
(.48)\end{array}$ & $-1.39, .50$ & & $\begin{array}{l}.24 \\
(.35)\end{array}$ & $-.44, .93$ & & $\begin{array}{l}.03 \\
(.12)\end{array}$ & $-.22, .27$ \\
\hline
\end{tabular}

Note. ${ }^{* *} p<.001,{ }^{* *} p<.01$. Group is coded as $1=$ control and $2=$ savoring. The findings for each model remained even when controlling for difficulty paying bills, education, and retirement status. SE = Self-esteem. 
Table 9

Anxious Attachment Predicting Post-Task Affect

\begin{tabular}{|c|c|c|c|c|c|c|c|c|c|c|c|c|c|c|c|}
\hline \multirow[b]{3}{*}{ Predictor } & \multicolumn{3}{|c|}{ Positive Affect } & \multicolumn{3}{|c|}{ High-Arousal Positive Affect } & \multicolumn{3}{|c|}{ Low-Arousal Positive Affect } & \multicolumn{3}{|c|}{ Negative Affect } & \multicolumn{3}{|c|}{ Poignancy } \\
\hline & \multirow[b]{2}{*}{$R^{2}$} & \multicolumn{2}{|l|}{ Beta } & \multicolumn{3}{|c|}{ Beta } & \multicolumn{3}{|c|}{ Beta } & \multicolumn{3}{|c|}{ Beta } & \multicolumn{3}{|c|}{ Beta } \\
\hline & & (SE) & $95 \%$ CI & $R^{2}$ & (SE) & $95 \%$ CI & $R^{2}$ & (SE) & $95 \% \mathrm{CI}$ & $R^{2}$ & (SE) & $95 \% \mathrm{CI}$ & $R^{2}$ & (SE) & $95 \% \mathrm{CI}$ \\
\hline Group & $.63^{* * *}$ & .83 & $-.03,1.68$ & $.64^{* * *}$ & .80 & $-.12,1.72$ & $.62 * * *$ & .01 & $-.71, .72$ & $.72 * * *$ & -.07 & $-.45, .31$ & $.81 * * *$ & -.15 & $-.40, .10$ \\
\hline & & $(.43)$ & & & $(.47)$ & & & $(.36)$ & & & (.19) & & & $(.13)$ & \\
\hline Anxious & & -.02 & $-.52, .48$ & & -.24 & $-.76, .28$ & & -.22 & $-.74, .30$ & & $.02(.16)$ & $-.29, .33$ & & -.05 & $-.18, .09$ \\
\hline Attachment & & $(.25)$ & & & $(.26)$ & & & $(.26)$ & & & & & & $(.07)$ & \\
\hline Post Event & & $.88 * * *$ & $.76, .99$ & & $.78^{* * *}$ & $.64, .91$ & & $.69^{* * *}$ & $.54, .83$ & & $1.14^{* * *}$ & $.67,1.61$ & & $.97 * * *$ & $.87,1.07$ \\
\hline Affect & & $(.06)$ & & & $(.07)$ & & & $(.07)$ & & & $(.24)$ & & & $(.05)$ & \\
\hline Anxious & & .01 & $-.27, .29$ & & .14 & $-.17, .44$ & & .07 & $-.23, .36$ & & -.01 & $-.19, .17$ & & .03 & $-.05, .12$ \\
\hline Attachment & & (.14) & & & (.15) & & & (.15) & & & $(.09)$ & & & $(.04)$ & \\
\hline
\end{tabular}

Note. ${ }^{* * *} p<.001$. Group is coded as $1=$ control and $2=$ savoring. The findings for each model remained even when controlling for difficulty paying bills and age. 
Table 10

Age Predicting Post-Task Affect

\begin{tabular}{|c|c|c|c|c|c|c|c|c|c|c|c|c|c|c|c|}
\hline & \multicolumn{3}{|c|}{ Positive Affect } & \multicolumn{3}{|c|}{ High-Arousal Positive Affect } & \multicolumn{3}{|c|}{ Low-Arousal Positive Affect } & \multicolumn{3}{|c|}{ Negative Affect } & \multicolumn{3}{|c|}{ Poignancy } \\
\hline & \multirow[b]{2}{*}{$R^{2}$} & \multirow[b]{2}{*}{ Beta (SE) } & \multirow[b]{2}{*}{$95 \%$ CI } & \multicolumn{3}{|c|}{ Beta } & \multicolumn{3}{|c|}{ Beta } & \multicolumn{3}{|c|}{ Beta } & \multicolumn{3}{|c|}{ Beta } \\
\hline & & & & $R^{2}$ & (SE) & $95 \%$ CI & $R^{2}$ & (SE) & $95 \%$ CI & $R^{2}$ & $(\mathrm{SE})$ & $95 \%$ CI & $R^{2}$ & $(\mathrm{SE})$ & $95 \%$ CI \\
\hline Group & $.80^{* * *}$ & $\begin{array}{l}1.35^{* * *} \\
(.42)\end{array}$ & $.52,2.17$ & $.65^{* * *}$ & $\begin{array}{l}1.69^{* * *} \\
(.48)\end{array}$ & $.73,2.64$ & $.64^{* * *}$ & $\begin{array}{l}.36 \\
(.48)\end{array}$ & $-.58,1.30$ & $.71^{* * *}$ & $\begin{array}{l}-.25 \\
(.15)\end{array}$ & $-54, .04$ & $.79^{* * *}$ & $\begin{array}{l}-.20 \\
(.14)\end{array}$ & $-.48, .08$ \\
\hline Age & & $\begin{array}{l}.02 \\
(.02)\end{array}$ & $-.01, .05$ & & $\begin{array}{l}.03 \\
(.02)\end{array}$ & $-.01, .06$ & & $\begin{array}{l}.01 \\
(.02)\end{array}$ & $-.03, .04$ & & $\begin{array}{l}-.01 \\
(.01)\end{array}$ & $-.02, .004$ & & $\begin{array}{l}-.01 \\
(.004)\end{array}$ & $-.01, .004$ \\
\hline $\begin{array}{l}\text { Post } \\
\text { Event }\end{array}$ & & $\begin{array}{l}.89^{* * *} \\
(.01)\end{array}$ & $-.03,-.01$ & & $\begin{array}{l}.81^{* * *} \\
(.06)\end{array}$ & $.69, .94$ & & $\begin{array}{l}.74^{* * *} \\
(.08)\end{array}$ & $.59, .89$ & & $\begin{array}{l}1.13^{* * *} \\
(.24)\end{array}$ & $.65,1.59$ & & $\begin{array}{l}.95^{* * *} \\
(.05)\end{array}$ & $.86,1.05$ \\
\hline Affect & & & & & & & & & & & & & & & \\
\hline Age $X$ & & -.01 & $-.03, .01$ & & -.01 & $-.03, .01$ & & -.003 & $-.02, .02$ & & .003 & -.002, .01 & & .003 & $-.003, .009$ \\
\hline Group & & $(.01)$ & & & $(.01)$ & & & $(.01)$ & & & $(.003)$ & & & $(.003)$ & \\
\hline
\end{tabular}

Note. ${ }^{* * *} p<.001$, Group is coded as $1=$ control and $2=$ savoring. 


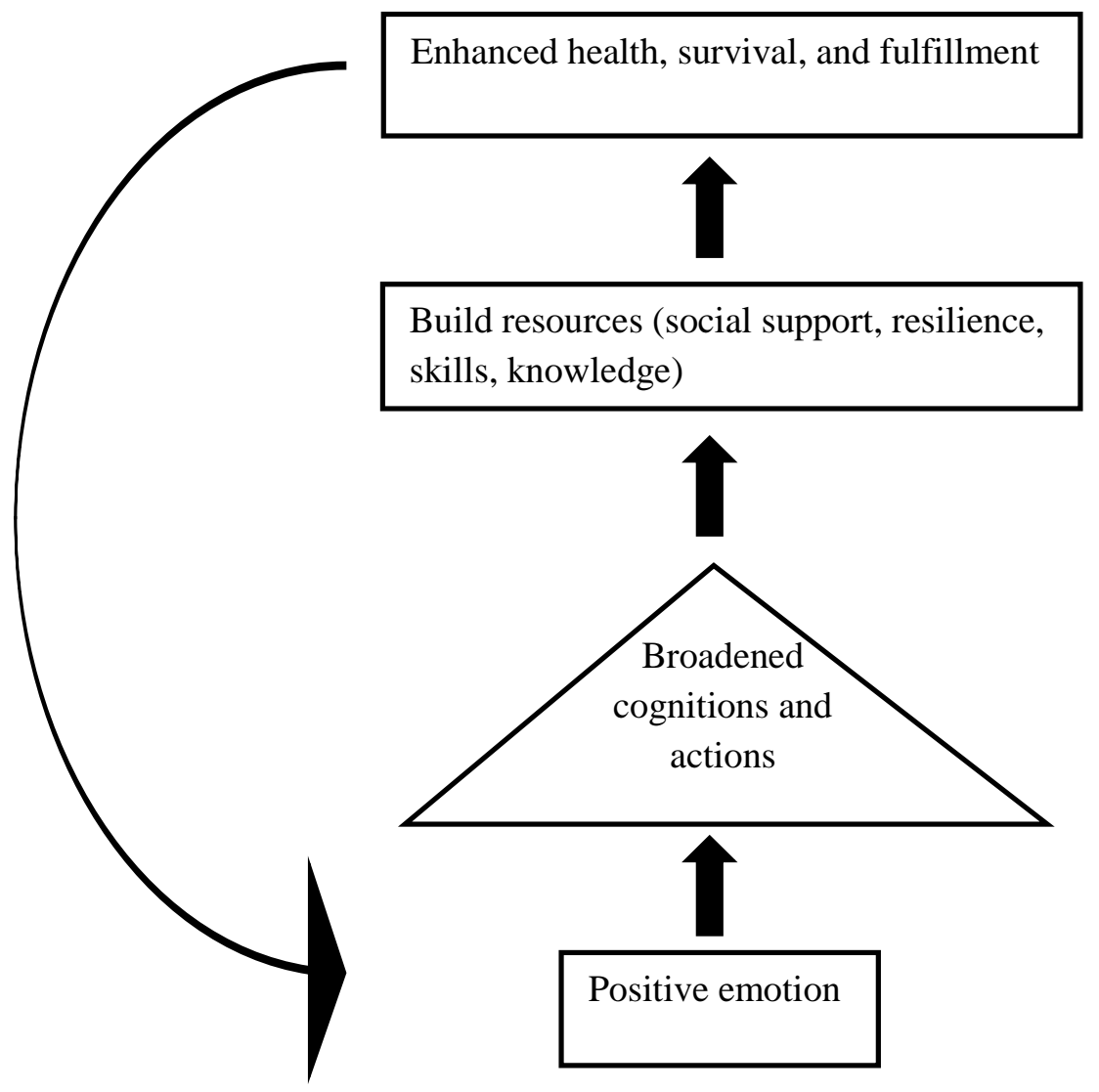

Figure 1. Upward spirals of positive emotion (adapted from Fredrickson \& Joiner, 2002). 


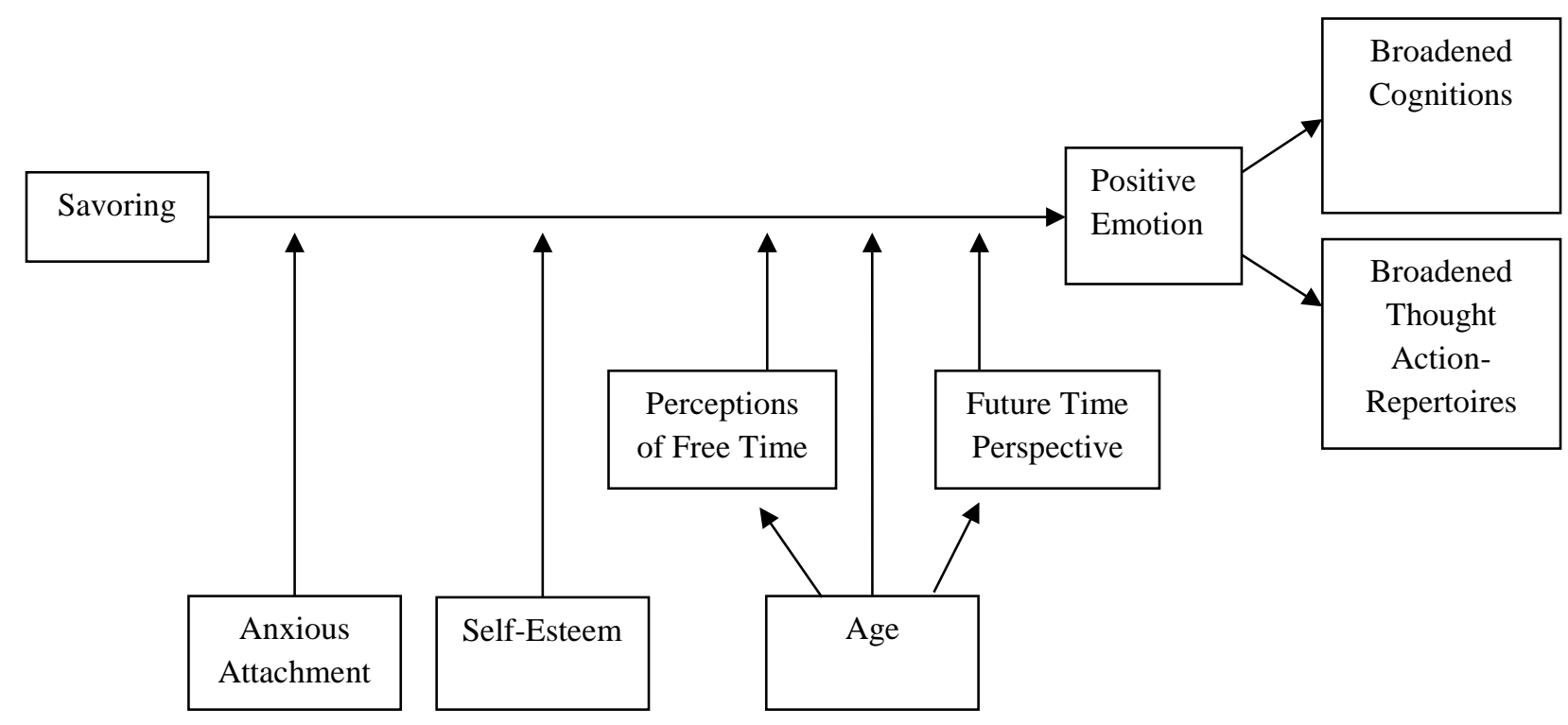

Figure 2. Full conceptual model. 


\begin{tabular}{|c|c|c|c|c|c|c|c|c|}
\hline Consent & $\begin{array}{l}\text { Pre-Study } \\
\text { Survey }\end{array}$ & $\begin{array}{c}\text { Affect } \\
\text { Assessment }\end{array}$ & $\begin{array}{l}\text { Positive } \\
\text { Event } \\
\text { Recall }\end{array}$ & $\begin{array}{c}\text { Affect } \\
\text { Assessment }\end{array}$ & $\begin{array}{l}\text { Savoring } \\
\text { Induction or } \\
\text { Control } \\
\text { Task }\end{array}$ & $\begin{array}{c}\text { Affect } \\
\text { Assessment }\end{array}$ & $\begin{array}{l}\text { Broadening } \\
\text { Effects }\end{array}$ & $\begin{array}{c}\text { Post- } \\
\text { Experiment } \\
\text { Questions } \\
\text { and } \\
\text { Debriefing }\end{array}$ \\
\hline & $\begin{array}{l}\text { Demographics } \\
\text { Attachment } \\
\text { Self-esteem } \\
\text { Future time } \\
\text { perspective } \\
\text { Perceptions of } \\
\text { fee time } \\
\text { Trait Savoring } \\
\text { Mindfulness }\end{array}$ & PANAS & $\begin{array}{c}\text { See } \\
\text { Appendix } \\
\text { A. }\end{array}$ & PANAS & $\begin{array}{c}\text { See } \\
\text { Appendices } \\
\text { B and C. }\end{array}$ & PANAS & $\begin{array}{l}\text { Global- } \\
\text { local } \\
\text { processing } \\
\text { task } \\
\text { Twenty } \\
\text { statements } \\
\text { test }\end{array}$ & $\begin{array}{c}\text { See } \\
\text { Appendix L. }\end{array}$ \\
\hline
\end{tabular}

Figure 3. Study procedure timeline. 


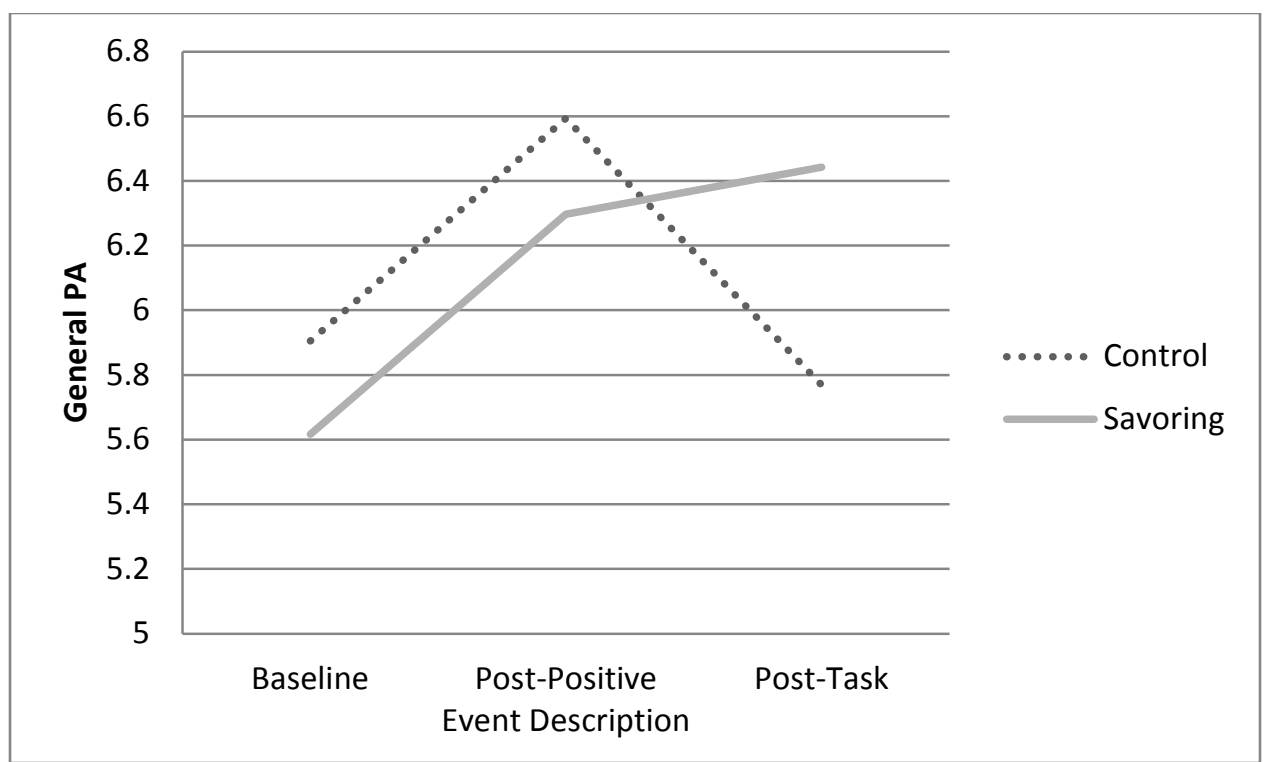

Figure 4. General PA subscale means for the control and savoring group across all 3 emotion assessments. 
EXPERIMENTALLY-INDUCED POSITIVE EMOTIONS

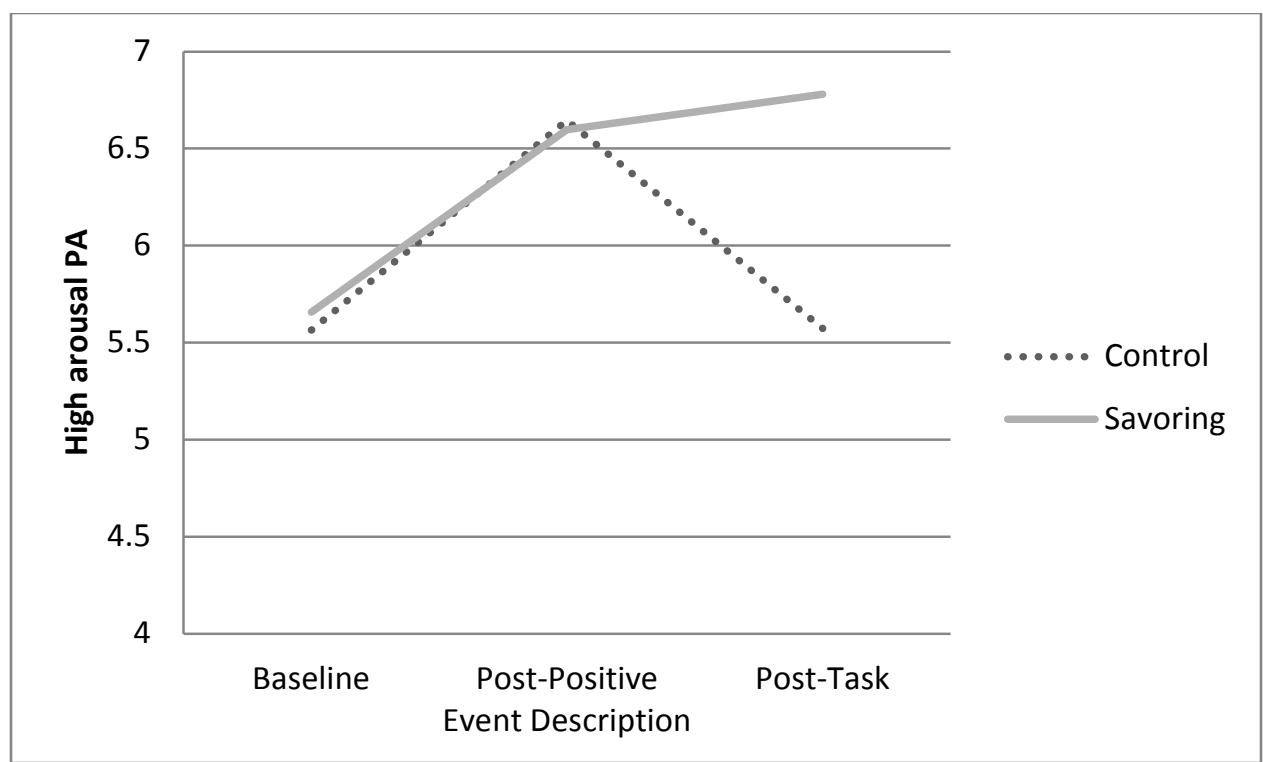

Figure 5. High-arousal PA means for the control and savoring group across all 3 emotion assessments. 
EXPERIMENTALLY-INDUCED POSITIVE EMOTIONS

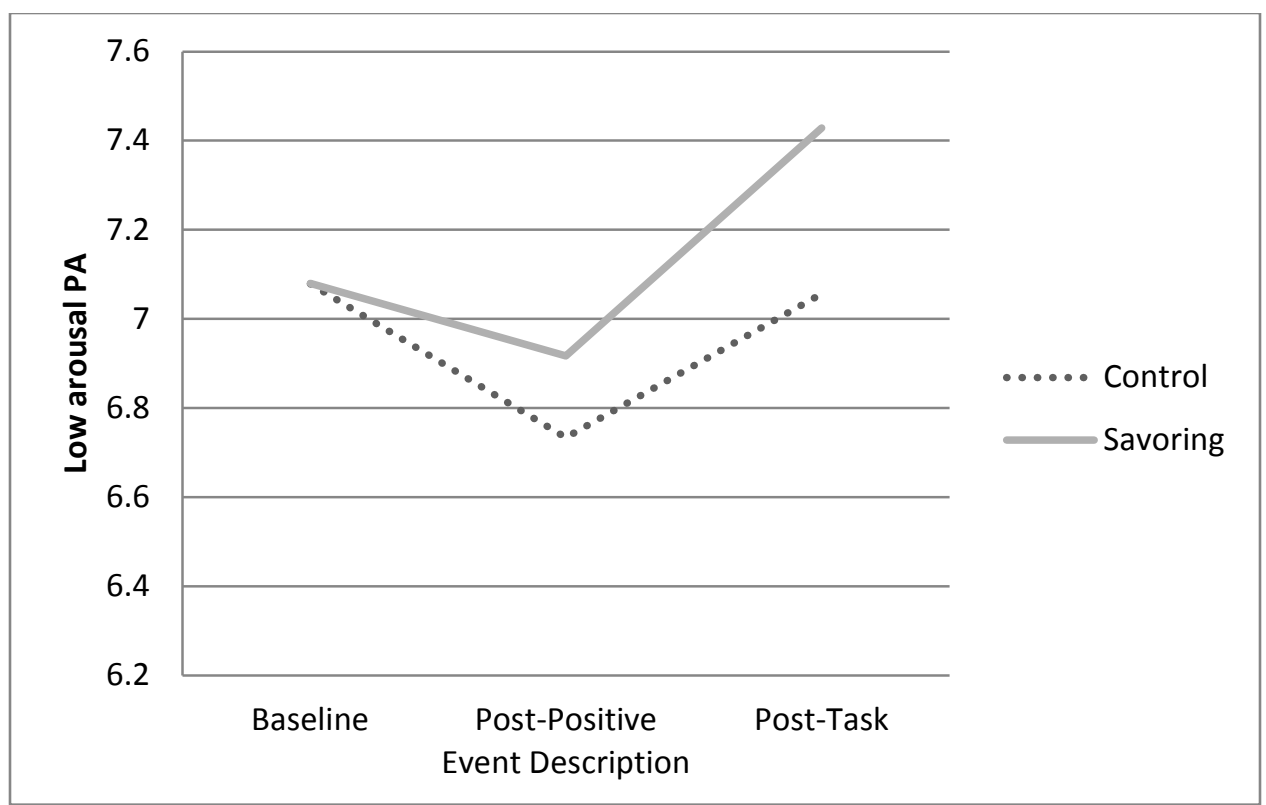

Figure 6. Low-arousal PA means for the control and savoring group across all 3 emotion assessments. 
EXPERIMENTALLY-INDUCED POSITIVE EMOTIONS

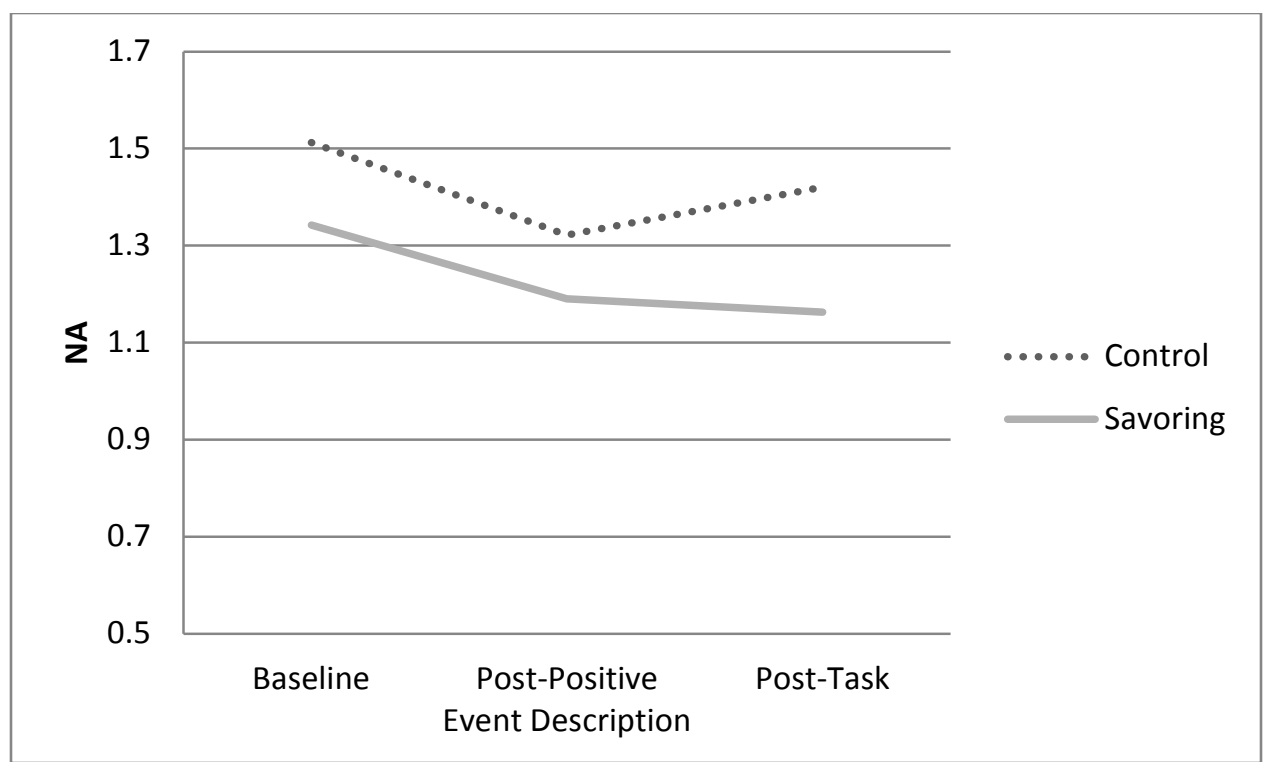

Figure 7. NA subscale means for the control and savoring group across all 3 emotion assessments. 


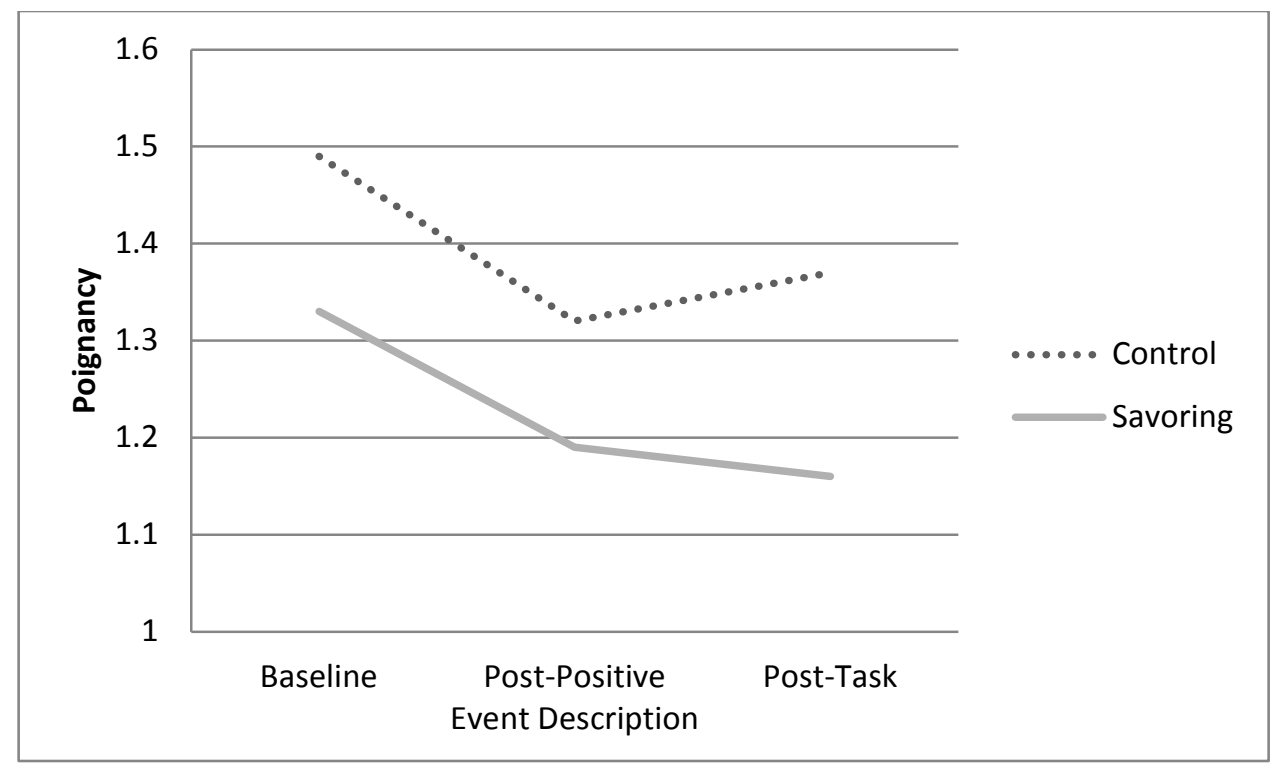

Figure 8. Poignancy means for the control and savoring group across all 3 emotion assessments. 


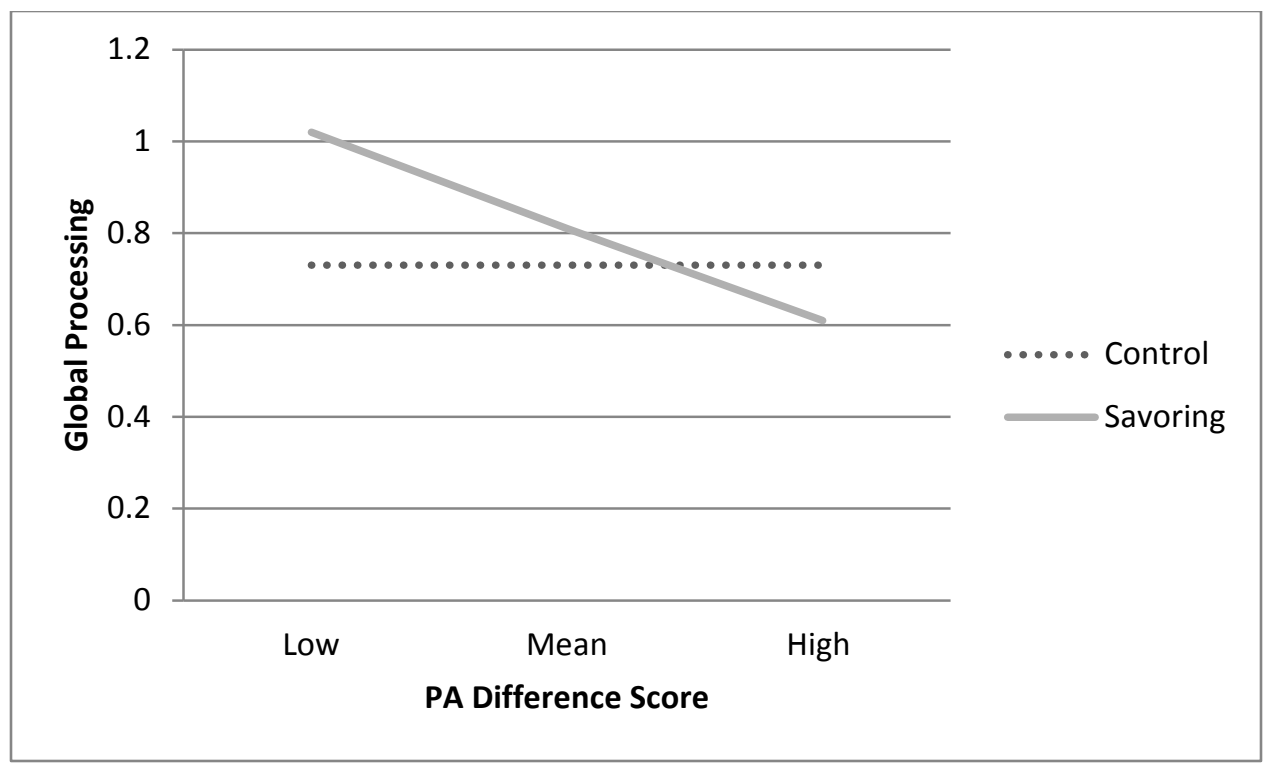

Figure 9. PA difference score and global-local processing by group (Note: higher difference scores indicate greater increases in PA from the positive event recall to after the task). 
EXPERIMENTALLY-INDUCED POSITIVE EMOTIONS

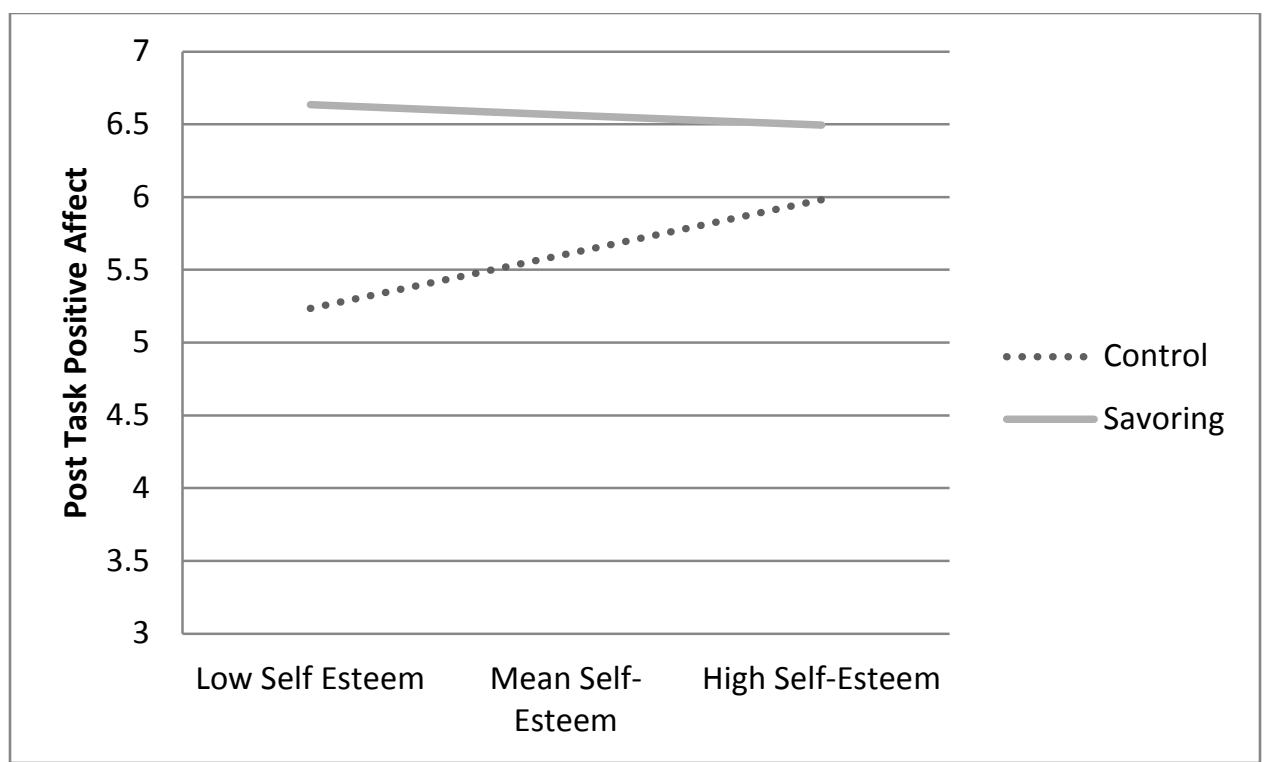

Figure 10. Self-esteem and post-task general PA by group. 


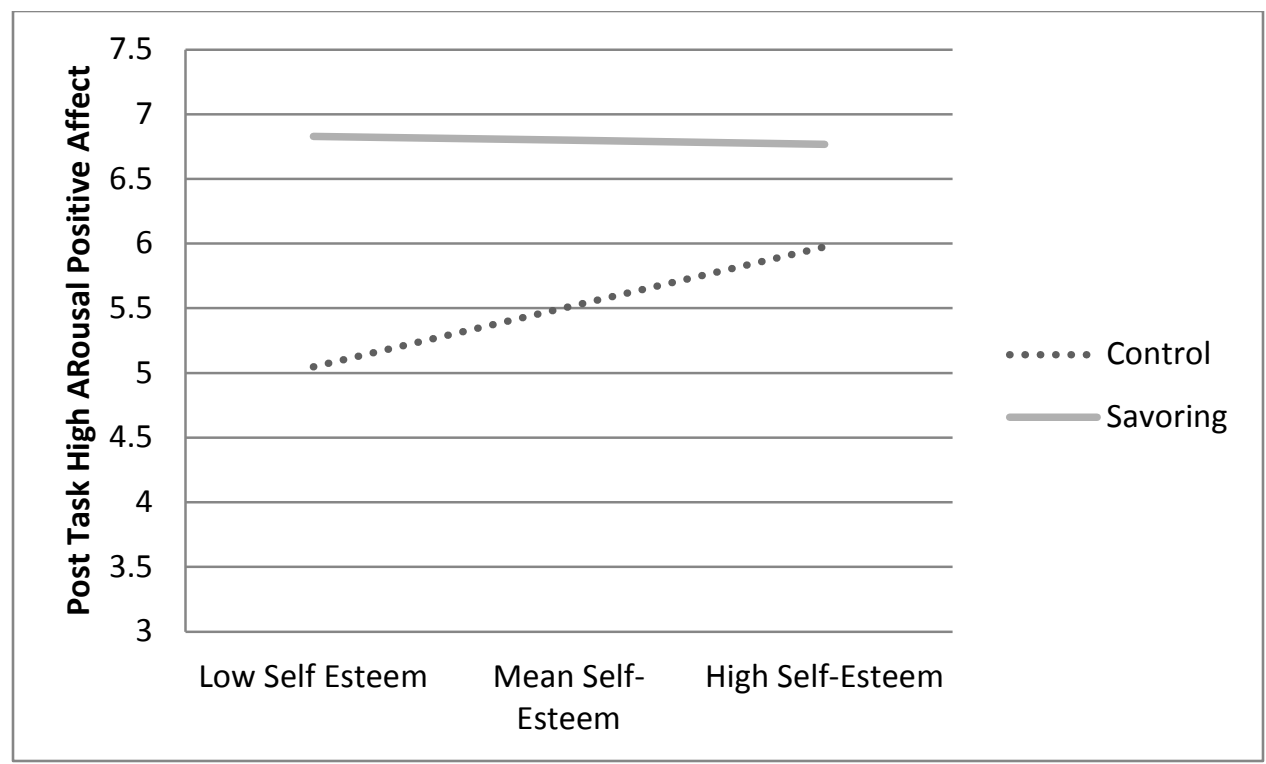

Figure 11. Self-esteem and post-task high-arousal PA by group. 

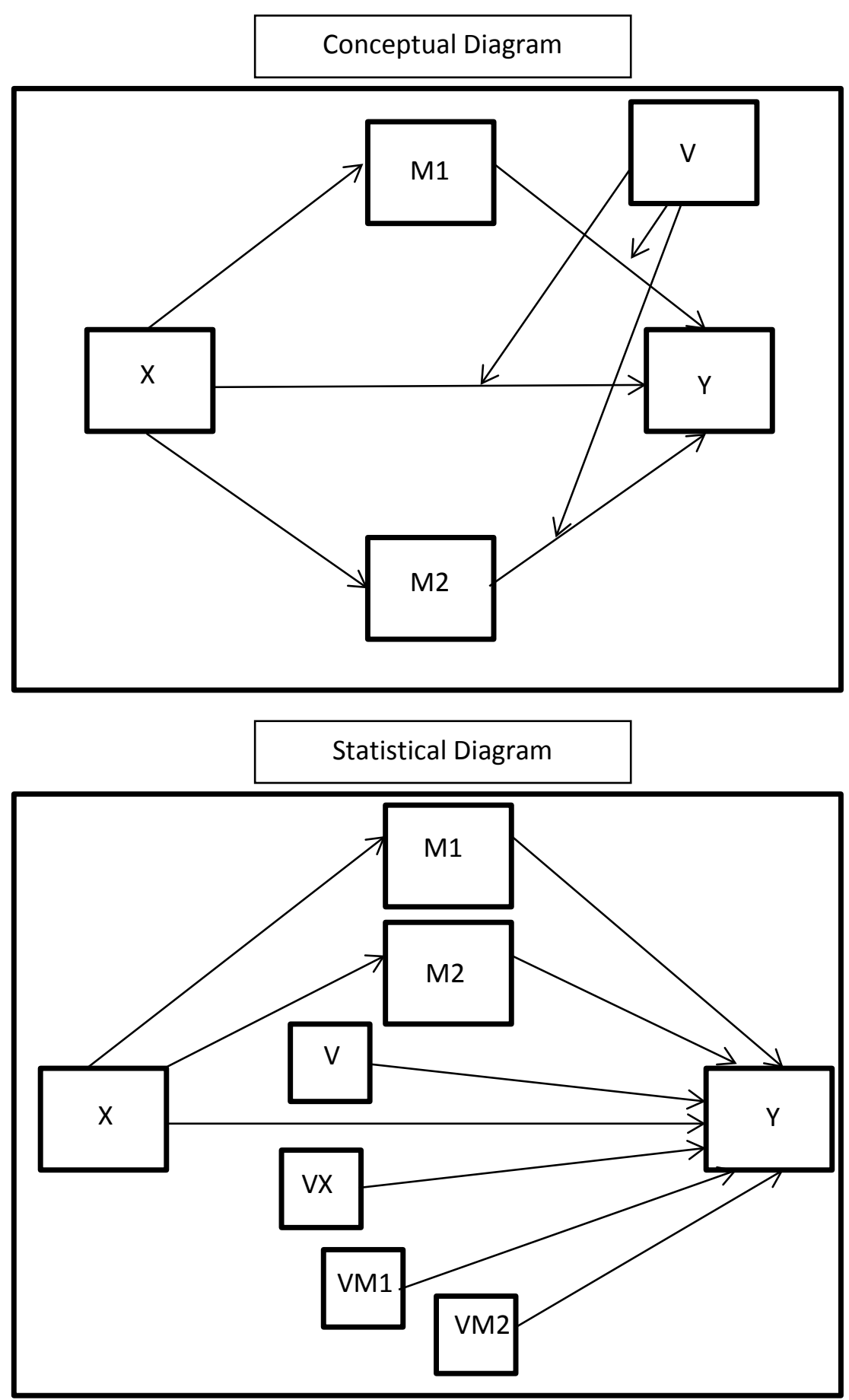

Figure 12. Conceptual and statistical model for research question 4 (Adapted from Hayes, 2013). 


\section{Appendix A}

\section{Demographics}

Please answer these basic questions about yourself.

Date: Time:

Day of the week (Circle one): Sunday Monday Tuesday Wednesday Thursday Friday Saturday Please indicate your gender: Male Female Other/Prefer not to specify

What is your birth date (MM/DD/YYYY)?

How old are you?

What is your race/ethnicity? (Circle all that apply)

a. White/Caucasian

b. Black/African-American

c. Asian or Pacific Islander

d. Latino or Hispanic

e. Native American, Eskimo, or Aleut

f. Other/prefer not to specify

What is your zip code?

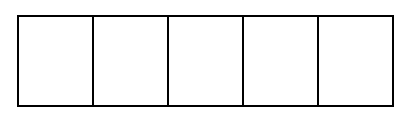

On a scale of 1-7, with 1 being very difficult and 7 being not difficult at all, in general how hard is it for you to pay your monthly bills? (Please circle one)

Not at all
N little

What is your yearly household income?

If you still receive support from your parents or guardian, what is their yearly income?

How are you paid? (Please circle-leave blank if you do not work)

Salary / Hourly / Both

Are you retired? (Circle one) Yes / No

If not, what is your occupation?

Marital Status: (Circle one) Married / Single / Divorced or Separated / Cohabiting / Widowed

Education: (Circle one)

a. Some high school

b. Graduated high school

c. Some college 
d. Graduated college

e. Some graduate school

f. Finished graduate school

How many hours do you work a week on average? (leave blank if you do not work)

If you are currently a student, what is your GPA?

Do you have kids? Circle one: Yes No

If yes, what are their ages?

Approximately how many hours of sleep did you get last night?

Have you ever been diagnosed with ADHD? Circle one: Yes No 


\section{Appendix B}

\section{Positive Event Recall}

Experimenter: “Now, I’m going to ask you to think of a very positive experience that you could describe to me. So, take some time to think of a personal experience that has happened to you that made you very happy, and that still makes you feel really good when you think about it. It can be something that happened very recently, or it can be something that happened in the past, as long as it's something that still makes you happy when you think about it. Once you think of something that you'd be willing to describe to me, let me know.”

"Would you please describe your experience in detail? For example, you can describe what happened, people involved, and how it made you feel."

Possible prompts:

Is there anything else about the experience that made you feel good? Do you still think about it? Does it still make you happy? What else did you do when it first happened? Did you feel any specific emotions? 


\section{Appendix C}

\section{Savoring Induction Instructions*}

First, think about your positive memory that you just described. How would you label this good feeling? Think about this feeling and take a deep breathe, relax, and begin to think about the memory.

Think about each aspect of the event. Allow images related to the memory come to mind. Think about the sensations you experienced during that memory. The smells, tastes, feelings, sights, sounds. Close your eyes and swish your good feelings around in your mind. Let your mind wander freely through the details of the memory, while you are imaging the memory.

Think about all the things that needed to happen for you to experience that event. Think about how lucky you are for that event to have happened or how great you are for it to have happened.

Now close your eyes, relax, and continue to replay the event in your mind and re-experience the feelings associated with the event.

*Adapted from methods used by Bryant et al., 2005 and McMakin, Siegle, \& Shirk, 2011. 


\section{Appendix D}

\section{Control Condition}

First, think about your usual daily morning routine. Then take a deep breath, relax, close your eyes, and begin to think about this routine. Allow any thoughts to come to mind while you think about this. Let your mind wander freely as you envision yourself going through this routine as thoroughly as possible from your memory.

Now close your eyes, relax, and continue to think about this and experience the feelings associated with your morning routine. 


\section{Appendix E}

\section{PANAS}

This scale consists of a number of words and phrases that describe different feelings and emotions. Read each item and then mark the appropriate answer in the space next to that word. Indicate to what extent you feel this way right now.

Use the following scale to record your answers:

\begin{tabular}{|c|c|c|c|c|c|c|c|c|}
\hline $\begin{array}{c}\text { Very } \\
\text { slightly } \\
\text { or not at } \\
\text { all }\end{array}$ & A little & & Moderately & & $\begin{array}{c}\text { Quite a } \\
\text { bit }\end{array}$ & & Extremely \\
\hline 1 & 2 & 3 & 4 & 5 & 6 & 7 & 8 & 9 \\
\hline
\end{tabular}

at ease

calm

relaxed

happy

joyful

delighted

cheerful

enthusiastic

lively

energetic

sleepy

sad

worried

guilty

angry

afraid

active

alert

attentive

determined

excited

inspired

interested

proud

strong 


\section{Appendix F}

\section{Attachment}

The statements below concern how you feel in emotionally intimate relationships. We are interested in how you generally experience relationships, not just in what is happening in a current relationship. Respond to each statement by circling a number to indicate how much you agree or disagree with the statement.

\begin{tabular}{|c|c|c|c|c|c|c|c|}
\hline & $\begin{array}{l}\text { Strongly } \\
\text { Disagree }\end{array}$ & & & & & & $\begin{array}{l}\text { trongly } \\
\text { Agree }\end{array}$ \\
\hline $\begin{array}{l}\text { 1. I'm afraid that I will lose } \\
\text { my partner's love. }\end{array}$ & 1 & 2 & 3 & 4 & 5 & 6 & 7 \\
\hline $\begin{array}{l}\text { 2. I often worry that my } \\
\text { partner will not want to stay } \\
\text { with me. }\end{array}$ & 1 & 2 & 3 & 4 & 5 & 6 & 7 \\
\hline $\begin{array}{l}\text { 3. I often worry that my } \\
\text { partner doesn't really love } \\
\text { me. }\end{array}$ & 1 & 2 & 3 & 4 & 5 & 6 & 7 \\
\hline $\begin{array}{l}\text { 4. I worry that romantic } \\
\text { partners won't care about me } \\
\text { as much as I care about them. }\end{array}$ & 1 & 2 & 3 & 4 & 5 & 6 & 7 \\
\hline $\begin{array}{l}\text { 5. I often wish that my } \\
\text { partner's feelings for me were } \\
\text { as strong as my feelings for } \\
\text { him or her. }\end{array}$ & 1 & 2 & 3 & 4 & 5 & 6 & 7 \\
\hline $\begin{array}{l}\text { 6. I worry a lot about my } \\
\text { relationships. }\end{array}$ & 1 & 2 & 3 & 4 & 5 & 6 & 7 \\
\hline $\begin{array}{l}\text { 7. When my partner is out of } \\
\text { sight, I worry that he or she } \\
\text { might become interested in } \\
\text { someone else. }\end{array}$ & 1 & 2 & 3 & 4 & 5 & 6 & 7 \\
\hline $\begin{array}{l}\text { 8. When I show my feelings } \\
\text { for romantic partners, I'm } \\
\text { afraid they will not feel the } \\
\text { same about me. }\end{array}$ & 1 & 2 & 3 & 4 & 5 & 6 & 7 \\
\hline $\begin{array}{l}\text { 9. I rarely worry about my } \\
\text { partner leaving me. }\end{array}$ & 1 & 2 & 3 & 4 & 5 & 6 & 7 \\
\hline $\begin{array}{l}\text { 10. My romantic partner } \\
\text { makes me doubt myself. }\end{array}$ & 1 & 2 & 3 & 4 & 5 & 6 & 7 \\
\hline
\end{tabular}




\begin{tabular}{|c|c|c|c|c|c|c|c|}
\hline & $\begin{array}{l}\text { Stron } \\
\text { Disag }\end{array}$ & & & & & & $\begin{array}{l}\text { trongly } \\
\text { gree }\end{array}$ \\
\hline $\begin{array}{l}\text { 11. I do not often worry about } \\
\text { being abandoned. }\end{array}$ & 1 & 2 & 3 & 4 & 5 & 6 & 7 \\
\hline $\begin{array}{l}\text { 12. I find that my partner(s) } \\
\text { don't want to get as close as I } \\
\text { would like. }\end{array}$ & 1 & 2 & 3 & 4 & 5 & 6 & 7 \\
\hline $\begin{array}{l}\text { 13. Sometimes romantic } \\
\text { partners change their feelings } \\
\text { about me for no apparent } \\
\text { reason. }\end{array}$ & 1 & 2 & 3 & 4 & 5 & 6 & 7 \\
\hline $\begin{array}{l}\text { 14. My desire to be very close } \\
\text { sometimes scares people } \\
\text { away. }\end{array}$ & 1 & 2 & 3 & 4 & 5 & 6 & 7 \\
\hline $\begin{array}{l}\text { 15. I'm afraid that once a } \\
\text { romantic partner gets to know } \\
\text { me, he or she won't like who I } \\
\text { really am. }\end{array}$ & 1 & 2 & 3 & 4 & 5 & 6 & 7 \\
\hline $\begin{array}{l}\text { 16. It makes me mad that I } \\
\text { don't get the affection and } \\
\text { support I need from my } \\
\text { partner. }\end{array}$ & 1 & 2 & 3 & 4 & 5 & 6 & 7 \\
\hline $\begin{array}{l}\text { 17. I worry that I won't } \\
\text { measure up to other people. }\end{array}$ & 1 & 2 & 3 & 4 & 5 & 6 & 7 \\
\hline $\begin{array}{l}\text { 18. My partner only seems to } \\
\text { notice me when I'm angry. }\end{array}$ & 1 & 2 & 3 & 4 & 5 & 6 & 7 \\
\hline $\begin{array}{l}\text { 19. I prefer not to show a } \\
\text { partner how I feel deep down. }\end{array}$ & 1 & 2 & 3 & 4 & 5 & 6 & 7 \\
\hline $\begin{array}{l}\text { 20. I feel comfortable sharing } \\
\text { my private thoughts and } \\
\text { feelings with my partner. }\end{array}$ & 1 & 2 & 3 & 4 & 5 & 6 & 7 \\
\hline $\begin{array}{l}\text { 21. I find it difficult to allow } \\
\text { myself to depend on romantic } \\
\text { partners. }\end{array}$ & 1 & 2 & 3 & 4 & 5 & 6 & 7 \\
\hline $\begin{array}{l}\text { 22. I am very comfortable } \\
\text { being close to romantic } \\
\text { partners. }\end{array}$ & 1 & 2 & 3 & 4 & 5 & 6 & 7 \\
\hline
\end{tabular}




\begin{tabular}{|c|c|c|c|c|c|c|c|}
\hline & $\begin{array}{l}\text { Strongly } \\
\text { Disagree }\end{array}$ & & & & & & $\begin{array}{l}\text { Strongly } \\
\text { Agree }\end{array}$ \\
\hline $\begin{array}{l}\text { 23. I don't feel comfortable } \\
\text { opening up to romantic } \\
\text { partners. }\end{array}$ & 1 & 2 & 3 & 4 & 5 & 6 & 7 \\
\hline $\begin{array}{l}\text { 24. I prefer not to be too close } \\
\text { to romantic partners. }\end{array}$ & 1 & 2 & 3 & 4 & 5 & 6 & 7 \\
\hline $\begin{array}{l}25 \text {. I get uncomfortable when } \\
\text { a romantic partner wants to } \\
\text { be very close. }\end{array}$ & 1 & 2 & 3 & 4 & 5 & 6 & 7 \\
\hline $\begin{array}{l}\text { 26. I find it relatively easy to } \\
\text { get close to my partner. }\end{array}$ & 1 & 2 & 3 & 4 & 5 & 6 & 7 \\
\hline $\begin{array}{l}\text { 27. It's not difficult for me to } \\
\text { get close to my partner. }\end{array}$ & 1 & 2 & 3 & 4 & 5 & 6 & 7 \\
\hline $\begin{array}{l}\text { 28. I usually discuss my } \\
\text { problems and concerns with } \\
\text { my partner. }\end{array}$ & 1 & 2 & 3 & 4 & 5 & 6 & 7 \\
\hline $\begin{array}{l}\text { 29. It helps to turn to my } \\
\text { romantic partner in times of } \\
\text { need. }\end{array}$ & 1 & 2 & 3 & 4 & 5 & 6 & 7 \\
\hline $\begin{array}{l}\text { 30. I tell my partner just } \\
\text { about everything. }\end{array}$ & 1 & 2 & 3 & 4 & 5 & 6 & 7 \\
\hline $\begin{array}{l}\text { 31. I talk things over with my } \\
\text { partner. }\end{array}$ & 1 & 2 & 3 & 4 & 5 & 6 & 7 \\
\hline $\begin{array}{l}\text { 32. I am nervous when } \\
\text { partners get too close to me. }\end{array}$ & 1 & 2 & 3 & 4 & 5 & 6 & 7 \\
\hline $\begin{array}{l}\text { 33. I feel comfortable } \\
\text { depending on romantic } \\
\text { partners. }\end{array}$ & 1 & 2 & 3 & 4 & 5 & 6 & 7 \\
\hline $\begin{array}{l}\text { 34. I find it easy to depend on } \\
\text { romantic partners. }\end{array}$ & 1 & 2 & 3 & 4 & 5 & 6 & 7 \\
\hline $\begin{array}{l}\text { 35. It's easy for me to be } \\
\text { affectionate with my partner. }\end{array}$ & 1 & 2 & 3 & 4 & 5 & 6 & 7 \\
\hline $\begin{array}{l}\text { 36. My partner really } \\
\text { understands me and my } \\
\text { needs. }\end{array}$ & 1 & 2 & 3 & 4 & 5 & 6 & 7 \\
\hline
\end{tabular}




\section{Appendix G}

\section{Rosenberg Self-Esteem Scale}

Circle the answer that most closely reflects your opinion on each statement.

\begin{tabular}{|c|c|c|c|c|}
\hline & Strongly Agree & Agree & Disagree & Strongly Disagree \\
\hline $\begin{array}{l}\text { I feel that I am a } \\
\text { person of worth, at } \\
\text { least on an equal } \\
\text { plane with others. }\end{array}$ & 0 & 1 & 2 & 3 \\
\hline $\begin{array}{l}\text { I feel that I have a } \\
\text { number of good } \\
\text { qualities. }\end{array}$ & 0 & 1 & 2 & 3 \\
\hline $\begin{array}{l}\text { All in all, I am } \\
\text { inclined to feel } \\
\text { that I am a failure. }\end{array}$ & 0 & 1 & 2 & 3 \\
\hline $\begin{array}{l}\text { I am able to do } \\
\text { things as well as } \\
\text { most other people. }\end{array}$ & 0 & 1 & 2 & 3 \\
\hline $\begin{array}{l}\text { I feel I do not have } \\
\text { much to be proud } \\
\text { of. }\end{array}$ & 0 & 1 & 2 & 3 \\
\hline $\begin{array}{l}\text { I take a positive } \\
\text { attitude toward } \\
\text { myself. }\end{array}$ & 0 & 1 & 2 & 3 \\
\hline $\begin{array}{l}\text { On the whole, I am } \\
\text { satisfied with } \\
\text { myself. }\end{array}$ & 0 & 1 & 2 & 3 \\
\hline $\begin{array}{l}\text { I wish I could have } \\
\text { more respect for } \\
\text { myself. }\end{array}$ & 0 & 1 & 2 & 3 \\
\hline $\begin{array}{l}\text { I certainly feel } \\
\text { useless at times. }\end{array}$ & 0 & 1 & 2 & 3 \\
\hline $\begin{array}{l}\text { At times I think I } \\
\text { am no good at all. }\end{array}$ & 0 & 1 & 2 & 3 \\
\hline
\end{tabular}




\section{Appendix $\mathrm{H}$}

\section{Future Time Perspective}

Indicate your agreement with the following items:

\begin{tabular}{|c|c|c|c|c|c|c|c|}
\hline & $\begin{array}{l}\text { Very } \\
\text { Untrue }\end{array}$ & & & & & & ry \\
\hline Many opportunities await me in the future. & 1 & 2 & 3 & 4 & 5 & 6 & 7 \\
\hline $\begin{array}{l}\text { I expect that I will set many new goals in the } \\
\text { future. }\end{array}$ & 1 & 2 & 3 & 4 & 5 & 6 & 7 \\
\hline My future is filled with possibilities. & 1 & 2 & 3 & 4 & 5 & 6 & 7 \\
\hline Most of my life lies ahead of me. & 1 & 2 & 3 & 4 & 5 & 6 & 7 \\
\hline My future seems infinite to me. & 1 & 2 & 3 & 4 & 5 & 6 & 7 \\
\hline I could do anything I want in the future. & 1 & 2 & 3 & 4 & 5 & 6 & 7 \\
\hline $\begin{array}{l}\text { There is plenty of time left in my life to make } \\
\text { new plans. }\end{array}$ & 1 & 2 & 3 & 4 & 5 & 6 & 7 \\
\hline I have the sense that time is running out. & 1 & 2 & 3 & 4 & 5 & 6 & 7 \\
\hline There are only limited possibilities in my future. & 1 & 2 & 3 & 4 & 5 & 6 & 7 \\
\hline $\begin{array}{l}\text { As I get older, I begin to experience time as } \\
\text { limited. }\end{array}$ & 1 & 2 & 3 & 4 & 5 & 6 & 7 \\
\hline I have limited time left to live my life. & 1 & 2 & 3 & 4 & 5 & 6 & 7 \\
\hline I feel the importance of time's passing. & 1 & 2 & 3 & 4 & 5 & 6 & 7 \\
\hline
\end{tabular}

Additional items to assess focus on opportunities and limitations:

To what extent does each of the following describe your life?

年 $\begin{gathered}\text { Very } \\
\text { Unlike my } \\
\text { life } \\
\text { like my life }\end{gathered}$
\begin{tabular}{|l|c|c|c|c|c|c|c|}
\hline $\begin{array}{l}\text { Having an interest in things beyond my } \\
\text { own family. }\end{array}$ & 1 & 2 & 3 & 4 & 5 & 6 & 7 \\
\hline Searching for a sense of who I am. & 1 & 2 & 3 & 4 & 5 & 6 & 7 \\
\hline Discovering new parts of myself. & 1 & 2 & 3 & 4 & 5 & 6 & 7 \\
\hline Thinking a lot about death. & 1 & 2 & 3 & 4 & 5 & 6 & 7 \\
\hline Knowing there are things I'll never do. & 1 & 2 & 3 & 4 & 5 & 6 & 7 \\
\hline
\end{tabular}


Appendix I

\section{Perceptions of Free Time}

Please indicate how much you agree with the following statements.

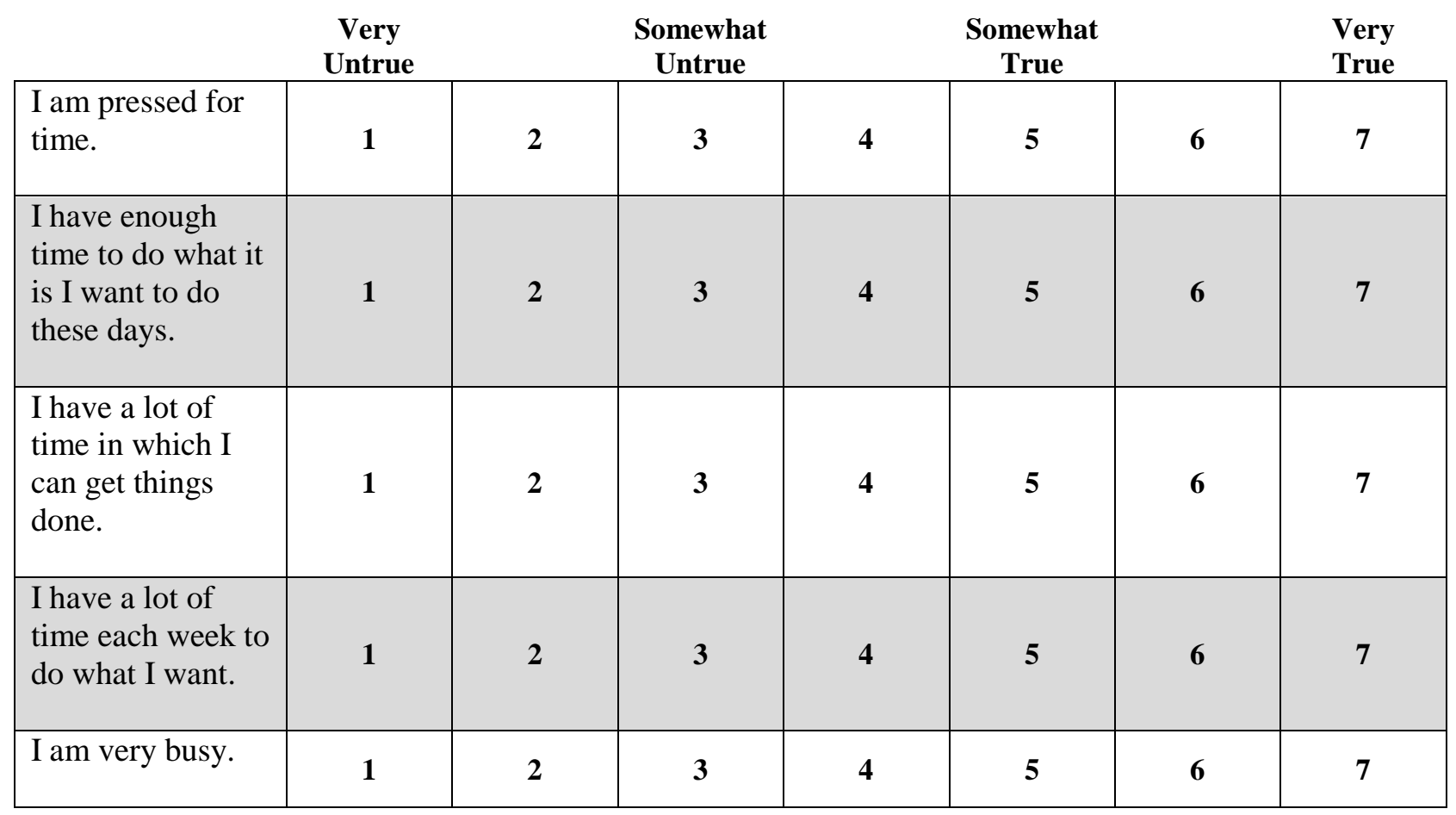




\section{Appendix J}

\section{Similarity Task}

For each set of figures, compare the bottom two figures to the top figure. Indicate (by circling) your first, immediate impression about which of the two bottom figures looks most like the top figure. Remember, there are no right or wrong answers!

Example figures:
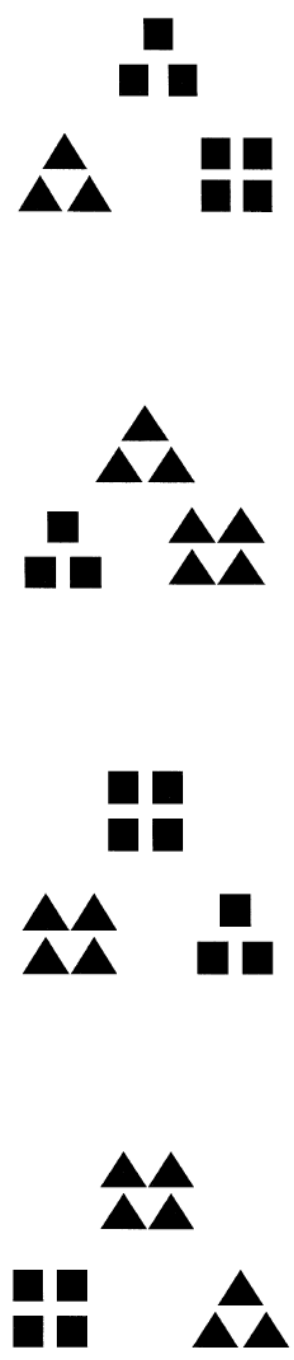


\section{Appendix K}

Imagery Task

Please list all the things you would like to do right now.

1.

2.

3.

4.

5.

6.

7.

8.

9.

10.

11.

12.

13.

14.

15.

16.

17.

18.

19.

20. 
Appendix L

\section{Post-Experiment Questionnaire}

At one point during this study, we asked you to describe a positive event.

How happy were you about this event when it first happened?

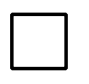

Not at all
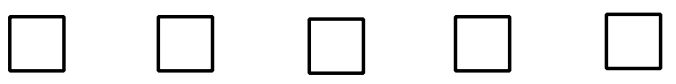

Somewhat

happy

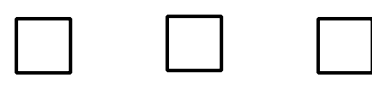

Extremely

happy

What emotions would you use to describe your feelings about the event?

How long ago did this event happen?

How much did you feel like this event was in your control?

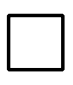

Not

at all
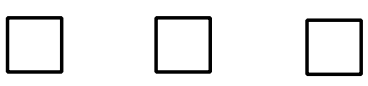

Somewhat

in my control

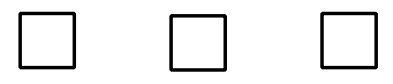

$\square$

Extremely

in my control

How spontaneous was this event? (Meaning you did not know it was going to happen in advance)

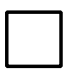

Not

at all
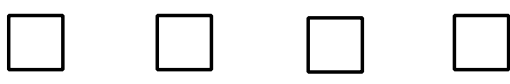

Somewhat

spontaneous
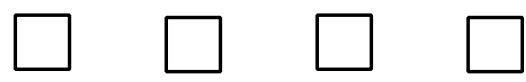

Extremely spontaneous

Is there anything else you want to add about the event? 
After you recalled the positive event, you were asked to do a thinking task that involved thinking about this positive event again or thinking about your morning routine. Please answer these following questions about the thinking exercise (you can be completely honest!)

How hard did you try during the thinking exercise? (Please mark anywhere along the line)

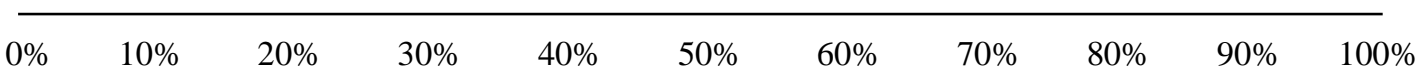

Not at all

Really hard

How distracted did you feel during the thinking exercise? (Please mark anywhere along the line)

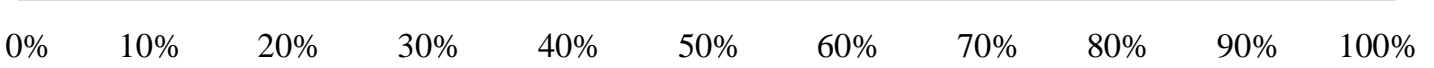

Not at all

Really distracted

If you were distracted during the thinking exercise, what did you think about instead?

How long did you feel the thinking exercise was?
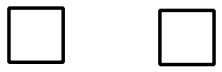

Not a

long time
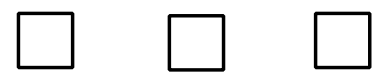
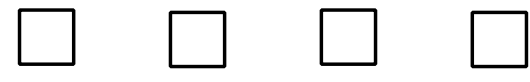

A very

long time

How much time do you think it took?

minutes, seconds 
Some people in this study were asked to think about their daily morning routine. If you were not asked to do this, please skip this question. If you were asked to think about your daily morning routine, how happy do you usually feel during your daily morning routine?

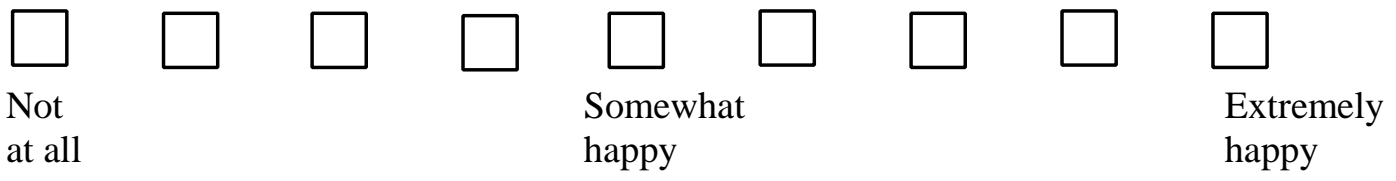

Some people in this study were asked to think about their positive event again during the thinking task. If you were not asked to do this, please skip this question. If you were asked to think about your positive event again, what aspects of the event did you focus on?

If you were not asked to think about your positive event again, please skip this question. What "senses" did you focus on when remembering your positive event? Circle all that apply:
Sights
Sounds
Smells
Tastes
Touch

You were asked at one point if you would be willing to donate money to a charity. If you decided to donate money, why? If you decided not to donate money, why not? 
Please indicate your agreement with the following statements about the thinking exercise (where you were asked to think about your positive event again, or to think about your daily morning routine).

\begin{tabular}{|l|c|c|c|c|c|c|c|}
\hline & $\begin{array}{l}\text { Strongly } \\
\text { Disagree }\end{array}$ & & & & & & $\begin{array}{l}\text { Strongly } \\
\text { Agree }\end{array}$ \\
\hline $\begin{array}{l}\text { I was impatient for } \\
\text { the task to end so I } \\
\text { could finish the } \\
\text { study. }\end{array}$ & 1 & 2 & 3 & 4 & 5 & 6 & 7 \\
\hline $\begin{array}{l}\text { My thoughts were } \\
\text { completely } \\
\text { absorbed by the } \\
\text { task. }\end{array}$ & 1 & 2 & 3 & 4 & 5 & 6 & 7 \\
\hline $\begin{array}{l}\text { I felt the task was a } \\
\text { relaxing break. }\end{array}$ & 1 & 2 & 3 & 4 & 5 & 6 & 7 \\
\hline $\begin{array}{l}\text { The task inspired } \\
\text { me to think } \\
\text { pleasant thoughts. }\end{array}$ & 1 & 2 & 3 & 4 & 5 & 6 & 7 \\
\hline $\begin{array}{l}\text { I was enjoying the } \\
\text { task and I did not } \\
\text { want it to end. }\end{array}$ & 1 & 2 & 3 & 4 & 5 & 6 & 7 \\
\hline $\begin{array}{l}\text { I was thinking } \\
\text { about what I was } \\
\text { going to do when } \\
\text { the study was } \\
\text { done. }\end{array}$ & 1 & 2 & 3 & 4 & 5 & 6 & 7 \\
\hline $\begin{array}{l}\text { I thought the task } \\
\text { was a waste of my } \\
\text { time. }\end{array}$ & 1 & 2 & 3 & 4 & 5 & 6 & 7 \\
\hline $\begin{array}{l}\text { I was thinking that } \\
\text { the task was going } \\
\text { on for a long time. }\end{array}$ & 1 & 2 & 3 & 4 & 5 & 6 & 7 \\
\hline
\end{tabular}

If you were feeling impatient during the thinking exercise, what sorts of things were making you impatient? 


\section{Appendix M}

\section{Savoring Beliefs Inventory}

\begin{tabular}{|c|c|c|c|c|c|c|c|}
\hline & $\begin{array}{l}\text { Strongly } \\
\text { Disagree }\end{array}$ & & & & & & $\begin{array}{l}\text { trongly } \\
\text { Agree }\end{array}$ \\
\hline $\begin{array}{l}\text { Before a good thing happens, I } \\
\text { look forward to it in ways that } \\
\text { give me pleasure in the present. }\end{array}$ & 1 & 2 & 3 & 4 & 5 & 6 & 7 \\
\hline $\begin{array}{l}\text { It's hard for me to hang onto a } \\
\text { good feeling for very long. }\end{array}$ & 1 & 2 & 3 & 4 & 5 & 6 & 7 \\
\hline $\begin{array}{l}\text { I enjoy looking back on happy } \\
\text { times from my past. }\end{array}$ & 1 & 2 & 3 & 4 & 5 & 6 & 7 \\
\hline $\begin{array}{l}\text { I don't like to look forward to } \\
\text { good times too much before } \\
\text { they happen. }\end{array}$ & 1 & 2 & 3 & 4 & 5 & 6 & 7 \\
\hline $\begin{array}{l}\text { I know how to make the most of } \\
\text { a good time. }\end{array}$ & 1 & 2 & 3 & 4 & 5 & 6 & 7 \\
\hline $\begin{array}{l}\text { I don't like to look back at good } \\
\text { times too much after they've } \\
\text { taken place. }\end{array}$ & 1 & 2 & 3 & 4 & 5 & 6 & 7 \\
\hline $\begin{array}{l}\text { I feel a joy of anticipation when } \\
\text { I think about upcoming good } \\
\text { things. }\end{array}$ & 1 & 2 & 3 & 4 & 5 & 6 & 7 \\
\hline $\begin{array}{l}\text { When it comes to enjoying } \\
\text { myself, I'm my own "worst } \\
\text { enemy.” }\end{array}$ & 1 & 2 & 3 & 4 & 5 & 6 & 7 \\
\hline $\begin{array}{l}\text { I can make myself feel good by } \\
\text { remembering pleasant events } \\
\text { from my past. }\end{array}$ & 1 & 2 & 3 & 4 & 5 & 6 & 7 \\
\hline $\begin{array}{l}\text { For me, anticipating what } \\
\text { upcoming good events will be } \\
\text { like is basically a waste of time. }\end{array}$ & 1 & 2 & 3 & 4 & 5 & 6 & 7 \\
\hline $\begin{array}{l}\text { When something good happens, } \\
\text { I can make my enjoyment of it } \\
\text { last longer by thinking or doing } \\
\text { certain things. }\end{array}$ & 1 & 2 & 3 & 4 & 5 & 6 & 7 \\
\hline $\begin{array}{l}\text { When I reminisce about } \\
\text { pleasant memories, I often start } \\
\text { to feel sad or disappointed. }\end{array}$ & 1 & 2 & 3 & 4 & 5 & 6 & 7 \\
\hline
\end{tabular}




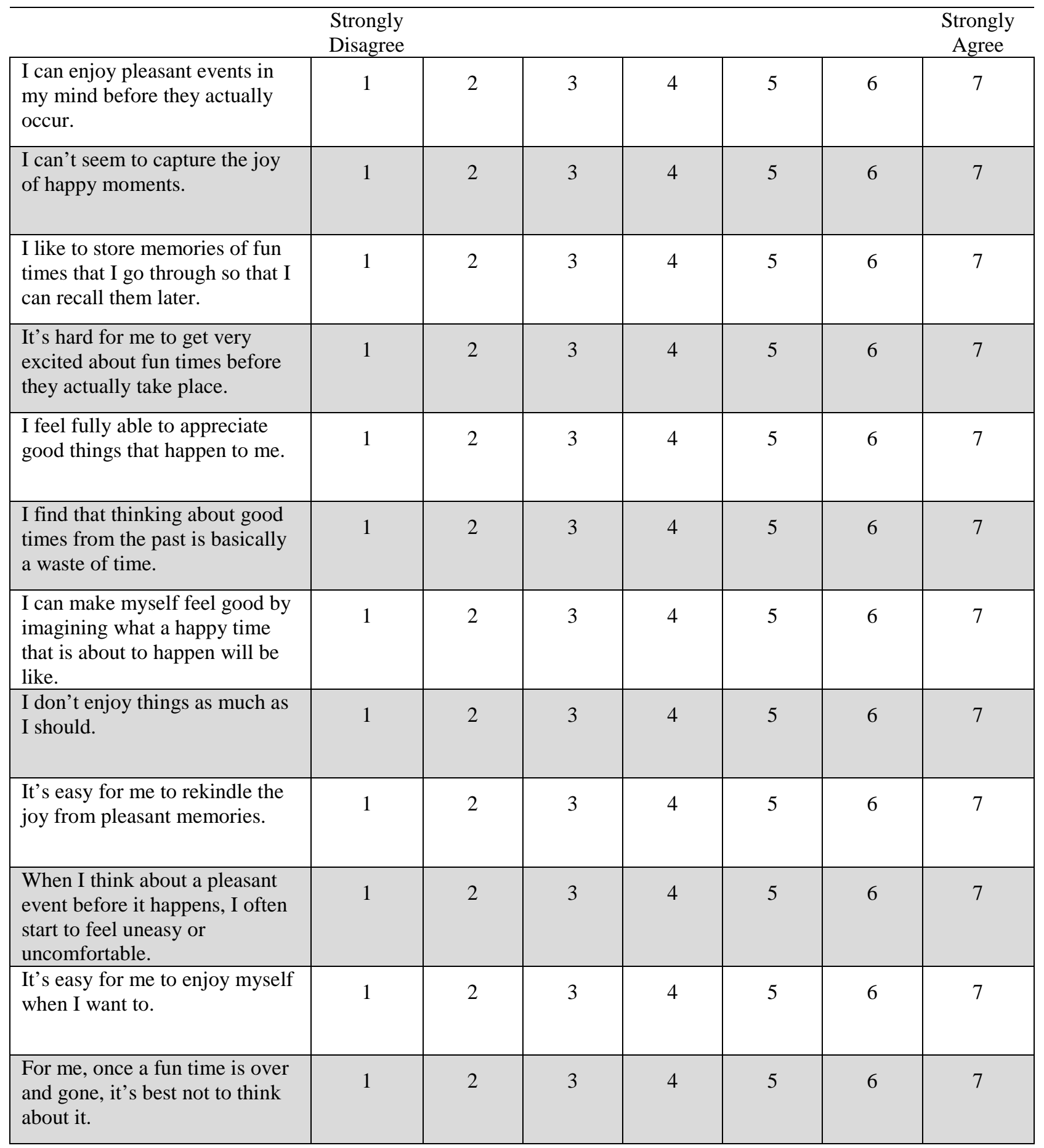




\section{Appendix N}

\section{Mindfulness}

Below is a collection of statements about your everyday experience. Using the 1-6 scale below, please indicate how frequently or infrequently you currently have each experience. Please answer according to what really reflects your experience rather than what you think your experience should be. Please treat each item separately from every other item.

\begin{tabular}{|c|c|c|c|c|c|}
\hline $\begin{array}{c}\text { Almost } \\
\text { Always }\end{array}$ & $\begin{array}{c}\text { Very } \\
\text { Frequently }\end{array}$ & $\begin{array}{c}\text { Somewhat } \\
\text { Frequently }\end{array}$ & $\begin{array}{c}\text { Somewhat } \\
\text { Infrequently }\end{array}$ & $\begin{array}{c}\text { Very } \\
\text { Infrequently }\end{array}$ & $\begin{array}{c}\text { Almost } \\
\text { Never }\end{array}$ \\
\hline 1 & 2 & 3 & 4 & 5 & 6 \\
\hline
\end{tabular}

\begin{tabular}{|c|c|c|c|c|c|c|}
\hline $\begin{array}{l}\text { I could be experiencing some emotion and not be } \\
\text { conscious of it until some time later. }\end{array}$ & 1 & 2 & 3 & 4 & 5 & 6 \\
\hline $\begin{array}{l}\text { I break or spill things because of carelessness, not paying } \\
\text { attention, or thinking of something else. }\end{array}$ & 1 & 2 & 3 & 4 & 5 & 6 \\
\hline $\begin{array}{l}\text { I find it difficult to stay focused on what's happening in } \\
\text { the present. }\end{array}$ & 1 & 2 & 3 & 4 & 5 & 6 \\
\hline $\begin{array}{l}\text { I tend to walk quickly to get where I'm going without } \\
\text { paying attention to what I experience along the way. }\end{array}$ & 1 & 2 & 3 & 4 & 5 & 6 \\
\hline $\begin{array}{l}\text { I tend not to notice feelings of physical tension or } \\
\text { discomfort until they really grab my attention. }\end{array}$ & 1 & 2 & 3 & 4 & 5 & 6 \\
\hline $\begin{array}{l}\text { I forget a person's name almost as soon as I've been told } \\
\text { it for the first time. }\end{array}$ & 1 & 2 & 3 & 4 & 5 & 6 \\
\hline $\begin{array}{l}\text { It seems I am "running on automatic," without much } \\
\text { awareness of what I'm doing. }\end{array}$ & 1 & 2 & 3 & 4 & 5 & 6 \\
\hline $\begin{array}{l}\text { I rush through activities without being really attentive to } \\
\text { them. }\end{array}$ & 1 & 2 & 3 & 4 & 5 & 6 \\
\hline $\begin{array}{l}\text { I get so focused on the goal I want to achieve that I lose } \\
\text { touch with what I'm doing right now to get there. }\end{array}$ & 1 & 2 & 3 & 4 & 5 & 6 \\
\hline $\begin{array}{l}\text { I do jobs or tasks automatically, without being aware of } \\
\text { what I'm doing. }\end{array}$ & 1 & 2 & 3 & 4 & 5 & 6 \\
\hline $\begin{array}{l}\text { I find myself listening to someone with one ear, and } \\
\text { doing something else at the same time. }\end{array}$ & 1 & 2 & 3 & 4 & 5 & 6 \\
\hline $\begin{array}{l}\text { I drive places on "automatic pilot" and then wonder why } \\
\text { I went there. }\end{array}$ & 1 & 2 & 3 & 4 & 5 & 6 \\
\hline I find myself preoccupied with the future or the past. & 1 & 2 & 3 & 4 & 5 & 6 \\
\hline I find myself doing things without paying attention. & 1 & 2 & 3 & 4 & 5 & 6 \\
\hline I snack without being aware that I'm eating. & 1 & 2 & 3 & 4 & 5 & 6 \\
\hline
\end{tabular}

